can

G315. 13

4800

Invert.

Zool.

Bro us iñJPEL

tenting

$$
1900
$$





\section{Die Garneelenfischerei}

an der

oldenburgischen und preussischen Kiiste bis zum Dollart.

Von

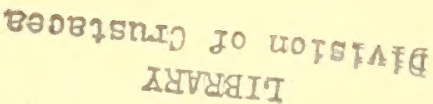

Professor Dr. Henking,

Generalsekretail des Deutschen Seefischerei-Vereins in Hamover. 


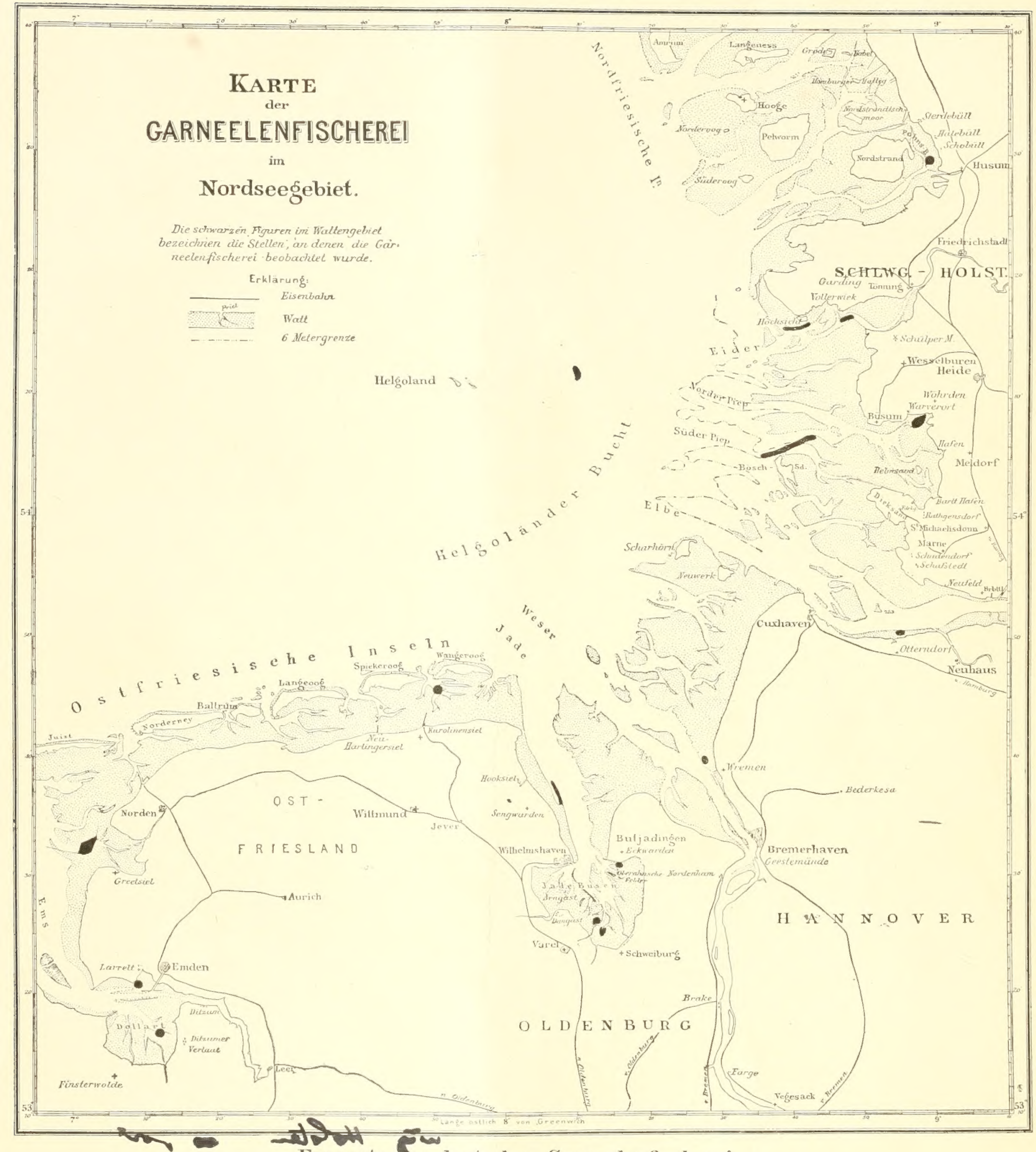


IIBRARY

Division of Crustacea

\section{Bericht fïr das Jahr $189 \%$.}

\section{Die Garneelenfischerei bei Varel.}

Auf dem Wege zum Hafen und zur Düngerfabrik bekommt man den ersten Eindruck der Vareler Granatfischerei*): Am Ufer des Wassers stehen die schwarz geteerten Leitkörbe und die daran zu befestigenden Fangkörbe in Haufen zusammengestellt.
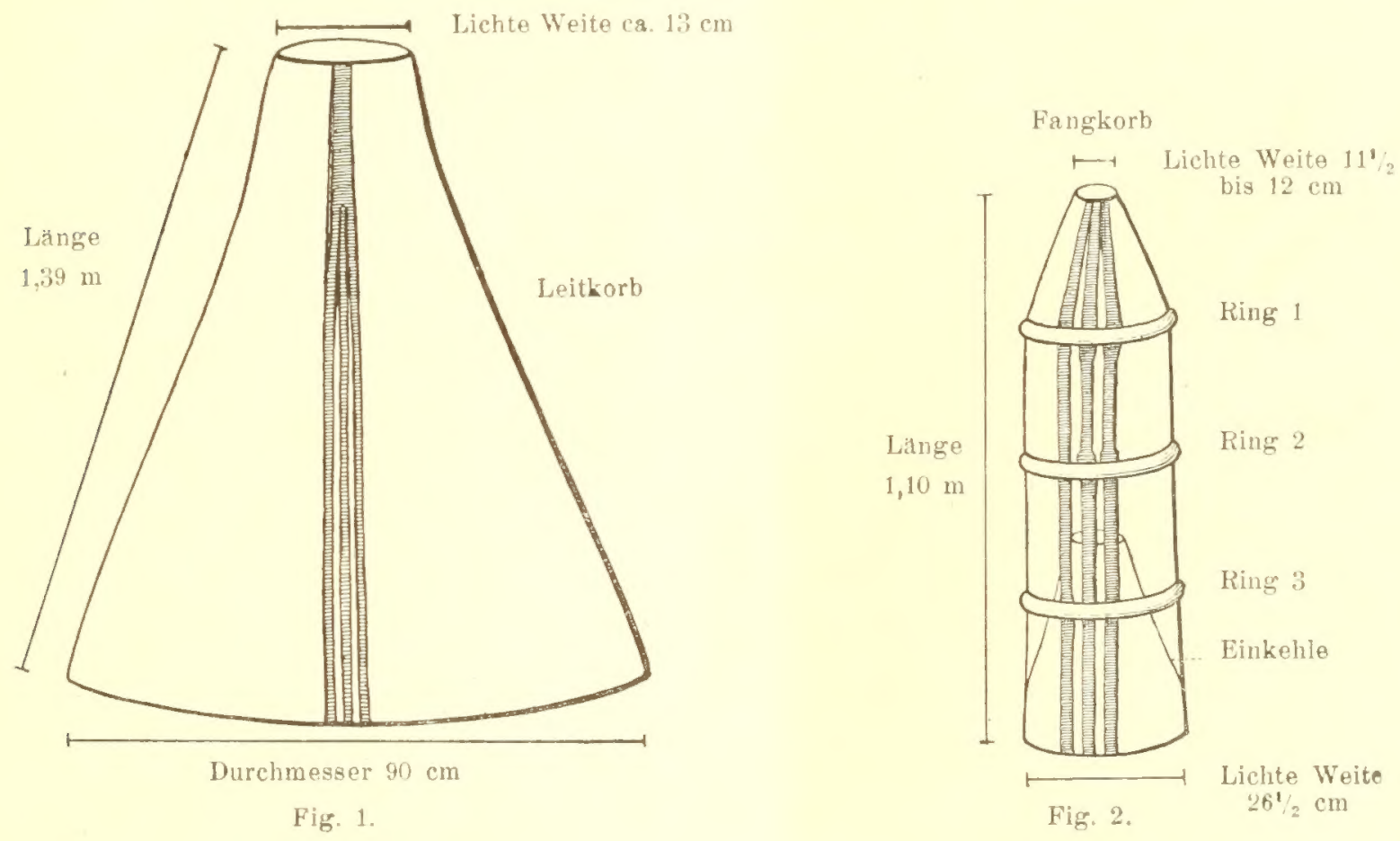

Die Leitkörbe (Fig. 1) haben folgende Dimensionen (ein Exemplar wurde gemessen, die andern waren ziemlich ähnlich):

Vordere Mündung: Durchmesser ca. $90 \mathrm{~cm}$,

Hintere Öffnung: Durchmesser (lichte Weite) ca. $13 \mathrm{~cm}$,

Seitenlänge: ca. $1 \mathrm{~m} 3 \mathrm{~cm}$.

*) Man vergleiche zu der nachfolgenden Bechreibung die Angaben und die Abbildungen des weiter hinten folgenden Berichtes von 1898, Kapitel 2 (Seite 42 ff.). 
Der Leitkorb ist derartig gemacht, dass die kleine hintere Öffnung von etwa 25 Stäben gebildet wird. Jeder dieser Stäbe ist weiter nach vorne zu in drei Teile gespalten, welche nun wieder etwas auseinander gebogen sind. An dem vorderen Umfang würde man also 75 Stäbe oder besser $25 \times 3$ Stäbe zählen.

Der eigentliche Fangkorb (Aalkorb) hat die in Fig. 2 abgebildete Gestalt und eine Länge von 1 bis $1,20 \mathrm{~m}$. Die Zahl der ihn bildenden Stäbe ist verschieden; ich zählte 26, 27, 28 und 37 Stäbe. Die Körbe führen aussen 3 Ringe. Zwischen dem spitzen Ende und Ring 1 liegen die Stäbe sehr dicht; Länge dieses letzteren Faches 221/2 bis $23 \frac{1}{2} \mathrm{~cm}$. Zwischen Ring 1 und 2 sind die Stäbe durchweg in der vorgeschriebenen Maschenweite getrennt. An älteren Körben sieht man an den Absätzen am Ende der Stäbe, dass hier durch Ausschneiden nachgeholfen wurde. Zwischen Ring 2 und 3 sind die Maschen selten in der Weise wie in der vorigen Abteilung erweitert.

Zwischen Ring 3 und dem Korbanfang stimmt die Maschenweite nicht immer; hier wird ausserdem die hier einsetzende Einkehle das Aussieben erschweren.

Die Stäbe haben eine verschiedene Breite, wie aus der oben angegebenen verschiedenen Stabzahl hervorgeht.

Der Umfang zivischen Ring 1 und ? beträgt etwa $70 \mathrm{~cm}$. Wenn also auf diesem Umfang 33 Stäbe vorhanden sind, so haben wir 33 Zwischenräume von je $6 \mathrm{~mm}$ Breite. Es ist alsdann bei einem Umfang des Korbes von $80 \mathrm{~cm}$ ein durchlassbarer Raum von etwa $20 \mathrm{~cm}$ für Granat von einer Breite bis zu $6 \mathrm{~mm}$ vorhanden, während $50 \mathrm{~cm}$ des Umfanges geschlossen sind.

Ziemlich genau das gleiche Verhältnis ergiebt sich aus der Berechnung der beiden zu den Versuchen benutzten Faugkörbe (vergl. unten S. 30).

Die Körbe werden scheinbar an allen Enden der Priele auf der Jade ausgestellt, am Vareler Tief, der Schweiburger Balge usw., wie auch östlich von der Insel Arngast in den vor Dangast liegenden Prielen. Von Dangast ans geht aber kein Priel anf das Watt; daher gehen die Fischer von hier mit Schlickschlitten (ostfries. „Kraier“) zur Entleerung ihrer Geräte, während von Varel ans Fahrzenge benutzt werden. So trafen wir in der Schweiburger Balge

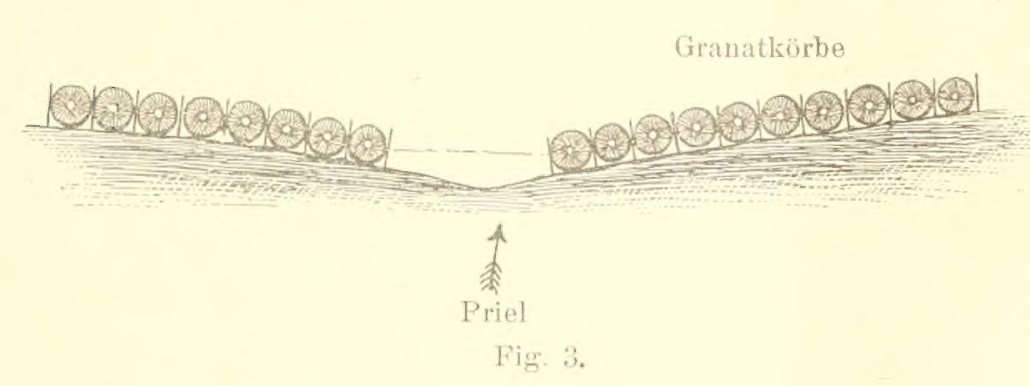
einen Fischer mit einem einmastigen, vorn gedeckten Fahrzeug mit Mittelschwert beim Entleeren seiner Körbe.

Die Körbe stehen am Rande der Priele und sind derart gerichtet, dass sie mit ihrer weiten öffnung den Ebbestrom aufnehmen (Fig. 3). An schmalen Prielen und einigen „Versuchsstellen" findet man wohl vereinzelte Körbe, gewöhnlich aber bilden sie längere Reihen. Ich habe solche von 24, ja sogar ts Körben gezählt. Oft stehen viele Reihen auf verhältnismässig kleinem Terrain, ihre Zahl ist also im Jadebusen eine sehr 
grosse. In der Sförmigen Biegung des Vareler Tiefs zählte ich auf ziemlich kurzem Terrain 18 soleher Reihen.

Was im übrigen die Stellung der Körbe anbetrifft, so berührt der Leitkorb mit seiner grossen Eingangsöffnung etwa den Boden. Im übrigen steht die Axe des Geräts ziemlich genau horizontal, wenigstens war es der Fall bei den Hunderten von Granatkörben, welche ich in der Jade darauf hin in fanggerechter Aufstellung angesehen babe (Fig. 4).

Nebenstehende Skizze verdeutlicht die Art der Aufstellung. Der Fangkorb steht demnach horizontal eine ziemliche Strecke über dem Boden (vgl. Taf. I Fig. 2).

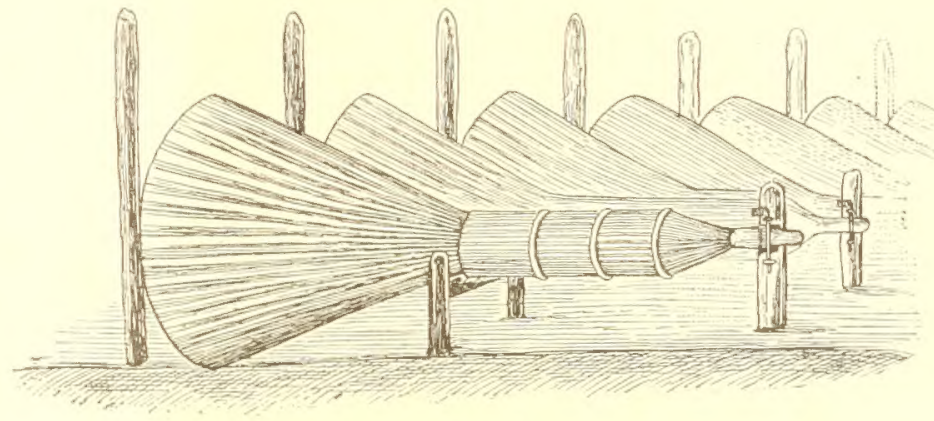

Fig. 4 .

An schlechten Stellen kommt es jedoch wohl vor, dass eine Ansammlung von Sand bei den Körben sich einstellt. Ohne Fürsorge würden an solchen Stellen die Körbe schliesslich ganz unter dem Sande verschwinden. Da sie ausserdem einen schlechten und verunreinigten Fang bringen, so werden sie von den Fischern an solchen Stellen entfernt.

In den einzelnen Reihen schliessen die Leitkörbe seitlich dicht an einander (Taf. I Fig. 3). Wo das nicht der Fall ist, werden auch kume Flägel benutzt, welche ebenfalls aus geteerten Staben hergestellt sind.

Am 2S. Juni, nachmittags ca. j) Uhr, suchten wir die Körbe über Niedrigwasser auf. Sie hatten also die Tagtide ahgefischt. Fang sehr schlecht, nur einige Granat in den Körben, ausserdem einige Quallen. Ein Fischer, welcher seine Körbe nachsah, schüttete den Fang ohne weiteres fort. Die Bente war eben wertlos, doch würden die Quallen, falls sie im Gerät blieben, in Fäulnis übergehen und den nachfolgenden Fang zum Absterben bringen.

Um festzustellen, wie viel Giranat durch die Körbe durchgehen, hatte ich zwei Netze angefertigt, welche aus Seidengaze bestanden und über den eigentlichen Fangkorb gezogen werden konnten. Durch zwei Bügel wurden sie gespannt gehalten und ihnen andererseits ein grösserer Abstand von den Fangkörben gegeben. Diese äusseren Netze wurden hinten zugebunden und vorn wurden sie anf das Ende des Leitkorbes geschnürt. In dieser Weise stellten wir sie am Nachmittag des 2S. Juni anf, damit sie über die Nachttide an Ort und Stelle blieben.

Am Morgen des 29. Juni waren wir alsdann rechtzeitig zur Stelle, um den Fang nachzusehen. Die Netze hatten sich gut gehalten. Der Fangkorb mitsamt dem äusseren Netz wurde vorsichtig von dem Leitkorb abgenommen. In dem Boot wurde dann zunächst der Inhalt der äusseren Netze in bereit gehaltene Eimer entleert, sodann der Stöpsel von dem Fangkorb abgezogen und der Fang ebenfalls in einen Eimer geschüttet. Dann wurde jeder Teil für sich gewogen und weiterhin analysirt. Es ergab sich dabei das nachfolgende Resultat. 
I. Seidennetz mit Maschen von $1 \square$ mm lichter Weite. (Cylinder Gaze No. 0000 von Landwehr [Berlin]).

a. Im äusseren Netz:

Gesamtgewicht der durchgesiebten Granat $=201 / 2$ Pfund.

Meist Granat von etwa $40 \mathrm{~mm}$ Länge*), auch grössere von 46 bis $48 \mathrm{~mm}$, ferner solche von $30 \mathrm{~mm}$ bis herab zu $16 \mathrm{~mm}$ totaler Körperlänge. Ausserdem mässig viel Mysis, ferner Stintlarven, einige Gobius und kleine Sprott.

1 Granat von $52 \mathrm{~mm}$ Länge war breit $\mathrm{S} \mathrm{mm}$, hoch $6 \mathrm{~mm}$.

$$
\text { b. Im Fangkorb: }
$$

$3^{1 / 2}$ Pfund Granat.

Gemessen wurden

1. ein grosses mit Eiern:

Länge $64 \mathrm{~mm}$, Breite $9^{1 / 3} \mathrm{~mm}$, Höhe $8 \mathrm{~mm}$.

2. o mit Eiern:

Länge $64 \mathrm{~mm}$, Höhe $8 \mathrm{~mm}$.

3. mit Eiern:

Länge $58 \mathrm{~mm}$, Breite $\mathrm{s}^{3} / \mathrm{mm}$, Höhe $: 1 / 2 \mathrm{~mm}$.

4. ein Granat ohne Eier:

Länge $80 \mathrm{~mm}$, Breite $12 \mathrm{~mm}$, Höhe $9 \% \mathrm{~mm}$.

Die meisten Granat hatten eine Länge von 35 bis $40 \mathrm{~mm}$.

$$
\text { Dimensionen des Fangkorbes: }
$$

Stabweite $;$ bis $8 \mathrm{~mm}$.

Letates Fach lang 201/2cm. - 26 Stäbe, breit 11 bis $19 \mathrm{~mm}$.

Lichte Weite am Eingang: Durchmesser $24 \mathrm{~cm}$.

Umfang des Korbes ca. $69 \mathrm{~cm}$.

11. Seidenet: mit Maschen con ca. 0,6 $\square$ mm lichter Weite. (Cylinder Gaze No. 00 von Landwehr [Berlin]).

Gesamtfang des äusseren Netzes $=17$ Pfund.

Durchschnittslänge der Granat: 35 bis $42 \mathrm{~mm}$.

Zusammensetzung des Fanges wie oben.

Inhalt des Fangkorbes $=3$ Pfund, ferner einige kleine Dorsch.

$$
\text { Dimensionen des Fangkorbes: }
$$

Entfernung der Stäbe von einander $51 / 2,6,7,8$ bis $9 \mathrm{~mm}$.

Stabbreite ca. $18 \mathrm{~mm}$ ziemlich übereinstimmend.

Vorhanden 27 Stäbe. - Letztes Fach lang $23^{1 / 2} \mathrm{~cm}$. Umfang des Fangkorbes ca. $69 \mathrm{~cm}$.

3) Die Làngenmessungen sind stets von dem Ende der zusammengelegten Schwanzflosse bis zur Spitze der Schuppe der zweiten Antenne genommen. 
In einem der aufgestellten Fangkörbe (ohne äusseres Netz) betrug der Fang grosser Granat: $3 / 4$ Pfund $=22+$ Stück.

Grösse der Granat fast durchweg it bis $59 \mathrm{~mm}$,

Breite $8 \%$ bis $9 \mathrm{~mm}$,

Höhe $S \mathrm{~mm}$.

\section{Die Düngerfabrik zu Varel.}

Sie liegt rom Jadebusen nicht sehr weit entfernt. Verarbeitet wurden zur Zeit des Besuches am 25. Juni hauptsächlich Knochen, welche zu hohen Bergen aufgetürmt waren, auch Hornteile von Kadavern. Feines Knochenmehl fand sich in grossen Haufen.

Dagegen waren die Granatmengen äusserst gering, bestanden auch aus ziemlich grossen Granat.

Die Verarbeitung des Granat zu Dünger war nicht zu sehen.

\section{Die Garneelenfischerei bei Eckwarden in Butjadingen.}

Da am 29. Juni es ummöglich war, mit Carolinensieler Granatfischern von Wilhelnshaven aus in der. Jade zum Granatkuren zu gehen, da die Fischer wegen geringen Ertrages bei Ankunft die Fischerei gerade aufgegeben hatten, so dampften wir mit der Barkasse herüber nach Eckwarden. Hier stehen am Ende des Prieles der "Ahne“, etwa südlich vom Eckwarder Speicher, lange Reihen von Granatkörben und sperren, von N. nach S. sich erstreckend, das breite Priel fast völlig ab. Die Stellung der Körbe ist dieselbe wie diejenige bei Varel. Ein Fahrzeug liegt in der Nahe danernd vor Ankel und ging von ihm aus ein Fischer gerade mit einem auf dem Wasser schwimmenden Kraier zur Entleerung des Fanges.

Ausser den Körben bemerkten wir einige Granatfuken (Fig. 5), d. h. aalreusenförmige Fanggeräte aus Netzwerk, welche in einer der Korbreihen am nächsten nach Land zu standen. Fünf Stück dieser Granatfuken standen fermer unweit eines Molenkopfes. Wir besuchten sie und zogen eine der Fuken empor.

Die Maschen zwischen den letzten beiden Bügeln und auch im Ende des Nełzes hatten eine Weite von $10 \mathrm{~mm}$ zwischen zwei Knoten. Die Maschen zwischen den beiden Bügeln

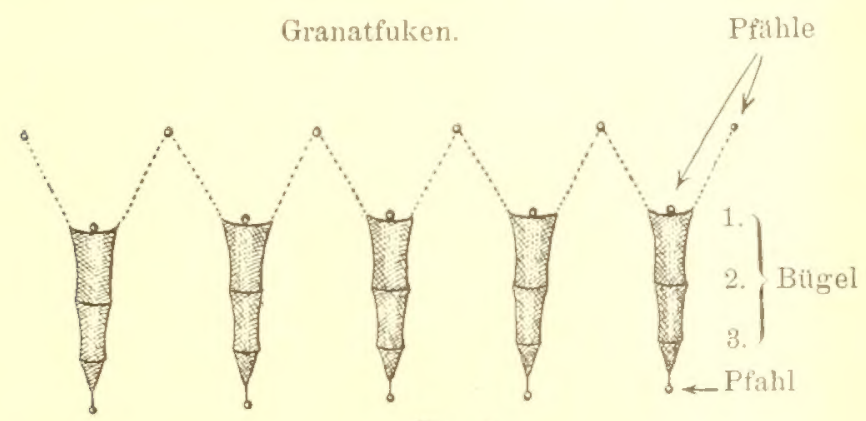

Fig. 5.

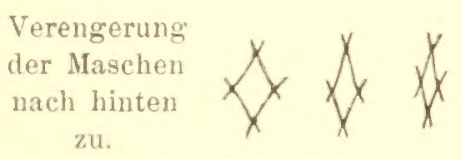

Fig. 6 .

2 und 3 standen infolge der Bügel offen. Hinter dem letzten Bügel 3 nach hinten zu standen die ersten Maschen ebenfalls noch offen, verengten sich dann aber allmählich nach der Spitze zu, wo das Netz zusammengeschnürt war (siehe Fig. 6). 
Die Entfernung vom letzten Bügel (3) bis zum zusammengeschnürten Netzende betrug $45 \mathrm{~cm}$. Der Durchmesser des letzten Bügels $42 \mathrm{~cm}$. Der Abstand von Bügel 2 und 3 betrug $\mathbf{i 5} \mathrm{cm}$.

Der Inhalt der Granatfuken betrug nicht viel Granat, darunter auch solche von nur etwa $20 \mathrm{~mm}$ Länge, ausserdem eimige kleine Schollen, ferner Quallen und Taschenkrebse.

\section{Die Garneelenfischerei bei Carolinensiel.}

Am 29. Juni nachmittags, ¿ Stunden vor Niedrigwasser, fischten wir mit dem Boot des Fischers Janssen in der Oster Balge, östlich von Martens Watt, bei flanem Nordwestwind, an einer Stelle, wo zwei Wattströme zusammenfliessen und eine lebhafte Kabbelung im Wasser verursachten.

Der Fang war nur gering, jedesmal ziemlich viele (einige Dutzend) kleine Schollen, ziemlich viel Carcinus maenas, einige Aalmutter. Wenig Granat, meist jedoch recht grosse von 72 bis is mm Totallänge, öfter Algenklumpen.

Aus dem Fang werden vom Fischer zuerst die nicht gewünschten Sachen, also Butt, Krabben, Muschelschalen usw., ausgesucht, dann kommt der Rest auf das Sieb (Fig. ") und wird durch

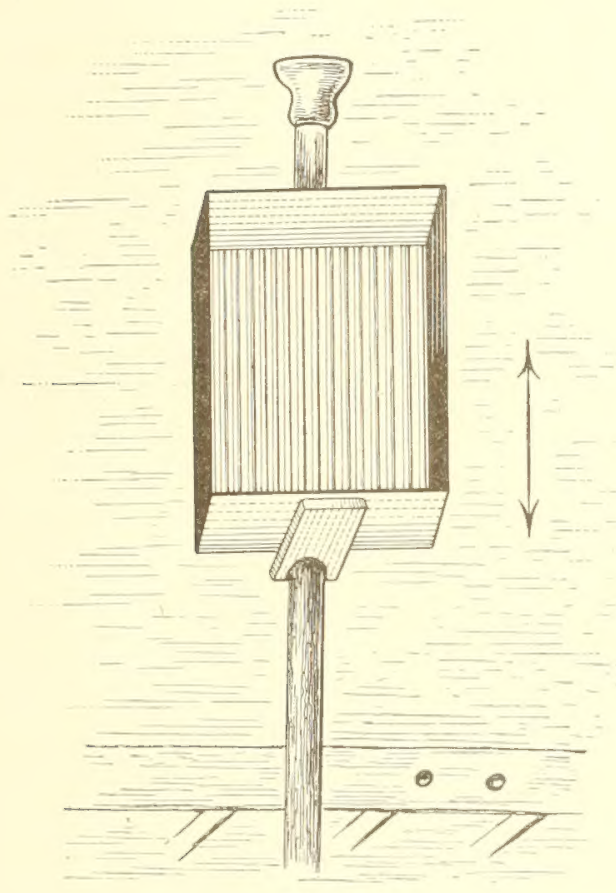

Fig. 7.

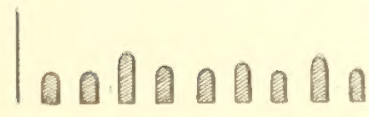

Querschnitt durch den Siebboden (Carolinensiel).

Hin- und Herziehen des Siebes auf dem Schiebestock, mit abwechselndem Aufklopfen des Siebes auf den Stock, von den kleinen Granat befreit. Der Schiebestock ist über den Bootrand vorgeschoben, sodass die kleinen Granat sofort in das Wasser fallen.

Das zur Anwendung kommende Sieb entsprach seinem Zweck sehr vollkommen. Der Abstand der Stäbe betrug meist $8 \mathrm{~mm}$, aber auch wohl $71 / 2$ bis $9 \mathrm{~mm}$. Ausserdem sind die Stäbe noch abgerundet. Die Granat liegen nach dem Sieben auf dem Rücken oder auf der Seite.

Die Dimensionen des Siebes betragen: Länge etwa so $\mathrm{cm}$, Breite $63 \mathrm{~cm}$, Höhe $3^{1 / 2} \mathrm{~cm}$.

Dieses Sieb arbeitete noch gründlicher als dasjenige, welches Granatfischer von Neuharlingersiel in Wilhelmshaven hatten. Sie führten zwei Sorten von Sieben. Die Maschenweite beider Sorten betrug übereinstimmend 6 bis 7 mm, dieselben scheinen sich nur dadurch zu unterscheiden, dass die einen aus viereckigen Stäben bestanden, die andern aus Stäben mit abgerumdeten Ecken. Letztere mögen wohl intensiver sieben.

Der Gesamtfang am 29. Juni betrug in 5 Zügen mit der Kurre (Fig. 8) etwa 10 Liter fast nur grösserer Granat, doch schwand beim Sieben die Menge auf etwa $1 \frac{1}{2}$ Liter des schönsten grossen Granat. 


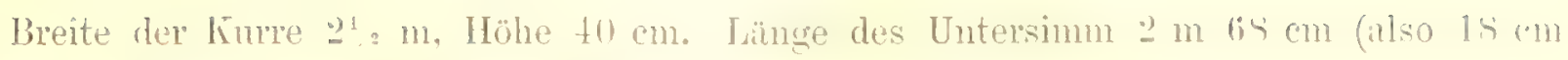
lïnger als der Bügel breit ist). Inïnge des Netzes

:3 m. Maschen im Steert 1.2 mm.

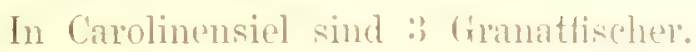

\section{Die Garneelenfischerei bei Norden.}

Die Granatfischerfahrenge ron Norden, welche in der Nähe des Schweinsrürelen in Norder Aussentief zum Fischen henutst werten. sind offene, schmale, vorn und hinten zugeschïrte lboote von geringer Grösse mit einem Inast. Es erwies sich wegen der Kleinheit der Finmeuse als unthunlich, sogleich mit dem repäck zum Fischen zu

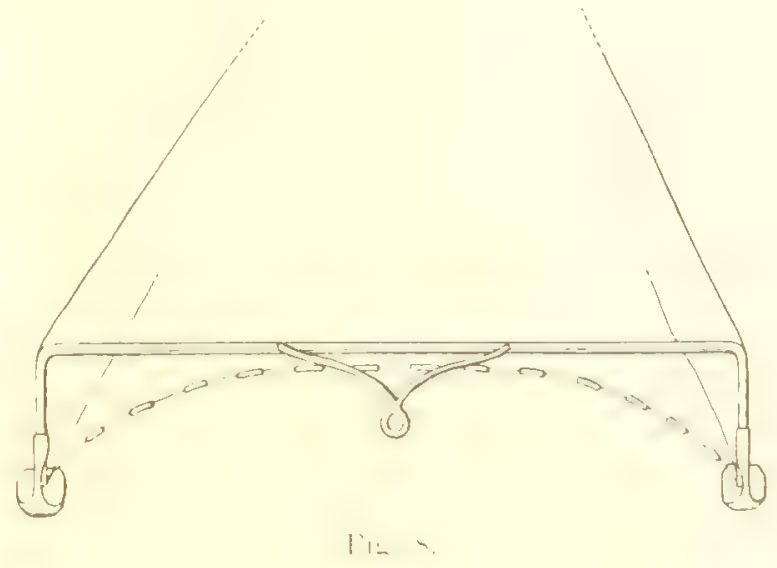
gehen und etwa von fireetsiel die Reise fortzusetzen. Daher begnügten wir uns, am 1. Juli die rerïte zu besichtigen.

Die Kurren sind rienlich genan so wie in Cirolinensiel, die Maschen etwis enger,

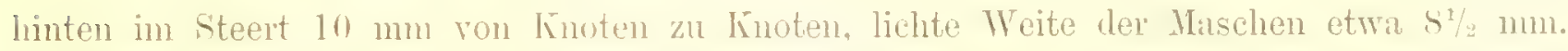

Interessant ist das hier henutzte Sieh, (Fu. ! u. 10). Es besteht aus einem Holzreifen ron etwa $45 \mathrm{~cm}$ Durehmesser mit einem halhkieistörmigen flachen Bentel aus Netzgeftecht von 1? mm Durchmesser. Aus den Angahen der Fischer entnahm ich. dass das Aussiehen der Gianat mit diesem Gerit im Wasser stattfindet, nicht, wie sonst, in der Lutt.

Der Fischer, welchen wir anfresucht hatten, war mit der bahl der vorhandenen Granat riollig zufrieden, eine $A b$ nalume war nach ihm in keinel Weise zu bemerken. Seinen

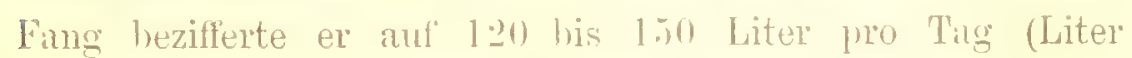
ca. $1 \%$ Pfund). Die grossen Grimat werden nach ihm beson-

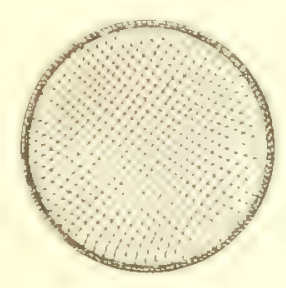

Fig. 1. Von oben. Granatsieb ron Norden. ders im Herbst gefungen. Die derzeit gefingenen waren nicht sehr gross.

In Norden sind zur Zeit s Granatfischer.

\section{Die Garneelenfischerei bei Larrelt.}

In Larrelt wird von g Fischern ausschliesslich mit dem Granathamen gefischt (Hig. 11). Es ist dieses ein Pfahlhanen von etwa $t^{1}$ : $m$ rorderer öfnumgsbreite, bei $1 \mathrm{~m}$ vorderer Öfnumgshöhe, dabei ca. 8 m Länge (also ein sehr kileinex Hamen).

Die Maschenweite beträgt rorn im Ilanen $20 \mathrm{~mm}$, hinten $10 \mathrm{~mm}$. Lei einem zum Trockneu anfgehänsten Hamen liegen die Maschen in der letzten Hälfte des Tetzes fast dicht :unf einander und sind seschlossen.

Die Hamen standen etwa querab rom Wy thelsumer Vorwerk in Zahl von 30 Stück umittelhar neben einander in einer Reihe und sperren die Fischers Balge an ihrem oberen Ende fast ganz ah. Abhandlungen des Dentschen Seefischerei-Vereins. Band V 
Die Fischer fischen ifter $\%$ B. 1) mit der Vorflut. Sie lassen alsdam die, wemn in Ruhe befindlich, anfrezogenen Hamen in das Wassel hinab und bleiben einige Stunden dabei

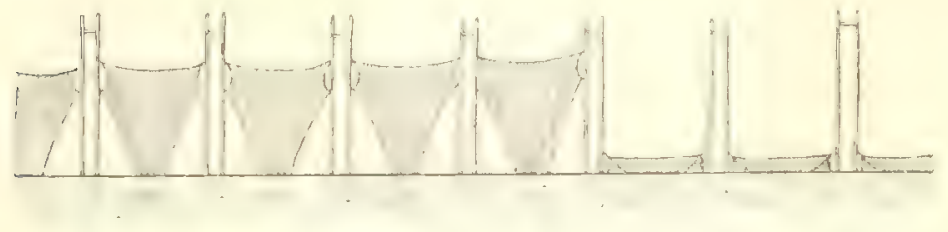

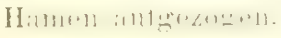
li: 11 oder in der Nähe und entleeren die Hamen. Dann ziehen sie sie wieder auf.

Weiterhin fischen sie ?) nochmals über die erste Hälfte der Ebbe, kommen zu dem Zweck mit ihren Booten. lassen die Iamen fanggerecht herunter, bleiben einige Stunden dabei, entleeren die Hamen und ziehen sie his zum nächsten Fing wieder in die Höhe, wobei das Ende der Hamen im Wasser Hottiert.

Vormittags 5) $\frac{1}{2}$ Uhr (2. Juli) kamen die Fischer von Larrelt mi entleerten in unserer Gegenwart die ITamen. Sie schütteten den Inhalt in Weidenkörbe. Er betrug für jeden Hamen

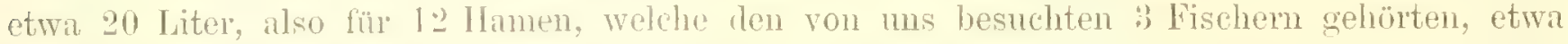

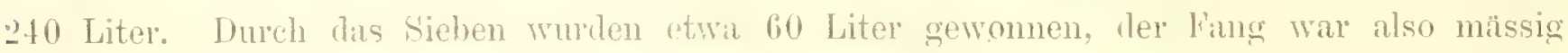
gewesen. Jedem Fischer gehören gewöhnlich + Hamen.

Der Vorgang bei Entuahne des Fanges war folgender:

Wïhrend ¿ Fischer die Hamen entleerten, siebte einer die Granat durch. Er füllte rlas Sieb riemlich mit fimat und schüttelte es dam im Boot hin und her. Die kleinen fielen durch das Sieb anf' den Borlen des Fahrzenges.

Bei einer dem Fang entnommenen Probe waren von etwa 100 Granat 12 Stück abgestorben. Die äbrigen erholten sich in einer Wasserkumme sehr bald und schossen hin und

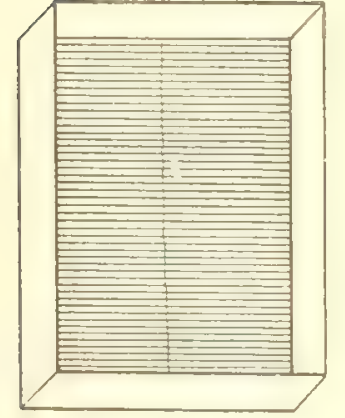

Iiig. 12. her. Die kileinsten der Entschlüpften hatten eine Lünge von $1+$ mm, die grüssten von $45 \mathrm{~mm}$.

Die gesiebten Lssgranat messen ziemlich durchwey $59-6.5 \mathrm{~mm}$ in totaler Lïnge bei $9 \mathrm{~mm}$ Breite und $7 \frac{1}{2}$ mm Höhe.

In rlen Siehen von Larrelt (lig. 12) befinden sich runde Lisenstäl)e, welche cinen Abstand von etwil (; mm haben. Die Stäbe laufen quer durch den liasten; der Fischer siebt, indem er den Lasten von rechts nach links und ungekehrt schüttelt.

Die oben bleibenden dicken Girmat schüttet der Fischer in einen liorb für sich, die dümnen häuten sich am Boden des Finzenges an. Von Zeit zu 'Zeit füllt er jedodn seinen Kasten mit dem durchgesiebten Material und entleert ihn ïluer IBord.

Der Beifang betrug hier cinige Butt, Quallen, Taschenkrehse und Sprott. Letztere waren tot. Wine Schar von Möven mu Seeschwalben trieh sich in der Nähe umher und wartete ant' die Bente, welche für sie bei der Entleerung des Hamens ahfiel. Zumeist werden sie sich der mit dem Wasser forttreibenden toten Sprott bemächtigt, haben. 


\section{Die Garneelenfischerei von Ditzumer Verlaat.}

Unweit der hollindischen Grenze, ziemlich weit al rom Ibollart liest bitzunce Verlant, woselhst 16 Fischer sich zur Grinatfischerei auf las Dollartwatt hegehen. Sie fischen dort:

1. mit kleinen Hamen (wie in Larrelt) und

2. mit Körben ans Weiden (Taf. VIII, Fig.;:2).

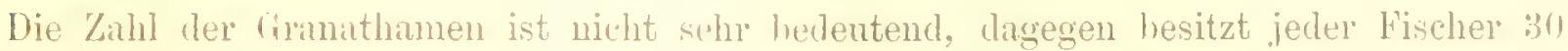
his jo Granatkörbe, sodass also im Ganzen etwa b00 Körloe vorhanden sein mögen.

Ien Fang mit löorben halten die lischer für besser, da der Granat in ihmen länger lelst. Inre Augabe, dass die Tiere in Steert der Hamen sehr rasch flau werden, erscheint mir im Hinblick aul das trübe und seichte Wasser der letzten Dollatrtrimnen, in denen die Hamen aufgestellt werlen, recht glauhwürdig.

Die Fischer ans Verlaat haben emen sth weiten Wegr zum Watt. Ilit zweiräderigen Karren fahren sie bis zum letzten Deich, dann komm der Schlickschlitten (Kraier) als Vehikel, um sie über das mehr als eine Stunde breite Watt zn den Fangplatzen zu führen. Diese Schwierigkeit des Transportes in Verhindung mit dem Umstande, dass Ditzmer Veriat von der Eisenbahn durch einen breiten Landstrich und durch das Limsbett getrennt ist, bewirlit, dass die Fischer nur dasjenige an Granat mitnehmen, was sie fun ihren Bedarf und für die Fütterung ihrer Enten nötig haben. Was darüber ist, lassen sie sogleich auf dem Dollart zul'ïck.

Im äbrigen tindet eine 'I'rennung der für den Alenschen und der für das Vieh bestimnten Granat erst in der Wohmmg der Fischer statt. Sie benutzen dazu ein aus dümmen Metallstäben bestehendes Sieb, bei welchem die Stïhe einen Abstand ron .) $1 / 2-6 \mathrm{~mm}$ haben. Am Riunle des Siebes befinden sich einige Metallhaken, relche zur Stütze einer ron der lecke der Hausdiele (gleichzeitig Küche und Netzramm) herabhängenden šchlinge dienen. In ihr wird das mit Ciranat getüllte sieb leicht vorwärts und riückwiilts geschwenlet und die dümeren Granat fallen durch.

Die kleinen Granat werden auf grossen, in mehr als 'lischhöhe über dem Boden angebrachten grossen 'Tafeln an freier Luft getrocknet und erteilen der ganzen Ortschalt einen charuliteristischen Geruch. Wem sie trocken sind, werden sie in einem kleinen Häuschen anfigestapelt als Wintervorrat für das reflügel.

In einem andern Häuschen sind die Einten untergehracht. Das Lamd ist mit Wassergräben durchzogen mol jeder frischer' hat einen 'T'eil

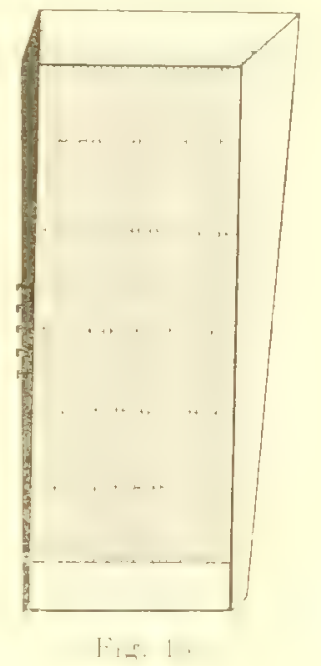
eines solchen Grahens mitsant dem Lntenhähschen eingefriedigt. Von dem Eutenhäuschen führt. ein Bretterboden schrïg zu dem Wassel mnd hier hielten sich hei unserer Anwesenheit die Enten zahlreich auf. Auffillend war es mir, dass die Enten sämtlich an Durchfall zu leiden schienen, wenigstens spritzten sie bedenklich oft ihren flüssigen Kot in einem Strahl von sioh. 
Um Zeit zu sparen, überzog jeh im Hanse der Fischer zwei Weidenkörbe mit den reparierten Netzen und zeigte den Fischern genan, in welcher Weise sie die Körbe am Abend (‥ Juli) aufstellen möchten.

Am andern Morgen (3. Tuli) wurlen wir durch die Fischer rechtzeitig vom Fahrzeug im Dollart abgeholt. Anfings auf flotten Wrasser fahrend, schoben sie uns schliesslich in dem flachen Boot über: den Schlick his $z u$ den Fangplätzen. Die Körbe hatten, ganz wie im Jadebusen, über die Nachttide gefischt. Die Körbe mit den umhüllenden Netzen waren von den Fischem durchaus richtig aufgestellt und hatten sehr gut gefangen. Es liess sich daher ein recht gutes Bild von der sieluenden Wirkung der Körbe gervimen.

In Nachfolgenden ist die Amalyse der Finge gegeben.

T. Seidennetr mit engeren Maschen (vgl. Seite :30):

Inhalt des Fangkorbes selbst $=6$ Pfund,

Inhalt des insseren Netzes $=17$ Pfund,

Linge des Fanghorbes $=8 \pm \mathrm{cm}$,

Umfang desselben $=6 \pm \mathrm{cm}$ in der Mitte,

Läuge des Endtrichters = $2: 31 \% \mathrm{~cm}$,

Stabrveite: $51 / 2,6,4,61 / 2,11 \mathrm{~mm}$.

II. Seidennetz mit weiteren II aschen (vgl. Seite :30):

Inhalt des Fingkorbes selbst $=1: 3$ Pfund,

Inhalt des äusseren Netzes $=12$ Pfund,

Länge des Fangkorbes $=90 \mathrm{~cm}$,

Umfang: Mitte 591/2, Anfing des mittleren 'Teiles 5\%, Ende desselben $6.3 \mathrm{~cm}$

'l'richterlänge 2:; $\mathrm{cm}$,

Stabweite $5,: 3,51 \%, 15^{1}: \mathrm{mm}$.

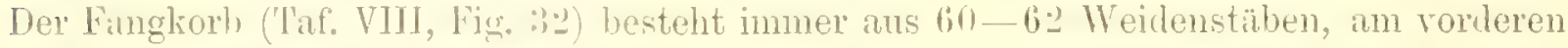
Einkehlenende jedoch aus 120 Stähen, welche parweise zusammenliegen (hinter einander). Es kommen hier eben zu den bo Stähen des Korbes noch reitere 60 Stäbe der Einkehle.

Der Leitiorb besteht an seinem spitzen Ende ebentalls ans 60 Stäben. Nach der vorderen weiten Oeffinung zu werden dann noch Weidenstäbe dazwischen eingeschoben.

Die Leitkörbe sind so locker gearbeitet, dass zwischen ihren Stïhen vielfach noch Lamm für einen durchschwimmenden Hering bleiht.

An die Leitkörbe schliessen sich nach vorn noch Elügel (sog. l'ammschütten) von etwa 11/2 m Lünge an ('Tafel VIII, lïg. : :

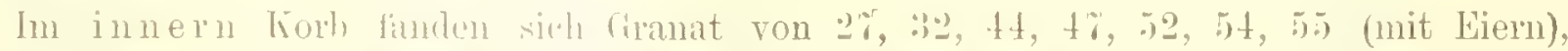

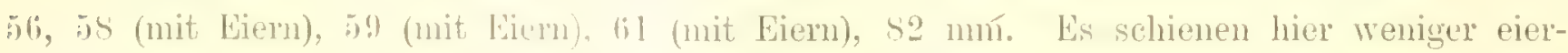
tragende f vorhanden zu sein, als an den andern Orten.

$\operatorname{lm}$ ï usseren Netz, also dureh die Stäbe gegangen, waren sehr viele Granaten von

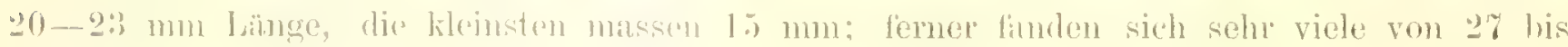




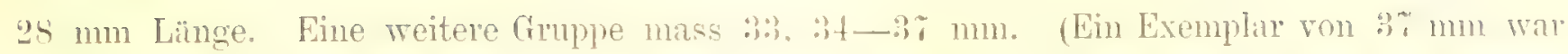
fast $6 \mathrm{~mm}$ breit, ; mm hoch.) Die grössten, welche in grösserer Zahl rorhanden waren, massen 39-45 mm. Vereinzelt waren jedoch anch ganz grosse cranat durch die weiten Maschen des umregelmissigen horbes nach aussen gelangt.

\section{Die holländische Garneelenfischerei im Dollart.}

Ein grosser' 'Teil des Dollartwattes wird von hollindischen Granatfischern benutzt. Da deren Anshente von denselben 'Tieven herrührt, welche anch den deutschen Granatfischem als Fangobjekte dienen, so war es, an ein klares Bild zu gewinnen, wünschenswert, anch von deren Fangmethode etwas kemen zu lemen. Es war das leicht möglich durch einen Austlug nach dem Hauptorte der hollindischen Gruatfischerei, nümlich nach Finsterwolde. Wir hegaben uns dorthin unter Benutzung der Eisenbahn nach Neuschanz.

In Finsterwolde wird anscheinend ansschliesshich mit dem Granathamen gefischt, welcher ganz ähnlich ist, wie derjenige von Larrelt. Lr ist nur wenig lïnger als dieser, hat am Ende etwas engert Maschen und dient sleichzeitig wohl dem Fischtang, wie aus einer Einkehle geschlossen werden kann. Das zmm Anssieben henutzte Sieb ist ähnlich wie in Larrelt, nur laufen hier die Metallstähe der Lünge nach üher den Boden des Siebes. Auffallend ist es, dass hier die Fischerei mit Körben völlig unbekannt zu sein scheint. Anf eine Frage nach solchen brachten die Fischer einen Handkort), wie er zum Iransport der Granat benutzt wird.

\section{Zusammenfassung.}

So sehr auch die Reise nach den oldenburgischen firmattingplätzen und denen der ostfriesischen Küsste rom Wetter und äusseren Lmstünden begünstigt wurde, so litt sie doch hinsichtlich der Jarle an dem Übelstande, dass ler V'ang derzeit nur sehr geringfügig war. Einen richtigen Einblick in die Bedentung der oldenburgischen Granatfischerei und in die Verwendung der kieinen Granat als Dünger, sei es direkt oder durch Vermittelung der Iareler Düngerfabrik hahe ich nicht exhalten. ehensowenig wie beobachtet werden komnte, in welcher Weise der frisch aufgenommente Fing weiter hehandelt wird. Hierfür trafen wir es recht ungünstig.

Gut zur Anschaumg kam dagegeu der Umfang der dortigen Fischereieinrichtungen, die langen Reihen der Gramatlï̈rbe, deren Zahl mit 4500 bis 5000 Stück* wohl nicht zu hoch angegeben ist. Neben dieser hedentenden Zahl ron Fangkörben verschwinden die hier gebrauchten Stell- und Schleppnetze, deren Zahl anf nu 25-30 taxiert ist.

Zu anderen Zeiten muss der Fang anf der Jade sehr reichlich sein, denn für Virrelerhafen, Dangast und Schweiburg wird er im tahre 1896 atuf s00000 Liter essbare Granct geschätzt und die Menge der gefangenen kleinen soll hierzu in Verhältnis wie 51/z: 1 stehen, 1. 1. für 1896 mindestens 4400000 Liter betragen haben. Da ms ferner mitgeteilt wurde. dass der Erlös der Fischex ans den kleinen tranat etwa dieselbe summe ansmache, wie der.

*) Bericht des Terbandes der Handels- und Gewerbevereine für das Herzogtum (1denburg für das Jahr 1s!ti, S. 181 
Erlös ans den von ihnen gefungenen essharen Grannt, so lïsst sich anch hieraus ein lä̈ckschluss auf die IIenge der kleinen dirnat machen, wem die Fischer ans dem Verkauf der letzteren pro Liter in Durchschnitt mu 1 Pfennig erzielt haben. Weiter aber lässt sich ermessen, welche Bedeutung die kieinen Granat für das wirtschaftliche Leben der Fischer angenblicklich haben.

Während nach der vorstehend angegebenen Statistik die /ahl der mitgelangenen kleinen Granat ausserorlentlich gross ist, hat sich bei den oben mitgeteilten Versuchen (S. 29 - 30 ) muzreifelhaft gezeigt, diss die l'angkirhe recht gut sieben.' Denn die Menge derjenigen kleinen Grauat, welche duch die Maschen des Fangkorbes nach aussen geschlüpt war und nun durch das umgelegte inssere Netrqefaugen gehalten wurde, betrug in einem Netz etwas mehr, in zweiten Netz etwas weniger als das 6 fache vom Fang des Fangkolbes. Das ist eine sehl bedentenle Leistung, welche umsomehr Erstamen erregen muss, weun beachtet wirl, dass eigentlich nur der mittlere 'I'eil des liorbes sieben kamn, nïmlich der 'T'eil zwischen iten drei äusseren Ringen. Im hinteren trichterfömig zugespitzten 'Teil stossen dagegen die Stäbe dicht zusanmen, im vorderen 'T'eile verhindert die Einkehle das Entschlïpfen der Granat.

Demnch sind bei den Versuchon eimige b'ehlerguellen zu beachten:

1. Die Körhe hatten eine stwas grössere Stahweite als die oldenburgische Verordnung in minimo verhangt, wenigstens in dem vorher exwähnten mittleren 'leile. Das war ein Zufall; die lö̈he wurden beliebig grenomnen und herveisen nur, dass die fischer ein Verständnis für den Wert der Mtassreggel hahtenth, indem sie sich nicht ängstlich an die Minimalgrenze der vorgeschiehenen Stabwate kitmmern.*)

․ Der Fang war in ganzen, wie gesagt, nur gering. Es mag dieses für eine gründliche Selbstauslese seitens les Fanghortes günstig sein, während bei einem grossem Fang und besonder bei schwarmweisem Aultreten des Granat, die Tiere sich gegenseitig mehr am Entschlüpfen hindern. Es müsste die Sulbstuluslese der Körlye nochmals zur Zeit des reichsten Fanges geprüft werden, wenn man klar sehen will.

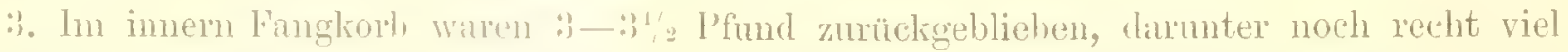

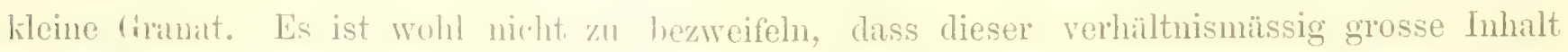
durch die Anwesenheit des änsweren Seidennetzes hedingt war. In diesem Netz betim sich das Gewimmel der ansgesiebten dinanit nud deren Arbeiten mag wohl manches 'Tier ver-

Interessint ist cine Mittoilung les when citierten Berichts des Verbandes der Handels- usw. Vereine Olden-

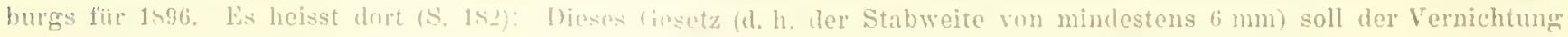
der bleinen ungeniessharen Granat prbausen, und tas anfungs vorhandene Vorupteil der Fischer ist jetzt gegen diese Schutzbestimmung vollends heseitigt; as wirkle hente der grosste Teil der fischer damit einverstanden sein, wenn man statt der Stabweite von fi mm eins sulcher vin minclestens a mm pesetzlich einfülnte

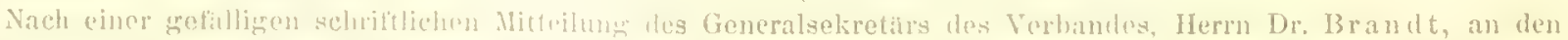

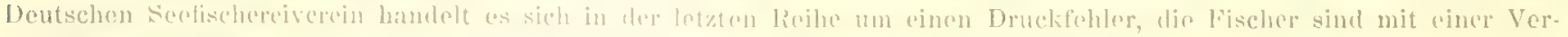

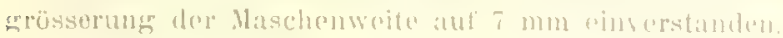




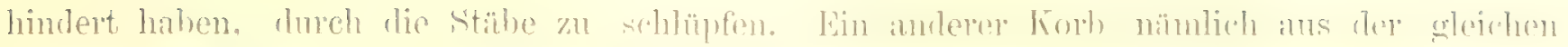
Reihe enthielt (wie s. 31 angegehen) mu " 1 l'fund.

Wie es zu Zeiten eines reichen Fanges sich mit der Selhstauslese der hörbe verhält, muss dahin gestellt bleiben: jedenfalls geht ans den Versuchen hervor, diss die Körbe geeignet sind, der grössten Mlenge kleiner Ciranit das Lint.chlüpfen zu gestatten.

Dahei entsprechen dir Köm ejentlich nur in ihrer Mitte den exhassenen Vorschriften und sind in dem moweilellalt wirkinmsten Lnolteil fast völig geschlossen.

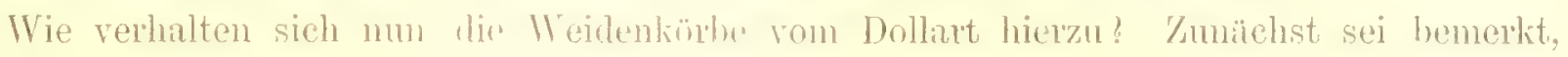

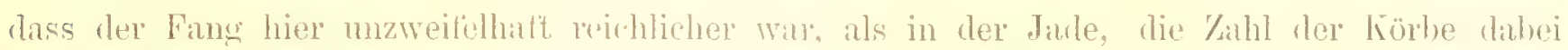
aber erheblich geringer. In Jitzumer Verlat sind 16 Fischer, in Dyksterhusen \%. Werden im Durchschnitt 40 Körhe pro lischer angenommen, so argieht das zwischen soo und $\$ 00$ Körbe. Die Verbatter Fischer versicherten anshlücklich, es gebe firanat genug.

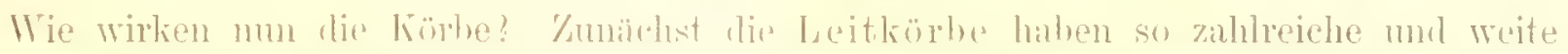

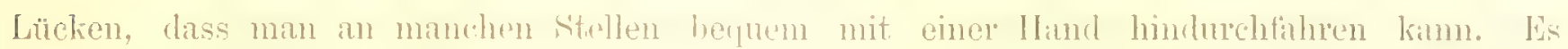
kömen daher durch ihre Stüne unzweitelhat viele Granat entschlüpten, welche in den glatten mond nur mit schmalen lingen versehenen deitkinhen der Vareler lionstruktion keinen Auswey finden wïrclen.

Die Fangkörhe ron Vurlat sind kleiner als diejenigen von Varel. Die von mir gemessenen hatten dinen Untang von bo- lit chn und eine länge von $84-90$ cm. Ls ist.

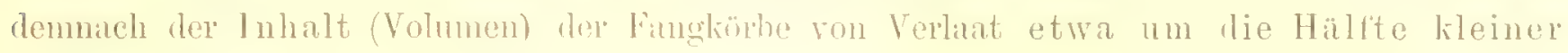
als derjenige ron Varel.

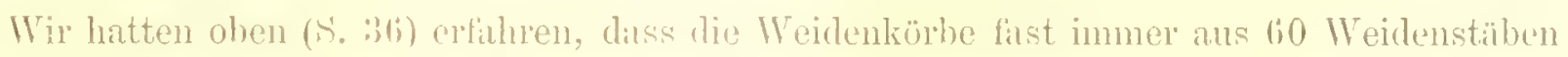

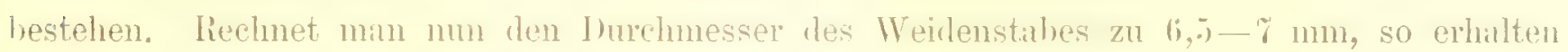
wir aut einen Umbing hes liorbes ron lio-lit "m eine geschlossene Fläche von $39-42 \mathrm{~cm}$, also eine durchlasshare Flähe von etwa 20 con, eine merkwärdige Übereinstimmung nit den

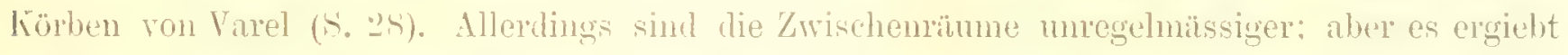

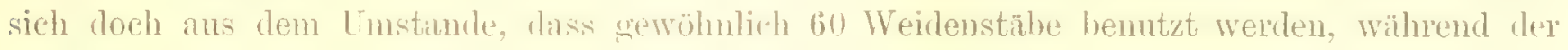
Unfing der Körbe ziemlich lerselbe bleibt, dass, wenn an einer stelle die Stäbe dichter an einander liegen, sie dafür an einer andern Stelle einen um so grösscren $A$ bstand haben müssen. Ich glauhe also, dass die Unregelmïssigkeit des Gethechtes unter den dargelegten Verhiltnissen keinen Anlass zur liesorgnis gieht.

Wie steht es mit dem Fang? Die beiden Versuchskörbe in der Jade hatten mitsant den ausseren Netzen im Ganzen $4+$ Pfund. die heiden Versuchskörbe von Ditzumer Verlaat. obgleich ihy Volumen um die Hälte kleiner ist. Ioch zusammen ts Pfund gefangen. Nimmt. man hierzu den Umstand, dass die leithörhe von Verlant entschieden mehr Granat durchlassen als diejenigen von Varel, so ist es muzweifelhalt, dass der Granatreichtum des Iollant. derzeit grösser war, als derjenige der dade. (oh es mit dem reitheren liang zusimmenhing. dass die Anslese der Weidenkörbe geringer war als diejenige an der darle, vermag ich niwht 
zu sagren. Die Auslese in den heiden Körben von Ditzumer Verlaat verhielt sich wie 1: I und wie :3: 1, in den beiden (allerlings rufällig besonders weitmaschigen) Vareler Körben dagegen wie $6: 1$.

7u Gunsten der Hangmethode von Verlat spricht die Weitmaschigkeit der Leitkörbe, welche unzweifelhaft schonender fingen als diejenigen von Varel. Dagegen werden wiederum die Fangkörbe von Varel, dank der gesetzlich vorgeschriebenen Maschenweite, denen von Verlat in Bezug aut" schonende Wirkung überlegen sein. Jedenfalls limn ich nach dem, was ich bisher gesehen habe, nicht mit Sicherheit sagen, ob die Gesamtwirkung der beiderseitigen Ferite (Leitkorb und Fangkorh) in Ditzmner Verlat und Varel wirklich erheblich von eimander verschieden ist. Eine schüdliche Wirkung würde dagegen durch Kombination eines Vareler Leitkorbes und eines Ditzumer Fangkorhes erzielt werden.

Nicht unwesentlich ist ferner der Umstand, dass eine Ahnahme der Granat im Dollart und der Unterems nach Aussage der Fischer vou litzumer Verlat nicht wahrunehmen ist, und die Angabe der Nordener und der Larrelter Fischer stimmt hiermit überein. Der Dollart würde also zu der Besuchszeit der Jale haben abgeben kömen, wenn die Garneelen nur so weite Wanderungen unternelmen möchten, was mir zweifelhatt ist. Ich glaube daher nicht, dass es bei den gegenwärtigen Verhältnissen angezeigt wäre, den Dollartfischem Änderungeu ihrer Fanggeräte vorzuschreiben.

Was die übrige Carneelenfischerei an der ostfriesischen Küste (mit der Kurre und dem Hamen) anbetrifft, so ist deven Betrieb so rationell wie mu möglich. Die durchgesiebten Granat kommen alsbald wieler in das Wasser zurück. '/wwar bliche hier die Möglichkeit, für die Siebe eine bestimmte Maschenweite rorzuschreiben, doch möchte ich das einstweilen tür rmnötig halten. Denn die anf' dem Siebe verbleibenden Garneelen sind für den menschlichen Genuss bestimnt und zu kleine There werden schwerlich jemals eine gesuchte Ware bilden. 


\section{Bericht fuir das Jahr 1898.}

\section{Die Garneelenfischerei bei Carolinensiel (25. Mai 1898).}

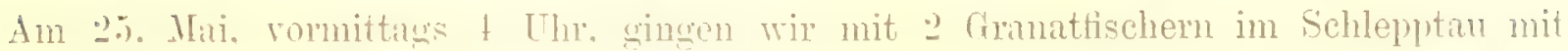
fallendem Wasser auf das Watt. Nathdem das Wasser soweit gesmken war, dass die Sunde rentlich frei wurden, hegannen the Fischer mit tem Fang in der Oster Balge etra um 6 Uhr vormittags bed schönem, Warmem Wetter nit leiehtem ostlichen Wind. Es Waren im Ganzen + Fischerfahrzenge hier vorhanden. -- derselben fischten derart. dass hei dem flauen Winde

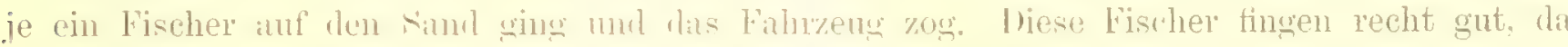

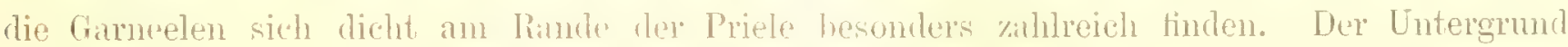
bestand aus reinem Sind. Thei - Fahrzeugen (Nartin und Franz Janssen) gingen wir an Bord; die Fischer unterstütaten die geringe Faht durch Fudern. Schliesslich liessen wir sie durch den Dampfer schleppen, immer zimulich an S.-Rande des Priels. Der l'ang geschah mit der Kurre.

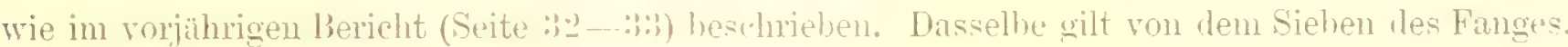

Das liesultat war folgendes:

\section{Fahrzeug Martin Janssen.}

Fang 1. Das Gewicht des Gesimtfinges betrug netto 19 Pfund. Hiermuter befimd sich etra 1 Pfund Beifang, bestehend aus Ouallen. kleinen Butt und Schollen, Steinpickem (Aspidophorus), T'aschenkrehsen (Carcims).

Garneelenfing netto is l'fimd.

Nach dem Sieben und nateh Entfermug des Beifunges blieb aus 18 Pfind Fang eine Aushente cresielsten Granats von ; l'fund.

Die kleinsten Grimat, Welche sich im Tetz fanden, hatten eine Länge ron :3.) mm. Das Netz hatte, wie früher schon angereben. im Stecrt Naschen ron 11 bis 1 :n $\mathrm{mm}$ im nassen

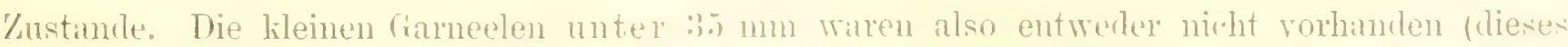
ist das Wahrscheinlichste, da sich sonst loch etwas gefintoen haben musste). oder wie werden schon durch das Netz roilig ausuesiebt.

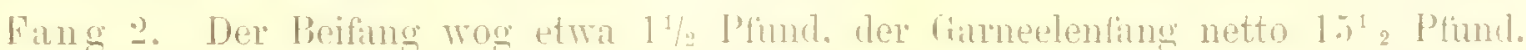

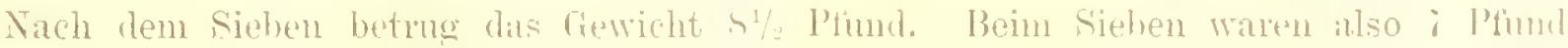
fortgefallen. 
Die kleinsten Granat im Netz massen 34 mm.

Dir kleinsten Grunat mit Hiern $50 \mathrm{~mm}$ an Lünge.

Die grössten Granat mit lirm s:i, S1, is mm. Das grösste Exemplar ohne Eier 90 mm. Die ganz grossen Granat simd auflillig durch ihre schneeweisse firhe und heissen daher bei den Fischern "Speckgranat"。

Sehr bemerkenswert war ac grosse Zahl Eier tragender of unter dem Fang. Von einer beliebig herausgegriffenen Handvoll der gesiebten Cranaten waren :3: Stück mit Eiern besetzt, mur 5 Stück ohne Eier. Ich fing alsclann mit einem liorbe heim Sieben von den durchfallenden kleinen Gancelen eine l'ortion anf: auch unter diesen fanden sich in einer heliebig gegriffenen Handvoll

:3.) Garneelen mit Eien.

:3! .. ohne Eier.

Die kleinsten mit Wiern unter diesen Gameelen massen 4 ! bis j:3 mm.

11. Fahrzeng Franz Janssen.

Der Korb wog "- Pfund, mit Granat eines Netzzuges (der Beifang war bereits ausgesmeht) $=1: 3^{1} \%$ Pfund brutto oder $11^{1 / 2}$ Pfind netto Garneelen.

Nach dem Sieben betrug das rewicht hrutto 12 Plund, also ohne Korb $=10$ Pfund netto. Abgesieht waren also nur 11\% P'fund.

Es war hier zweierlei zu hemerken:

1. war das Sieh enger. Die Stahweite betrug im Durchsehnitt mur i mm, die engsten Rillen massen ca. 5 mm. die weitesten 8 mm. Daher war das Resultat des Siebens nur sering. Ilie Gleityorrichtung fehlte.

2. Das Netz hatte im Ganzen etwas geringere Dimensionen als dasjenige von Martin. hatte dahei aher in Steert, Mischen von 14 bis 1.5 mm. Fs ist anzmnehmen, dass dieses Netz bereits etwas stäker siehte, sodass der Lifekt des Siehens mit dem Holzkasten geringer ausfiel.

\section{Die Garneelenfischerei auf der Jade (vor Varel) (26. Mai 1898).}

Am 25. Mai kamen wir nach der Vareler Schlense und liessen uns durch einen früheren Garneelentischer zum I'areler 'l'ief' und zu den dort anfgestellten Granatkörben führen.

bie lieihe von Fangkörben, welche wir über Niedrigwasser abends gegen ! Uhr antsuchten, hestanden aus einem vorderen Leitkorb ans Weiden mit recht weiten 7rischenrïumen und aus dahinter gesteckten sog. Aalkörben aus P'itch-pine-Stäben.

Wir wechselten zwei cler liörbe gegen die präparierten Körbe aus, welche wir mitgebracht hatten. Aus l'ig. 1 ('T'al: I) ist zn ersehen, wie die Fanggerïte (hier also Leitkorb aus Weilen und Fangkorh ans Pitch-pine-Stäben) anssehen und in welcher Weise die Seidennetze äher "2 Körhen befestigt waren.

l)ie Körhe, wolehe wir an die Fangrgerite ansetzten, hatten folgende Dimensionen: korl) 1. Lithge lo!) (m). 


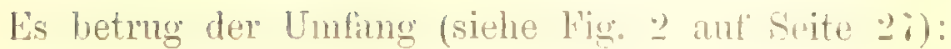
von Abteilung II (zwischen ling 1 und 2 ) . . . . . =

$$
\begin{aligned}
& \text { III (zwischen ling a und :3) . . . . . = } 55 \text {, } \\
& \text { IV (zwischen Ring :3 und dem liorbantung) }=7 \cdot 2 \ldots
\end{aligned}
$$

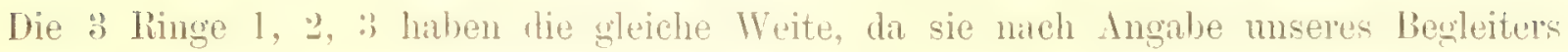
über dieselbe Scheibe gearbeitet werden. Der King an Anfang des Korbes ist jedoch weiter, derjenige am Ende erheblich enger. In $n$ m die Stabe einheitlich sind, so kommen gewisse Spammugen in die eimzelnen liegionen des liorbes, welche es bewirken, dass die Maschen in der Abteilung II im allgemeinen am weitesten, in Abteilung 111 dagegen enger sind.

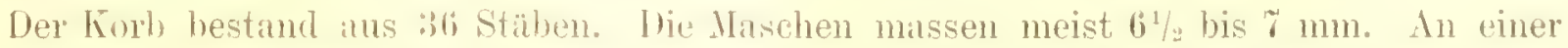
Stelle lagen die Stabe jedoch dicht zusammen. Lis kommt dies bei der Fabrikation der Körbe daher, dass der betreffende Fabrikant mit dem Raum nicht auskommt und dann zum Schluss sehen muss, wie er den liorly schliesst.

Korb II. Dieser Korb hatte eine Länge von $110 \mathrm{~cm}$.

$$
\begin{gathered}
\text { Umfang von Abteilung II } \text { if } \mathrm{cm} \text {, } \\
\text { " }
\end{gathered}
$$

Die Durchlassweite dieses Korbes wa etwas geringer als diejenige rom Korb I, im Durchschnitt in der Ahteilung 11 etwa 6 mm, derint, dass etwa die Hälfte der Lüeken etwas über $6 \mathrm{~mm}$ mass, die audere Hälte etwa jo bis is mm.

Diese beiden Körbe wurlen alsu nit (iazenetzen aus Seide (lichte Weite der Maschen ca. $1 \square m m$, Crriesgaze No. Is ron Landwehr [Berlin]) üherzogen, um das Verhältuis der grossen und kleinen tiameelen lestzustellen.

Die Körbe mit dem Überzug wurden in derselben Weise befestigt, wie im Vorjahre (vergl. Fig. 1 Tiuf. I). Am 26. Mai des Abends üher Niedrigrasser gegen 10 Uhr aufgestellt, wurden sie am folgenden Morgen um 10 Uln bei Niedrigwasser entleert. Sie fingen also zur Nachtzeit.

Der Fang war folgender:

liorb I mit Netzhülle:

In der Netzhülle (man sieht in Fis. I 'T'at:. I, wie die Netzhülle durch den gemachten Hang unten beutelig herabhängt) beland sich mit dem Eimer ein Gewicht ron 8 l'fund, der Eimer wog $t^{1 / 2}$ Pfund, also der (ansgesiebte) Fang netto :1\% Pfund.

Im inneren Korb hefand sich ein Fang mit Eimer ron $4^{1 / 2}$ Pfund brutto, der Eimer wog ca. $3^{3 / 4}$ Pfund, danach hetrug der Fang netto ca. $3 / 4$ Pfund.

Korb II mit Netzhülle:

In der Netzhülle befand sich ein Fine mit Eimer von brutto 1르 Pfund, der Eimer wog S Pfund, also betrug der Fang netto 4 Pfund.

Der Fang in hölzernen Korb betrug netto ca. 1/2 P'fund. (Stückzahl unten angegeben.) Ier Beifang bestand in allen Fïllen aus eingen klemen Fischen (Stint, Sprott, Herings- 
larven, Liparis, Gobius, 1 Aspidophorns) und in dem engen Netz ans zahlreichen Mysis. Carcinus schien dagegen noch völlig zu tehlen.

Bei cliesem Nachtfang enthielt der imnere Holzkorb II im Ganzen folgende '/ahlul Garneelen:

$$
\begin{aligned}
& \text { 1.5 'liere ohne Eier, } \\
& \text { :I " mit Eiern. }
\end{aligned}
$$

Die Grössenverluälnisse derselhen waren:

a) Carmeelen aus dem imeren Holzkorth mit Eiern (der ganze Fing wurde gemessen):

$$
\begin{array}{cccccc}
1 & \text { Stück von } 4 \% & \text { mm Länge, } \\
2 & . & . & 50-5,5 & . & . \\
4 & . & . & 60-102 & . & . .
\end{array}
$$

b) Garneten aus dem inneren Holzkorb ohne Eier (nach beliehig gegriffener l'robe):

$$
\begin{aligned}
& 1 \text { Stück ron } 1: 3 \quad 1 m m \text { Linnge, } \\
& \text { I . . . . }
\end{aligned}
$$

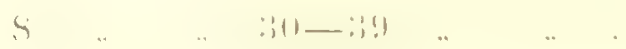

$$
\begin{aligned}
& \Rightarrow \quad . \quad 40-49 \quad . \quad \text {. }
\end{aligned}
$$

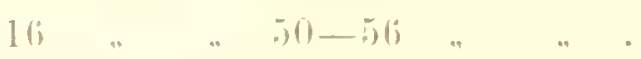

c) Garneelen aus dem insseren feinen Netz (in einer Handvoll):

$$
\begin{aligned}
& \text { ¿ Stiuck ron ! } 1 \text { mm tänge, } \\
& 1 \text {. } 14 \\
& \text { i .. . . } \\
& \therefore 47 \quad . \quad . \quad 30-39 \\
& \because: \quad . \quad+\quad 40-4 i \\
& 1 \text {. . . 50- } \\
& \text { (unter letzteren 으 Stück nit Eiern). }
\end{aligned}
$$

Eine Handvoll der entschlïpften Garneelen enthielt also:

$$
\begin{aligned}
& \text { (i) 'Tiere ohne Eier, } \\
& \text { ¿ } \text { mit Eiern. }
\end{aligned}
$$

Die Körbe wroden ahermals anfrestellt und zwar rormittags sogleich nach der Entleerung. Sie blieben num den 'l'ag über stehen und zwar bis abends 10 Uhr. Sie fingen also über Tage. Das liesultat war folgendes:

Korh I :

a) Gewicht des banges aus lem imeren Holzkold) brutto (d. h. mit Eimer') 4': I'fund, Gewicht des Eimers 1 ${ }^{1}$ i Pfind, danach der Fimg srosser firanat netto $3^{1 / 4}$ P'fund.

b) Gewicht des Fanges in feinen Netz hrutto I: P'fund, davon ab Gewicht des Eimers s l'timol, bleibt

$$
\text { Fang kleiner (ilanat netto I Pfund. }
$$


Korb II :

a) Der Fang des Holzkorhes betrug brutto ! Pfund, Limer i $1 \frac{1}{2}$ Pfund, also Fang grosser Gramat netto $l^{\prime 2}$. Pfund.

b) Fang des feinen Netzes hetrug brutte 12 Pfind, Eimer it/2 Ptimd, danach Fang kleiner Granat netto 1\% $^{1} / 2$ l'und.

Der Beifung im II olzkorh war dem Gewicht uach geringfügig; es waren einige kleine Stint, ein kleiner Stichling und Butt, mehrere kleine Liparis, anch ein kleiner Hering von 8 cm Länge bis zur Schwanzilosse vorhanten.

Im feinen Netz finden sich einige kleine Larven von Stint und Hering, mehrere Syngmathms. Mysis reichlich, doch etwas weniger als tigs vorher: einige Corophimm.

Eine beliehig gegriffene Handroll des Fanges ans dem imeren Holzkorb II ergah 81 grosse Gramat ohne Eier ('lingestang),

14 . . mit Eiern.

Eine Haudvoll ans dem immeren Holzkort, I ergab

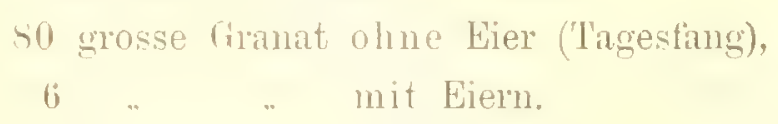

Unter io Tieren (natürlich olne Eier), welcht auf das (ieschlecht untersucht wurden, befand sich liein , es waren lanter Weibchen.

Die Garneelen hatten folgende Grössen:

1. ? mit Eiern ans dem imneren Holzkorb

$$
\begin{aligned}
& 17 \text { Stück ron .j1-.99 mm länge, } \\
& \because 3 \text {. }
\end{aligned}
$$

2. ()hne Eier (aus einer Handvoll)

$$
\begin{aligned}
& \text { I Stück ron } \\
& 10 \text {. . . } 31 \text { - } 10 \text {. . . . . } \\
& \text {.8) . . . 40 } 40-49 \\
& \text { 1.i .. . in- in } \\
& 1 \quad \text {. . . . }
\end{aligned}
$$

3. Aus dem äusseren feinen (iazenetz (alle ohne Eier)

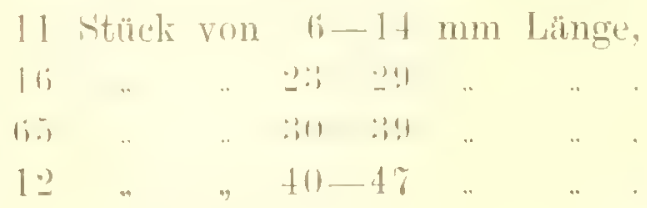

In übrigen gebe ich zur Ergatnzung dieses und des vorjährigen Berichtes noch einige Abhildungen. In Fig. ’- ist eine leihe von Körben dargestellt, bei denen sowohl der Leithorb als auch der Fangkorts ans Pitch-pine-stäben bestehen. In Fig. :3 sieht man in die Öthung der Leitkörbe hinein. Bei beiden Figuren sieht man in Hintergunde noch weitere lieihen von Garneelenkörben. Die Anfinalmen fanden etwa über Niedrigwasser stat.t. 
Die Knochenfabrik vou Varel, welche sonst die kleinen Granat verubeitet hat, war im Herbst 189 abgehnunt. Der Neuhau war noch nicht völlig beendet. Ein Einblick in den Betrieb der Fabrik konnte somit nicht gewonnen werden.

\section{Die Fischerei auf der Aussenjade zwischen Wilhelmshaven und Hooksiel (2\%. Mai 1898).}

Auf der Anssenjade wird in nenerer Zeit eine ziemlich intensive Granatfischerei mit der. Kurre betrieben und zwar hamptsichlich mit Schaluppen. Diese Fahrzenge gehören besonders nach Neuharlingersiel, einige aher auch nach Varel. Auch das Motorboot der Finma Siefken in Varel betrieb im Inai lsgs eine anscheinend trfolgreiche rischerei in der angegebenen Wasserstrecke.

Die Fischerei findet gewöhnlich derart statt, dass die lahrzenge mit der Ebbe abwärts wehen nach Hooksiel, um dimm mit dere ersten Flut aufwärts nach Wilhehmshaven zu zu fischen. Sie halten sich dabei ziemlich dicht an Rande der entblössten Wattflachen. Eine Slup ron Nenharlingersiel, welche mit der Fht stromanfwärts treibt mol die Kume') nachschleppt, ist in Fig. 4 (T'af. I) abgebildet. Wir sind an Bord dieser Schaluppe gervesen.

In Fig. 5) (Taf. II) ist die Kurre soeben eingewunden, der vordere Fischer hat gerade den mit dem Fang gefüllten Steert and Deck geholt. Nan sieht aus dem kleinen Umfang des Beutels, dass der an 20. Mai 1898 beohachtete Zug nicht sehr reich war, zumal der Beifang noch abgerechnet werden muss. Dieser Beifang bestand aber aus vielen Krabben (Carcinus) und ziemlich viel kleinten Schollen, sowie einigen Aspidophorus. Ahgesehen hiervon enthielt der Fang fast nur grosse firmat, wenig kleine. So wurde denn auch von den Fischeru gar nicht gesiebt, obgleich sich wohl äberall ein oder mebrere Siebe an Bord befinden. Auf' dent genamnten Fahrzenge hatte das Sieb eine rrösse von $50 \times 2$ 2. $\mathrm{cm}$, mit Längsstäben. Diese

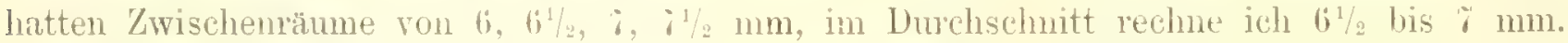

Die Ganeelen hommen nuth Entfernmes des Beifanges resp. math dem Sieben in einen durchlöcherten Blecheinsatz (Fig. 5, 'Tht'. 11, links neben dem Schornstein) und werden mit diesem in das kochende Wasser gesutzt, welches der Kessel des im Schiffsraum stehenden disemen Ofens enthält. Wenn das Wasser wiedermm kocht, können sie gleichzeitig mittels des Einsatzes aus dem Kessel herausgehoben werden. Der Kessel enthalt Seewasser, dem noch einige Ifund verstenerten Salzes zureftïgt sind.

Die gekochtem rarneelen werden auf eine siebartige Hürde seschüttet (Fig. 5), 'I'af. II, hinter dem Schornstein und links in Vopderorunde), um zu trocknen. Zunärhst aber werden sie mit Seewasser ühergossen.

Durch das Ühereiessen ïndert sich unverkembar der Geschmack der 'Tiere. Es muss nämlich bemerkt werden, dass nicht etwa für jeden trang nenes Wasser genommen wird, vielmehr dürte dieses otwa tiiglich nur ainmal geschehen. Dat num also mehrere Portionen 
im gleichen Wasser gekncht werden, so nimmt dieses alshald eine bouillonartige Beschaffenheit an, auch wird es nötig. später zn dem Wasser einige Pfund Salz nen hinzuzutügen. Die den gekochten Garneelen inhaftende Bonilon dünfte es sein, welche ihnen einen etwas herben Geschmack verleiht. Der Geschmack ist durchans nicht mangenehm, werden die Garneelen aher ahgespült, so wird der Ceschmack unverkembir etwas auders. Es lässt sich, wie mir scheint, daräher streiten, welcher lieschmack ler angenehmere ist. Jerlenfalls ist uns das Abspülen der gekochten Gameelen hier allein tutgegen getreten. Ein Nachsalzen der gekochten Garneelen seitens der Fischer findet wohl nirgend statt, dürtte anch wenig in ihrem Interesse liegen, da sie nu hosten daron haben würden, zumal sie, wie gesagt, verstenertes salz hemutren.

Dass die Ende Mai lsgs hier wefungenen frameelen, ohne gesiebt zu sein, ron durchreg ansehnlicher Grösse waren, lohrt ein Blick aut das 'lrockensieh, links im Vorlergrunde der Fig. -) ('Tat: II). Ls geht aber anch ans den Messungen hervor', welche ich an drei Handvoll Ganeelen aus :- Schleppnetzä̈gen (ron je etra einstündiger Daner) angestelit habe. Diese drei Handvoll hestauden aus

\section{6:5 'Tieren mit Eien, \\ S1 " olne Eier.}

Die geringste Grösse hatten die letzteren. die kleinsten massen $: 39,86$ und : $: 9$ mm. Die grosste Menge aber hatten in die jo $m$ m und stiegen vereinzelt zu $\%$ s und $80 \mathrm{~mm}$ an. Die Eiertragenden dagegen hatten tine gexingste Grösse von 50 bis 55 mm, das Maximum lag in den Sechzigem, doch stiegen auch nicht wenige bis weit über $80 \mathrm{~mm}$ empor.

Genane Angaben enthït folgende Tabelle, da die drei Handroll röllig analysirt wurden:

1. Garneten mit Fiern:

$$
\begin{aligned}
& \text { b0) Stürk yon b0-.j! } \mathrm{mm} \text { Lü̈nge. } \\
& \text { sis . " } 610-69 \\
& 1.5 \quad . \quad 70-i(i
\end{aligned}
$$

2. Garmeelen ohne Eier:

$$
\begin{aligned}
& \text { i Stück von :39-3:) mm Länge, } \\
& 2: 3 \quad \text {. } \quad . \quad+11-4 ! \quad \text {. } \quad . \\
& 40 \quad . \quad .50-5 ! \\
& \$ \quad . \quad 160-60.3 \\
& 1 \ldots \text { in } \\
& 1 \quad . \quad . \quad \text {. }
\end{aligned}
$$

\section{Der Garneelenfang auf dem Watt vor Wremen (28. Mai 1898).}

Der Dampfer lief am 2s. Mai zuerst las Watt vor Padinghüttel und Misselwarlen an. Wohl stanlen hier noch zrei Reihen ron Ptählen. Welche zu Granatfinggeräten gehört hahen mochten, feräte selhst wren jedoch nicht zu sehen. Wir dampften daher schlemnigst mu der 
Küste entlang nach Wremen zu und fanden thatsächlich anch erst hier, quer ab von Schmarren bis Rintzehn, eine grosse Grupe von Granatkörben aus Weiden, welche ebenso wie auf der Jade dicht aneinander gestellt waren. Die kleinste Reihe, welche ich zöhlte, bestand ans vier Körben, die grösste aus 29 Veidenköben und 2 framatfuken. Im Ganzen standen hier etwa 100 Körbe. Alle Körhe waren zu den Seiten eines in dem hohen Watt befindlichen Prieles aufgestellt. Das Watt bestand an den höchsten Stellen ans einem mit Schlick vermischten Sand, in welchen der Fus, nur wenig einsank, an ten niedrigen Flächen aus einem zähen Schlick, und hiel sank man halb-knietief' cin.

1. Die Weidenkörbe.

Wie immer ist das Weidengerït zusimmengesetzt ans a) Leitkorb, b) eigentlicher Fangkorl (Aalliorb).

a) Der Leitkorb bestand, athnlich wie am Dollirt, aus geradlinig der Länge nach verlanfenden Weidenstiben, welche ziemlich weite Zwischenräume zwischen sich liessen. Ich hahe solche bis zu $12 \mathrm{~mm}$ gemessen. Zahlreiche /wischenrüume hatten Maschen von $\mathrm{y}$ bis S mun. Der Leitkorl, siebt, jedentitls sehr gut und vollkommen. Lr hatte eine Länge von $131 \mathrm{~cm}$ (in einem Falle). Die vordere öffumg ist meist von oben nach mten ziemlich stark zusammengedrückt, hatte im voliegenden falle einen Breitendurchmesser von $108 \mathrm{~cm}$ und Höhendurchmesser vom $i ! \mathrm{cm}$. Die untere Kante des Gerätes lag dem Boden ziemlich dicht auf. sodass meist etwas Schlick an dem Vorderranle hineintrieb und diesen verdeckte.

Durch zwei Pfühle wird der Korl, voln in Lage gehalten, hinten sind ebenfalls zwei Pfähle in den Boden gesteckt. Sir lanten unter dem Korb schrigg zusammen und bringen dadurch das verjüngte Hinterende des liorbes derurt über den Boden, dass die Mittellinie des Gerätes etwa horizontal liegt. In Fig. (i (Taf. II) rechts sind clie Körbe in ihrer natürlichen Stellung zu sehen. In Fig. 7 ('l'uf. I1) sieht man von vorn hinein. Un das Hinterende des Leitkorbes war bei hen untersuchten köblen ein 'Tuch gewickelt, über welches der Fangkorb geschohen wurde. So kam ein dichter Abschluss zu stande.

b) Der Fangkorly hat etwa die Ciestalt einer bauthigen Vase ohne Fuss (vergl. Fin. 6, I'af: II). Ihas vordere trichterfüminge Stück ist über das Ende res Iseitkorbes geschoben, das hintere Ende durch einen Ballen von Hen verstoplt. Das Hinterende wird durch schräg in den Boden gesteckite Stöclier gretragen und dadurch horizontal über dem Schlammboden schwebend erhalten. Lin Strick verhindet die Pfähle mit einander, wird atuch krenzweis hinter dem Heupfropt durchgeführt, so dass diesel nicht heraustreiben kann. An der Innenseite des Heupfropfes befunden sich neist die kleinen Granat resp. Nysis, welche mitgefangen waren.

Thei Haupttypen von hörhen waren vorhanden. Die meisten waren in folgender Weise gebant: Dickere Weidenstabe (im Cianzen etwa 20) Stück) Jiefen in etwa 5 cm $\Lambda$ bstand der fänge nach über den Konb. Senkrecht dazu zogen andere Weidenstäbe derart, dass sie abwechselud äher und unter die Längsiähe sidh bogen. Sie schlossen eng aneinander, so

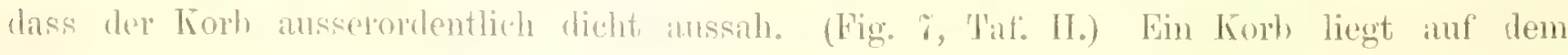




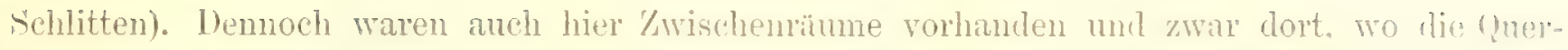
stïhe vor den Lüngsstäben ausbogen. Hier entstanden dreieckige, oft ziemlich weite Öffnungen.

Der zweite 'lypus war nach einem entgegengesetzten Prinzip' gehaut. Es fand sich hier nux eine geringe Zahl von (lnerstähen, dagergen zahlreiche Lüngsstäbe, welche einen Abstand von, wie ich schätze, durchschnittich i) nm hahen mochten. Sie waren also ähnlich gebaut wie die Granatkörbe des Jollart. In dieser Sorte habe ich jedoch nur ein einziges ziemlich neues Stück gesehen.

Ein dritter Typus vermittelte zwischen den beiden erstgenannten. Hier hestamr nämlich das vordere und hintere knde des Korbbaurhes aus dem dichten Geflerht nach Typus I. Das Mittelstück dagegen wies den Ban des 'I'ypus II auf.

In der oben erwïhnten langen Reihe ron Fanggeriten sah ich schliesslich noch einen der schwaren Vareler lörbe aus Pitch-pine-Stïhen.

$\because$ Garnkörbe.

An Garnkörben waren 2 Stück vorhanden, welche in Fig. 6, 'Taf. II, abgebildet sind. Sie bestanden nux ans Netzwerk. Die vordere Oiffumg war rechteckig, l25 cm hoch und $264 \mathrm{~cm}$ breit. Sie wurde durch zwei Seitenstabe offen gehalten. Diese Stabe waren an zwei in den firund geramme Plähle angebmden. Fin drittel dünnerer P'ahl stand mitten vor der Öffnung und diente dem straff gespamnten ()her- und Untersimm als Stütze. Das Untersimm stand wenig über dem Boden.

Nach hinten spitzte sich der Carnkorb trichterförmig zu, doch wurde das Netzwerk durch einen vorderen weiteren und zwei hintere engeve Ringe gespannt gehalten. Neben dem vorderen Holzring steckte jecherseits ein tragender Pfinl im Borlen. Von diesem ersten Ringe erstreckte sich anch eine Einkehle etwa bis zum zweiten Ringe. Hinten war das Netz zugebunden und an einem in den Borlen gesteckten Ptahl festgeheftet. Die Länge betrug vom ersten Bügel bis zun zugeschnürten Ende les lierïtes 142 cm. Die Maschenweite war vorn is mm, hinten $13-14 \mathrm{~mm}$.

Die Carnkörbe wareu leider hereits entleert.

3. Der Fang der Weidenkörbe.

Es wurde der Fang aus zwei Stück der querüber getlochtenen Weidenkörbe von dem betreffenden Fischer erworben und gewogen. Der ganze Fang beider Kürbe wog netto nicht. mehr als 2 l'tum und dabei ist zu bemerken, dass dieser F'ang von :3 'liden herrührte, da der Fischer die Geräte am vorhergehenden 'Tage nicht besucht hatte. Gena genommen rührt der Fang also von ㄹ Nachtticlen und I T'astisle her.

Nach dem Befunde komnte tïglich an der Angabe des Fischers, dass er früher mit 4 Körben meln' getangen halbe, als jetzt nit ungetahn ?0 Körben, nicht wohl gezweifelt werden.

Was die Grössenverhältnisse der Gameelen anbetrift, so massen die kleinsten des Fanges : $: 0-40 \mathrm{~mm}$, die grösste Henge zwischen $t 1$ und mit $166^{2} \mathrm{~mm}$ Litinge notiert.

Abhandingen des loutschen stefischurei-Vereins, band $\mathrm{V}$ 
Unter einer Handroll aus dem Fange befanden sich 113 Stïck ohne Eier und nur :) Stück mit. Eiem.

Die genanen Grössenverhilinisse der Garneelen aus einer Handvoll waren folgende:

1. Garneelen mit Fiern:

Die 3 Thiere massen hi-j!) num Lünge.

2. Tameelen ohme Eier:

4 Stück von 3\%-:39 mm Lïnge,

48 . " $40-49 \quad . \quad .$.

50 $\quad . \quad . \quad 50-.59$

1 . .

\section{Der Garneelenfang vor Otterndorf (7.-8. Juni 1898).}

A. Der Fang mit Garnkörben.

Am linken Flbufer auf dem Watt vol Otterndorf stehen eine Anzahl von Garnkörben und zwar, soweit es vom Ankerplatz gesehen werden komnte, stets paarweise.

Jeder dieser beiden Körhe bestand 1) aus der eigentlichen heuse von etwa 2 m Länge. Sie wurde durch 5 Holzringe nffen gehalten, wie aus Fig. 8, 'laf. II, zu ersehen ist. Die Dimensionen waren z. B. folgende:

Holzring I (am Eingang der lieuse.)

Netz I. Netz II.

Lichte Weite. . . . . . $43 \mathrm{~cm}$

Abstand vom ling I bis Ring II . 6:3, . 5t cm

Holzring II.

Lichte Weite. . . . . . 38 .

Abstand rom liking II bis Ring III $46 \ldots 4$. 44 ,

Holzring III.

Tuchte Weite. . . . . . 32

Abstand vom Ring III bis Ring IV 47 , 45 ..

Holzring IV.

Lichte Weite. . . . . . 30

Abstand rom ling IV his Ring V. $48, .46$.

Holzring $V$.

lichte Weite. . . . . 28 ..

Eniteil des Netres. . . . . 35 . 39.

Von Holzring $I^{\top}$ bis zum zugebun-

denen Ende des Netzes . . . 2i .

Die Rense hatte zwei Einkehlen und zwar Nummer 1 beginnend zwischen Ring I und II und endend hinter Ring II. Sie warde durch + Bändsel, welche an Ring III innen befestigt waren, quadratartig offen wohalten. 
Einkehle Nummer"2 begann zwischen ling III und JV und endete kitz hinter ling IV. sie war mit 2 Faden an ling $V$ hefestigt; ihre Öfrnung war also schlitzförmig gestaltet.

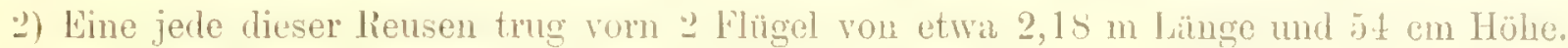
Die Flügel hatten, ebenso wie das rordere Stück der Reuse bis zur ersten Einkehle, eime Maschenweite von $14 \mathrm{~mm}$, während das übrige Stück der Reuse Maschen ron $10-11 \mathrm{~mm}$ anfries.

Je zwei Reusen waren derart nuheneinaniler aufgestellt, dass die inneren beiden Flügel an der ausseren Spitze zusammenstiessen. Die beiden äusseren Flügel erhielten durch vorgesetzte Netzstückn noch eine bedeutende Verlängerung, welche in dem näher in Betracht gezogenen Falle eine Länge von etwa $12 \mathrm{~m}$ hatten.

Die Aufstellung anf dem Elbwatt war derart, dass die geöffineten Flügel nach dem Lande zu schauten, das geschlossene lieusenende nich dem Flussbett.

Die hinteren Abschnitte zweier lieusen wurden mit den Gazenetzen am Abend des \%. Juni überzogen und am $\triangleleft$. Juni früh i Uhr entleert. Das Resultat war folgendes:

$$
\text { Reuse No. I. }
$$

a) Inneres lieusemetz:

Gewicht des Gesamtfanges . . . . . . 4 Pfund

Hierron ab der Beifang, bestehend aus ziemlich

viel kleinen Butt, einigen Stint und Stich-

lingern

$$
\text { Also (iarneelen netto } \frac{1}{3 \text { Pfund. }}
$$

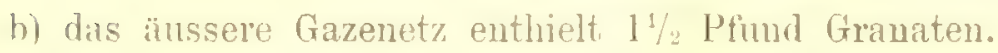

$$
\text { Reuse No. } 11 .
$$

a) Inneres Reusennetz:

Crewicht des Gesamtfanges . . . . . . 4 Pfund

Hiervon ab der Beifang (4ti kieine Butt,

$$
\begin{array}{r}
\text { einige Stinte, Stichlinge, etras , Seemoos") } \cdot-\frac{11 / 2}{21 / 2 \text { Pfund. }} \\
\text { Gametlenfang netto }
\end{array}
$$

h) Im äusseren Gazenet $\%$ Fing $=\stackrel{01}{1} 1 / 2$ Pfind.

Hierbei muss bemerkt werden, dass sich im vorderen Netzteil der Reuse ein kleines Loch befand, so dass der lang im Gazenetz dudurch ein wenig grösser ausgefallen sein dürtte. Drei kleine Butt im Gazenetz wurden zum Verräter des Loches.

Die Analyse des Fanges rrgab folgendes allgemeine Resultat:

Es wurde je eine Handroll ans dem immeren und dem äusseren Fange analysirt, davon waren 2206 Stïck ohme Eier,

1 „ nit Liern. 
In der Reuse gefangen waren von einer Handvoll

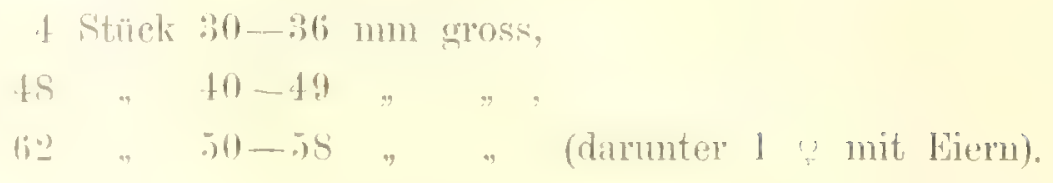

Ausserdem ein (iammanus.

Im ïusseren Gazenetz helanden sich muter einer Handroll

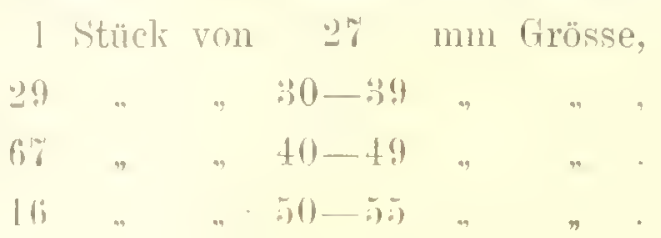

Ausserdem 11 Mysis, : Gamminus, 1 Stichling.

Es geht hieraus also hervor, dass aus der Reuse fast alle Thiere bis zu $39 \mathrm{~mm}$ Lünge entkommen waren und ferner der grösste 'Teil der zwischen 40_4! mm messenden Garneelen, sowie ferner der vierte 'T'eil der in die füntzig messenden Garneelen.

Die Garneelen waren fast sämtlich weiblichen Geschlechts, zwei kleine Proben enthielten

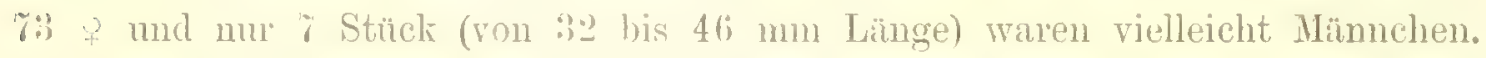

Die bei dem im allgemeinen kleinkalibrigen Fange sehr bedentende Siebkraft der Reusen wird aus ilnem Ban ohne weiteres verständlich. Die Maschen der Reusen von 10 bis $11 \mathrm{~mm}$ Weite werden durch nicht weniger als j) Bügel gespamt erhalten. Die Maschen sind allerdings an manchen Stellen trotzlem in lie Lunge gezogen. Die engsten Maschen befanden sich zwischen den beiden letzten Bügeln, aher selbst hier hatten die gestreckten Maschen noch eine Länge ron 1.2 mm und tine Breite von j mm. Der zugeschnürte Endliegel des Netzes hatte allerdings nach dem geschlossenen Ende immer enger werdende Maschen, sie massen aber auf halber Ilöhe des liegels noch $122 \mathrm{~mm}$ in der Länge und $8 \mathrm{~mm}$ in der Breite, beides in der lichten Weite. Dabei verdient hervorgehoben zu werden, dass die Reusen bereits auf das ïusserste straff gespannt waren. Ich habe vergeblich versucht, das Netz noch straffer anzuziehen.

Es würle eine völlig verkehrte Annahme sein zn glanben, eine solche farneelenreuse kömne durch strafferes Anziehen seitens der Fischer engmaschiger gemacht werden. Das ist. völlig ausgeschlossen.

B. (tranatiang mit kleinen Schleppuetzen.

Bereits an Abend, als wir wo otterntorf zu Anker lagen, kam aus der Oste ein kleines segelboot und trieh mit, der letzten lihbe am Watt entlang elbabwärts. Am andern Morgen war ein zweites. gunz ähnliches Bont. zn1 Stelle. Es ist in lïg. 9, 'T'af. III, abgebildet. Bei heiden diente ein Bügel, welcher otwa Form und frösse des Bügels eines Schiebehamens hatte (siehe 'Tat. VIH, Fig. :3(1)), als Finggerat. Tedoch wal die mutere Leiste stark mit Blei

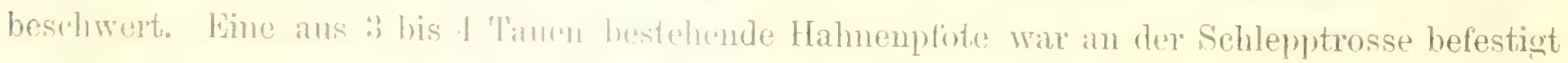

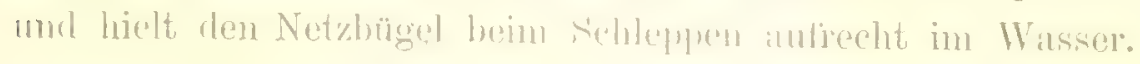




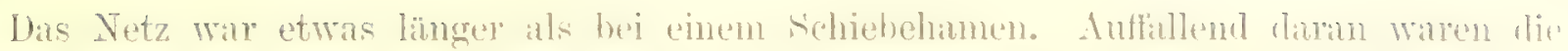

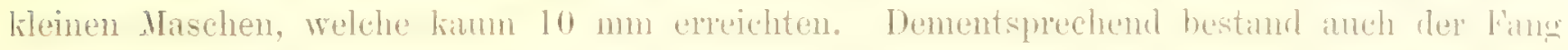
fast atuschliesslich aus sehr kleinen rameelen, I. h. aus den keinsten der vorstehond an-

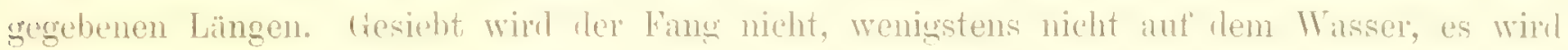
vielnehr alles mit nach Hans genommen. Dis kleine Naterial wird dort verfütert oder anch als l)iunger benutzt.

Diese Art der Fischerei, welche durch Fig. !), 'Taf. IIJ, endintert wird, inden hier das Boot gerade den Kumlamen schleppt, wird anscheinend nur von Gelegenheitsfischem ausgenbt. wenigstens waren die beiden benbachteten Hahzenge solche. Der Ertrag war in beiden Fälen. zum 'Teil wohl infolge der flanen Brise, ausserordentlich geringfügig. Sie ist jerloch nuzweifellat von allen Fischereibetroben, welche anf prenssischem Gebiete beobachtet wurden, die suhälichste.

\section{Die Granatfischerei in Süder-Dithmarschen (8. -9. Juni 1898).}

Der Granatfang wird in dere Umgebung ron Brunsbütel und in den Köögen mit Kúmen mnd streichern (sog. Krautjallen) betrieben. Len Centralpunkt für diese Fischerei bildet Marne, woselhst neuerdiogs anch eine Konserveufabrik tïr Garneelen errichtet werden soll.

Wirtschaftich am bedeutendsten ist in ganz Süder-Dithmarschen die Kinrenfischerei. Derzeit wurde sie hamptsichlich von Cuxharen aus betrieben, wohin sich die Kurrenfischerfahzenge dieses Küstenstriches zun srossen 'Teile begehen hatten. Es haben jerloch diese Fahrenge durchaus keinen besonderen 'Typus, man henutzt hierzu vielmehr allerlei kleine halboder auch ganz gedeckte Fahrenge, welche wohl allgemein die Bezeichmung "Jollen " fülıen.

Eine grössere Anzahl Gameelentischertahrzenge lagen am 'lage vor Pfingsten im Hafen von C'uxhaven, da der Fang derzeit in der Elbmünlung am reichsten war. Es wird diese 'T'hatsache ams den, was wil ans Carolinensiel und der Jade-Mündung erfahren haben. mol aus dem, was sich bald laraut aus der L'iep und Eider ergah, ohne weiteres verständlich. Anch wurde uns mitgeteilt, dass ein nenerdings in Neuhaus a. O. beschaftes Motorboot unterhalh cuxhaven Ganneelen mit der Kinve tische.

Unter den in cuxhaven liegenden Garneelenfischer-Fahreugen bemerten wir anch eins von Neufeld. So kam es denn, dass wir am S. Tuni im Hafen ron Neuteld die lischer nicht antrafen. Nur eine. Jolle lagr hier zu Anker, welche ausser eimem zum 'I'rocknen aufgehängten Buttnetz und einen Viehnetz anch eine kleine Cianeelenkmo an Borr hatte.

Hinter Nenteld den Deich entlang fahrend, fillt es dem Beschanel aut, eine wie hudentende Wattfäche, welche in grossen Breiten bereits zu einer nenen Eindeichung reil ist. sich dem urbar genachten Lande vorlagert. Lis sind nur wenige vitulen rorhanden, an denen es den Fischerfalnzengen möglich ist, das Land zu ureivhen: demnoch ist die hiel betrobene (ranneelentischerei bemerkenswert, wenn sie auch weit daron enternt, ist, die lieutentung zu haben. welche diesem schwer zugänglichen und wenig bekimnten Landstrich zugeschriehen wirl. 
Die wrohtigsten Orte för fiarveelenfischerci an diesem Küstenstrich sind Schaf'stedt nnd Schadendorf. Die \%eit gestattete es ms nicht, das Priel zu besuchen, in welchem die Fischerfahrzenge zu liegen pflegen. Wir hegnügten uns, einige hinter dem Deich des Kronprinzen-Koog liegende Fischerwohnungen aufzusuchen, zumächst den Fischer P. Wir sahen bei ihm eine nene Garneelenkurre. Sie hatte Maschen von 11 his 12 mm. Eine dem Fischer S. gehörende Finre ist in Fig. 10, Taf. III, abgebildet. Sie ist 6 Fuss breit, 2 Fuss hoch (gemessen $52 \mathrm{~cm}$ ) und 8 Fuss lang. Ihre Maschen betrugen ebenfalls 11 bis $12 \mathrm{~mm}$. Sie legen sich, wenn straff angespannt, sehr eng zusammen, wie aus der Abbildung hervorgeht.

Lie Art, wie diese Fischer den Fang sieben, ist sehr interessant und weicht erheblich von dem an allen anderen orten gefundenen Brauch ab. Sie sieben namlich zwei Mal. Die erste Sortierung findet draussen nach dem Fang statt. Sie benutzen hierzu ein hohes Sieb mit Längsstäben, üher welches sie den Fang hinlaufen lassen. Es mag dieses Sieb also ähnlich wirken, wie dasjenige, welches zum Sortieren von Sand oder Grand gebraucht wird. Das Sieb ist in Fig. 11, Tinf. III, liuks abgehildet. Ein Blick auf die Abbildung lehrt bereits, wie weite Maschen dasselbe hat, Ich mass sie zn $: \frac{1}{2}, 8,9,10 \mathrm{~mm}$, in einem zweiten Falle zu $7: / 2$, b, 9 bis $11 \mathrm{~mm}$.

Es ist jedoch einlenchtend, dass bei dem einfachen Herüberlauten über das schräg gestellte Sieb nicht alle kleinen Gameelen frei kommen. Daher findet noch eine zweite Auslese statt, diese allerdings erst nach item Kochen. Das Kochen geschieht zu Haus in einem gemanerten Herd, welcher mit augehorigem Schornstein in Fig. 12 (rechts) zu sehen ist. Die gekochten Garneelen werlen alsdam in den in Fig. 12 (links), 'I'af. III, ebenfalls dargestellten Schüttelapparat gebracht. Es ist dieses ein Gestell, welches im allgemeinen die Wirkung eines Trichters hat. Als Siebplatte dient in ihm ein mit (querstäben oder mit Quadratmaschen versehener Holzrahmen Fig. 11 (rechts). 'Taf. III. Der Schüttelapparat ist an zwei Ketten frei beweglich aufgehängt, sodass sirh anch das Sieb durch Kippen entleeren lässt. Das mit Querstäben versehene Sieb für die gekochten Garneelen hatte Öffnungen von $5^{1}{ }_{2}$ bis $6 \mathrm{~mm}$, dasjenige aus Drahtgeflecht (Quadratöfnumgen von $10 \mathrm{~mm}$, ein anderes Exemplar solche von $12 \mathrm{~mm}$.

Die durch das Sieb fallenden gekochten kleinen Gameelen werden an arme Lente abgegeben, die grösseren werlen verkauft.

Der Weg führte uns ron hier weiter nordwiirts nach der auf' den Karten als „Dielssand" bezeichneten Hallinsel, welches Wort man daselbst merkwürdigerweise gar nicht zu kennen schien. Das Land wird auch als König Friedrich VII. Koog hezeichnet.

An die Granatfischerei dieses linoges waren wir mit besonderen Erwartungen herangetreten; wir wurden sehr enttüuscht. Wir erfuren, dass es im Hafen vor der sog. Rugenorter Schlense eigentlich nur einem Gamelnfischer gïbe, und dieser war auf der Elbe abwesend. Die vereingelten Krautjallon spielen keine wesentliche Rolle.

Hiermit rerliessen wir das mit der Elbe direkt in Verbindung stehende Gebiet und 
wandten uns dem Nordunde der Halbinsel zu. Hier ist nur eine Stelle vorhanden. Welche als Liegeplatz für kleine Fischerfuhrenge in Betracht kommt, nïmlich ein langes l'riel im flachen Watt ror Rathjensdort, welches uns als der "Haten les nördlichen Rironprinzenkoog" bezeichnet wurde. Es fischen von hier aus einige $(t$ i) Fischer von st. Nichaelisdom ant Garneelen, und zwar mit kleinem Schleppnetz und mit Krautjallen unter Benutzung oflener Boote. Es fischen z. B. von einem Boote aus Vater, Intter, Schwiegersohn und T'ochter. Der Vater arbeitet mit Boot und Schleppnetz, der Schwiegersohn und die beirlen Damen steigen in das Wasser und schieben je eine Krantjalle. Der Fing soll an Bord gesieht werden. Die Fischer waren zum Fang ausgefahren, nur ein offenes Boot mit einer Krautjalle lig in dem Hafen, ein Sieb hefand sich nicht in ihm. Eine Krantjalle batte Haschen von $11 \mathrm{~mm}$.

Die Reise nordwints am Deich fortsetzend, kamen wir zll einem zweiten, das Watt in gewundenem Lauf durchsetzenden l'riel, dem sog. Barlt-Hafen. Fin Fahrzeug irgend welcher Art war hier überhaupt nicht zn sehen, anch wurde uns mitgeteilt, dass nur einige Fischer von Donn (so wurde St. Michaelisdonn hier allgemein genamnt) mit Krautjallen zum Garneelenfang ansgingen. Fischerboote seien hier überhupt nicht rorhanden.

Rasch ging die Reise daher weiter nach Meldortel. Haten. Auch hier, wo doch einige Lastfahrzenge zu Anker lagen, fehlt es völlig an lischerfihrzengen. Nur einige offene Boote werden gelegentlich zum lïschen benutzt. Garneelentischerei wird ron einigen Mïnnern und Franen ron Meldorf mit dem Schiebehmen ausgeüht.

\section{\%. Die Granatfischerei von Büsum (10. Juni 1898).}

Büsum kann unzweifelhaft als der Ort der bedentendsten Granatfischerei an der preussischen Küste betrachtet werden. Die Flotte der Garneelentischer ist jetzt bis aut' 30 Stück angewachsen. Damit ist nicht nur die höchste Zahl erreicht, welche an einem Orte rorkommt, sondern es sind hier auch die stattlichsten Fahrzeuge vorbanden, meist grosse gedeckte Kutter von wenigstens 25 cbm Brutto-Raungehalt ohne die Bümn.

So bietet dem schon ein Blick auf den Hafen von Büsum ein sehr interessantes Bild. Fig. 13, Taf. IV. Was mau sieht, sind fast sämtlich Garneelenfischerfahrzeuge, als solche kenntlich an der zum 'Trocknen am Mast aufgehängten Gameelenkurre.

Die Fischerfahrzeure, welche reichlich die Grösse der Norderneyer Schaluppen haben, müssen stark «ebaut sein, da sie zum Fischen weit hinaus gehen. Wir gingen am 11). Juni 1898 mit ihnen aut den Fang. An der , ,Littel-Plate“, welche die Norder-Piep und die Süder-Piep ron eimander scheidet, teilte sich auch die Fischerflotte. Eimige Fahrzenge segelten in die Norder-Piep, der grösste 'I'eil, welchem wir nachfolgten, wählte die Süder-Piep zum Fischen.

Die Kurre hat, der Grösse des Fahrzenges entsprechend, anselnnliche Limensionen. Die Länge des Kurrhammes betrïgt 20 Fuss, die Netzöfnung 10 F'uss. die Netzlinge etwa 30 Fuss. 
An dem Kurrenbann sind entwerler eiserne Klanen befestigt, ähnlich denjenigen, welche die Segelfischer in der Nordsee henutzen, oder auch eiserne Bügel von der gleichen Gestalt wie beim Baumschleppnetz der Fischdampfer. Die Netzöfnung hat hei Bemutzung der Kilanen eine Höhe vou $52 \mathrm{~cm}$, bei Benutzung der eisernen Bügel eine Höhe von $50 \mathrm{~cm}$.

Die Maschen des Tinremetzes betragen am Eingang 16 bis $1 \% \mathrm{~mm}$, im Steert $10 \mathrm{~mm}$.

Dit das Netz infolge seiner Grösse für die 2 Jann Besatzung reichlich schwer ist, so ist zux Erleichterung des Einholens eine simmeiche Eimrichtung angebracht. Die Sprenkel des Netzes haben nämlich eine Länge von etwa 10 Faden. An ihrem Ende ist ein Block festgemacht und die Kurrleine lïult durch diesen Block und wieder zum Schiff zurück. So wirkt die Eimrichtung wie ein lisschenzug.

Wir fischten mit der Kurre am Sütrande der Süder-l'iep auf": bis 4 Faden Wasser über Ebbe. Da hier ein ziemlich starker Strom lief und anch der Wind mit uns war, so wurden etwa : $: 5$ Faden Leine ansgegeben.

Der l'ik des Grosssegels wurde beim Fischen herabgelassen, wie aus Fig. 14, T'at'. IV, hervorgeht, welche ein anderes in mserer Nahe fischendes Fahrzeug darstellt.

Das Kimmen danerte 1\% Stunde. Damn wurde das eine Ende der Kurtrosse von den beiden Fischern angezogen und die Trosse an Deck des Fahrzenges aufgeschossen. In Fig. 15, I'al. IV, sieht man, wie das Netz an das Fahrzeng herangeholt ist, man sieht den runden Kurrbaum und fermer, dass das untere Ende der Kurrklanen dureh Aufbinden eines Eisenblockes noch beschwert ist. In Fig. 16, 'Taf. IV, ist der Bamm an Deck geholt, die Fischer sind beschältigt, das Eude des Netzes an Bord zu holen.

Dann wirl der lang an Deck entleert. Er ist ziemlich gross, auch der Beifang erheblich. Der Beifang bestand aus sehr zahlreichen kleinen Schollen und Scharben, 2 kleinen lochen, mehreren kiemen Kíliau. Diese hatten folgende Dimensionen:

\begin{tabular}{|c|c|c|c|c|}
\hline $4 ! \mathrm{mm}$ & $50 \mathrm{~mm}$ & (is) $\mathrm{mm}$ & $11: 3 \mathrm{~mm}$ & $12+\mathrm{mm}$ \\
\hline 17, & 51, & 65, & 109 & $126 \mathrm{~mm}$ \\
\hline & $55 \quad$, & & 115 & \\
\hline & $55 \quad$, & & $10 ! 9$ & \\
\hline & 54 & & & \\
\hline
\end{tabular}

lerner vorhanden ein kleiner Kkleist, viel Liparis, einige Gobius, sehr viel 'T'aschenkrebse (Cincinus), auch einige Lortunus, mehrere Serobicularia, Letztere sollen oft so häutig sein, lass das Netz nicht hoch zu bringen ist.

Die gefangenen Gameelen werken sogleich an Bord gesiebt. Die Siebe haben Längsstabe aus Eisendraht von ca. ¿ mm Stirke. Der Raum zwischen je ¿ Stäben wurte bestimmt

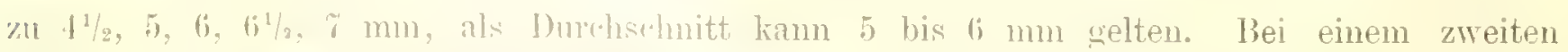
Sieb hatten die Maschen folgende IVeiton: $f^{1} / 2,5,51 / 2,6,61 / 2 \mathrm{~mm}$. Die Grösse des Siehes

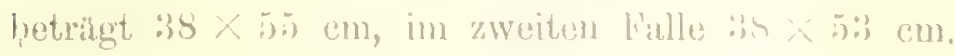




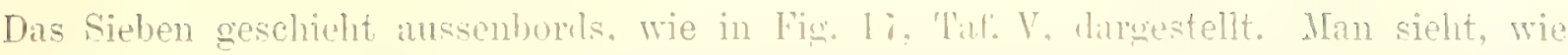
die Garneelen mit den Schwänzen durch die Mischen lagen. Mabei tancht der Fischer das wieb anch wiederholt in das Wasser und reinigt so die 'There zugheich ron dem Sand, welcher beim Fischen an ihnen hatten grehlieben ist.

Un die frösse des abgesiebten Guantuns zu bestimmen. wurden einige Eimer voll farmeelen gerrogen und gesiebt. Es regall, sich folgendes:

1. Der Eimer enthielt an ungewaschenem chanat netto . . . . . . ' c1/2 Pfumd

whesesieht wurden davon

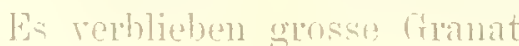

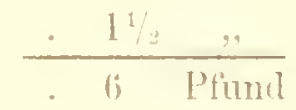

2. Im Fimer abgespülto Granal netho

ahgesiebt wurlen davon

Es rerblietren grosse (inimat . is Pfinit

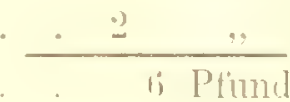

:3. Abgespülte Granat wrolen gevieht.

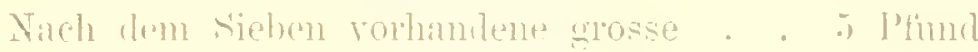

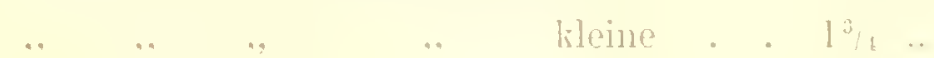

Der Beifang war in allen diesen Fallen rorher entfernt.

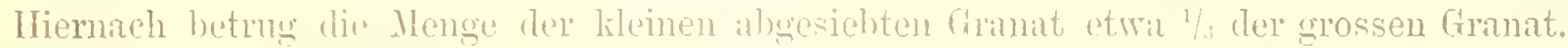
In einer Handroll der auseresiebten grossen foranate zählte ich:

39 Stürk mit Eiern, It Stück ohne Eirs, larmer abur '3 mit liesten hereits ansgeschl̈̈̈pter Eier. Hiervon waren ty Stück Wreibchen, t Stück Hïmnchen.

Was die Grössenverhältnisse anbetrillt. so waren vorhanden:

$$
\begin{aligned}
& 1 \text { von } 41 \text { 1mm Jülnge } \\
& \text { ㄷ․ } \\
& 1 \text {. } \\
& \text { 15. . . in - is .. . } \\
& \because \quad \text {. } 41111,4 !
\end{aligned}
$$

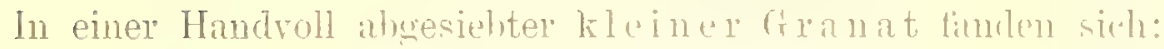

$$
11 \text { Stück mit Eiern. }
$$

119 ," ohne Eier.

Die Grössen waren folgendermatassen verteilt:

$$
\begin{aligned}
& 1 \text { Exemplar ron. 오 } 1 \text { mm Länge } \\
& 16 \text {.. .. } 3: 3-39 . \\
& \text { ii .. til }
\end{aligned}
$$

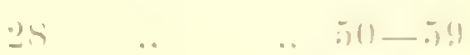

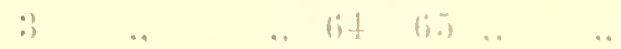

Die Behandlung des Finnges seitens der Fischer ist folgende:

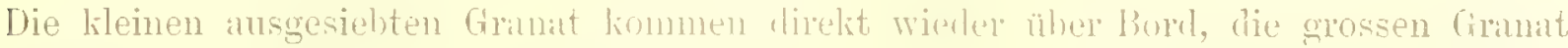

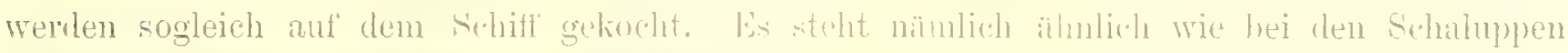


von Neuharlingersiel in Ram des Filnzenges ein eiserner Kochherd. Der Fussboden unter ihm ist cementiert. Der Shornstein ragt über Deck hinaus. Wenn das in dem Kessel befindliche Seewisser, dem noch einige Pfund Salz zugesetzt werden, zum Kochen gebracht ist, werden die gesiehten Gameclen in das Wasser geschüttet (Fig. 1s, Taf. V). Der bei Seite gelegte eiserne I leckel wird auf den Kessel gelegt. Kocht das Wasser alsdann wieder, so werden die Gameelen mit einem Kätscher aus dem Kessel gefüllt (Fig. 19, Taf. V) und zum Ablecken und Enkalten auf Sieben ausgehreitet. Dam geht es nach beendigtem Fang nach Haus und der Fang wird an die Händler abgeliefert, vielfach aber auch von den Fischern in Körben verpackt und direkt an die Konsumenten verschickt.

So blüht hier die Gameelenfischerei ersichtlich. Sie wird von Anfang März bis in den November betrieben, selten im Winter", weil alsdann der Fang spärlich ist. Der Fischer glaubt, die Garneelen seien im Winter in See. - Die ersten Gameelen werden im Närz ganz weit drussen in der Norder-Piep gefangen, in der Süder-Piep soll alsdann der Fang noch geringfügigs sein.

\section{Der Granatfang bei Warverort (11. Juni 1898).}

A. Der Fang mit Kurren.

Während von Büsum aus die Granatfischerei weit draussen getrieben wird, wo der Einfluss der freien Nordsee sich bereits stark geltend machen kanm, zumal Norder- und Süder-Piep bereits erhebliche Tiefen aufweisen, findet fast in dem letzten Ausläufer des nördlichen Priels jener Bucht, welche sich hier in das Ditmarschen-Land erstreckt, abermals eine ziemlich umfangreiche Garnetenfischerei statt. Sie bildet ein schönes Gegenstück zu derjenigen von Büsum: In Büsum starke und gedeckte Fahrzenge, deren Garneelenfischerei sich auf die äusseren Teile der Wattstrume beschränkt - in Warverort kleine offene Boote mit einer Fischerei nmmittelbar ror dieser Ansiedelung.

Zur Zeit unseres Besuches fmulen sich $1+$ offene Boote, mit denen die Garneelenfischerei mit Hilfe von Kurren betrichen wird. Fig. 20, 'I'af. V, gewährt einen Blick auf den kleinen Hafen von Warverort, in dem die lischerboote veraukert sind. Das segelartige Stück, welches am Mast hefestigt ist, ist die zum Trocknen aufgehängte Kure.

Die Kurren sint ungleich, haben eine von 2 bis $3 \frac{1}{2}$ und 4 m Breite wechselnde vordere Öfnnumg bei kaum 50 cm Höhe, wähend das Netz 4 bis $6 \mathrm{~m}$ lang sein mag. Die Netzmaschen betragen ca. $11 \mathrm{~mm}$.

Die von mir gemessenen Siehe hatten folgende Dimensionen:

No. 1. Holzkasten rom $34 \ll t 9$ cm Grösse. Die Bodenfliache bestand aus Längsstäben ron Eisendraht, welcher eine Dirke ron 2 mm hatte: ich mass die Entfernumgen der Stäbe zu (t), 5, $6, \% \mathrm{~mm}$.

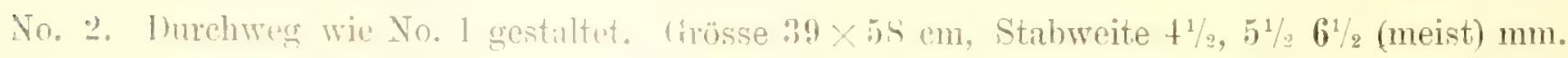
1)ie engen Stellen der siehnasehun kommen gewönnlich daher, dass die Eisenstabe verbogen sind. 
Dass die Siebe wirklich dazn benutzt werden, die in der Kurte gefungenen Gameelen sogleich wieder uber Bord zu sieben, haben wir beobachten können. als wir mit den Fischern zum Fang giugen. Doch wurde uns mitgeteilt, dass dieses Absieben nicht immer weschieht. sondern dass gelegentlich auch der ganze Fang mit an Jand gebracht wirl, um dort als Futter benutzt zu werden. Es wurde auch eimmal der Versuch gemacht, den Fischern den kleinen Fang zur Verarbeitung zu Futtermehl abzunehmen, doch ist dies bald anfregeben.

las Sieben wurde ron uns bei dem einzigen Boot beohachtet, welches einen eisemen Kochherd mitführte, um die Garneelen sogleich kochen zu können.

Es gieht, vielleicht von Wilhelmshaven abgesehen, lieinen zreiten ort an unserer Küste, ron dem ans die Kurrenfischerei so heynem hetrieben werden könnte, wie gerade Warverort. Die Boote branchen nux das geliummte Priel, welches die letate Verbindung mit dem Haten bildet, verlassen zu haben, dam sind sie bereits auf ihrem Fangplatz angekommen, nämlich in der .. Norder-Niele" oder dem Wöhrdener Hafenpriel, von dem die eigentliche .. Diele" oder das früher nach IIeldorfer Hafen führende Priel abzweigt. Ls ist diese Bezeichnung (Jiele) aus dem Grumde interessant, weil ein Süsswasserbach gleichen Namens, welcher bei Meldorf vorbeifliesst, sich in das Watt ergiesst. Doch mündet diese Süsswassermiele jetzt in das weiter südlich gelegene Fironen-I _och.

Die Fischer ron Warverort haben es somit äusserst bequem. Erst ungefah mit halber Ebbtide verlassen sie den Hafen, und mit der ersten Flut kehren sie schon wieder nach Haus zurück. Sie kömen daher bei diesem geringen Aufwand ron Zeit und Material schon mit einer geringeren Ausbente bestehen, welche allerdings während unseres Dortseins nur recht bescheiden war, zumal die Fischer infolge der warmen Wittermg Schwierigkeit hatten, ihre Ware abzusetzen.

Während in Büsum der Fang recht reichlich war, komte man ihn in Wartwerort also mur als gering bezeichnen. Dieser Lmstand in Gemeinschaft mit der anderen uns in Büsum mehrfach mitgeteilten 'Thatsache, dass die Garneelen von Warverort viel kleiner seien als diejenigen von Büsum, machten in mir den Wunsch rege, nicht nur die Verhaltnisse von Büsum, sondern auch diejenigen von Warverort genau kemen zu lemen. Dem wenn auf der gleichen Wasserader, wie sie die Piep mit ihrer Verlangermng in die Ditmarsche Bucht durstellt, derartige Verschiedenheiten rorkommen, so könnte das für etwaige gesetzliche Massregeln die grösste Bedentung haben.

Gleichzeitig konnte in Warverort noch ein interessantes Experiment rersucht werden. zu welchem die liurremetze in Büsum und anch in 'T'ömning zu gross waren, nämlich den Steert des Schleppnetzes mit dem feinen Gazenetz zn überziehen. Allerdings wurde anch hier das ziemlich kurze Netz lasch so weit, dass das ginze Gazenetz nicht mehr darüber gezogen werden konnte. dennosh aber liess sich ein kleines Stück des Steertes mit dem Gazenetz noch umhällen. 
Das Resultat war fulgendes:

1. Tn der Norder-aliele mude vormittags $!^{3} / 4$ Uhr, halbe 'Tide, erbentet:

a) Im steert del himere

$2{ }^{2}+$ Irft. netto meist grosse Garneelen (lieifang: Grosse Mengen von Carcinus maenas, ferner zahlreiche kleine Butt, 1 grosse Seenudel, mehrere Liparis, Frobius, \%ouress, Aspidophorus, Osmerus).

h) Im Gizenetz:

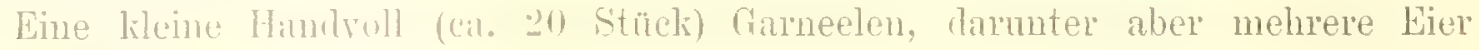
tragende.

2. In der Süder-Miele:

a) In Steert iler liure:

Netto $3 / 4$ Pfund ciarneelen.

(Beifang: Etwa lin Stürek Kleine Secnaleln, :30 Stück kleine Butt von 25) bis

40 mm Lïngt, ansserden zahlreiche der oben genannten 'Tieraten.)

b) Im (razenetz:

Tetto 1 P'tmid Garneclen.

Über die frösse iler Garmeelen ist folgendes auszusagen:

a) Garneelen aus dem Sterrt der Krurre:

In einer IIandvoll befanrlen sich :3!) Stück mit Ëern.

31, oll ne Fier.

:" Die Gilmeelen mit Hiern hatten folgende Dimensionen:

:3: Stück ron jo jol $\mathrm{mm}$ Lünge,

$$
\text { i. ". } 60-1 ; i, ., .
$$

wameelen oh no Hin":

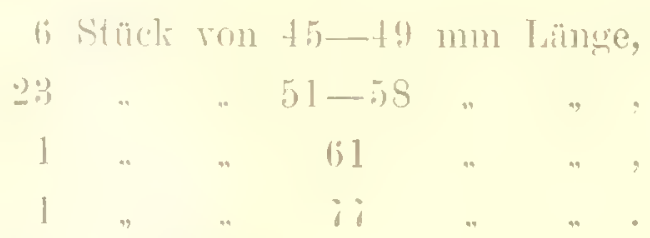

b) Girmelen aus dem fiazenetz:

In einej kleinen Handyoll fanden sich

42) Stürk olnue Eier,

2 " nut Eiern (von jo und si mm Lünge).

Die Garneelen ohme Eicr hatten folgende Dimensionen:

$$
\begin{aligned}
& \text { I!) sitürli ron :31 - : is mm Lünge. } \\
& 2(1) \quad \text {.. } 40-4 \text { ! } \\
& \therefore \quad \therefore-\quad \therefore
\end{aligned}
$$

Ans dem fiazenetz halue irh lann noch eine Anzahl von Garweelen a usgesueht, welche mir hesonders klein culer hesonder's gross erschienen. Sie massen: 


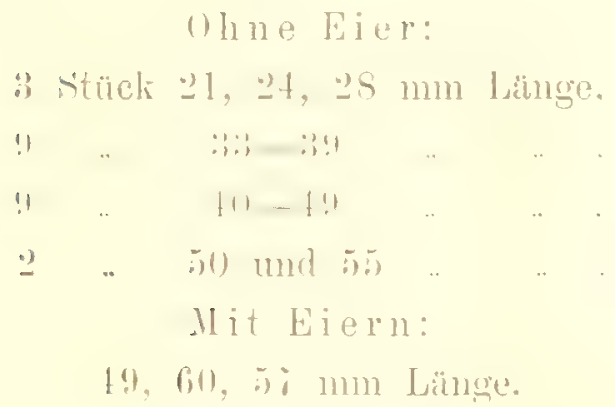

Es geht aus den vorstehenden Angahen also hervor, dass thatsärhlich die Garneelen

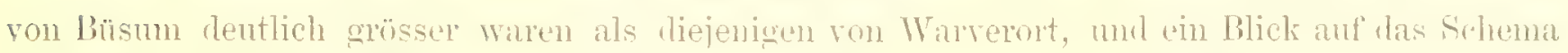
Seite bs und Tat. IX lehrt dies sofort. Oh, die Gronde in dem flacheren, mhigen Wasser von Warverort zu suchen sind orler in den geringen Unterschienten des Salqgehaltes oder der 'Temperatur', magg hier unerörtert bleihen. Folgenule Angiahen mögren darüher genügen:

1. In der Vitte der - vincler-l'iep (etwa querah

ron liojsh-sand).

Talzechalt: 2,450 (11. Stunde ror Xiedriowasser und auch bei Eintritt der Fint).

IV assertemperatur $\left.16.0^{\circ} \mathrm{resp}\right) 16.20^{\prime}$

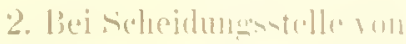

Sordex- und sibder-l'inp.

Sillygellalt: 2,300

(1'al. $2^{1} / 2$ Stunde natehl Huchwasicer).

Missertemperitur $16.1^{n}$
3. Nulerab vill IBisum.

Silycellalt: $2.37^{\circ}$ leal. 1 stumle nach Hocell-

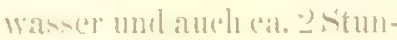
den nach Niedrigwasser). IV:asertemperatur $16,0^{\prime \prime} 0^{\prime \prime}$
4. Vor Warverult.

Norder- Hitele:

salzechalt: 2.5200 (balloe Ehbtidr).

Wassertempratur 17.8" 1 ! Siüler-Miele:

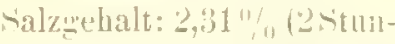
(len ror Niedrigwasser).

Silzehalt: $1.98^{\circ}$,

(hei Niedrigwasser).

II:asertemperatur $20,2^{\circ} \mathbf{C}^{\prime}$

Jedenfalls haben wir in .Jalelusen und unterhall, Wilhelmshaven, in der Elbe und ror Cuxharen und num anch vor Warverort und in der Piep dieselbe Erscheinung festgestellt: Die grösseren und meist Eier tragenden Garneelen weiter draussen (bei dieser Jahreszeit). die kleineren Garneelen näher an Land. Ein solcher Unterschies dürfte m. E. bei gesetzlichen Vorschriften nicht unbeachtet bleihen.

\section{B. Der l'ang mit Schiebehamen.}

In der Berguemlichkeit wit hei Warverort hithe ich die Fischerei mit Schiebehamen (Krantjallen, Streicher) sonst nirgend beobachten kömen, und höchstens hei l'önning lässt es sich amähernd so gut beobachten. Auf' der Süter-niele bei Warverort aber bewegen sich die Nämner und Franen, welche den Schiehehamen hantieren, geradezu zwischen den S'chleppnetzfischern, so dass es mir nicht nur möglich gerresen ist, die Art des Fanges genan zu sehen, sondern auch ron Boote ans direlit in die Kürbe der F'usstischer zu hlicken.

In Fig. 21, 'Taf: I'T, ist cine l'rau ahgebildet, welehe in der Umgebung maseres Bootes tischte. Sie hat den Stiel des Hamens sich ror den Leib gestemmt und sucht mit der einen Hand, während sie vorwärs schreitet, den beitang und die kleinen farneten ans den Handkorbe aus und wirft beides wieder in das Wasser. 
Die zum Verkauf bestimmten Gameelen werden alsdann in den auf dem Rücken der Frau befindlichen Korb entleert.

Ich sah nachher in den Korb «ler Frau. Die Garneelen entsprachen an Grösse ganz dem Fange der Schleppnetzfischer. Der Fang war nicht bedeutend, besonders kleine Garneelen sind mir darunter nicht aufgefallen.

Es sei hierbei bemerkt, dass eine derartige Garneelenfischerei mit Schiebehamen längs der ganzen Küste von ausserordentlich zahlreichen orten aus betrieben wird, wie anch aus der" "Statistik der See- und Küstenfischerei"*) hervorgeht. Dennoch dürfte die Ausbente wohl nirgends erheblich über den Lolsalkonsum hinansgehen.

\section{Die Granatfischerei von Tönning und Olversum (12. Juni 1898).}

Die urösste Menge der Garneelenfischer an der Eider wohnt in Olversum in nächster Nachbarschaft von Töming. Von Olversum gehen mehr als 10 gedeckte Fahrzenge zum Garneelenfang aus, vou 'Tömning un' einige. Die hier hetriebene Fischerei hat viel Ähnlichkeit mit derjenigen von Büsum, doch sind die Fahrzeuge in Büsum durchweg erheblich grösser und kräftiger, was damit in Zusammenhang steht, dass die Fischer von Büsum beträchtlich weiter hinausgehen müssen. Das stürmische Wetter, welches wir bei unserem Ausfluge und beim Fischen in der Fidermündung hatten, komnte uns hier nicht viel anhaben; bei Büsum würde das gleiche Wetter uns das Arbeiten wahrscheinlich ummöglich gemacht haben.

Vormittags am 14. Juni 1s!S gingen wir mit dem Kutter "Elisabeth" von Olversum mit erster Ebbe Eider-abwärts bis zum Hochsicht-Sand. Gegen den steifen N.N.W. mussten 2 Reffe in die Segel gesetzt werden. Bei Hochsicht trafen wir mit s anderen Granatfischerfahrzeugen zusammen.

Hier wurde die Kurte ansgeworfen. Die Kurre besteht ans zwei vorn abgerundeten eisernen Bügeln, welche durch den Kurrenbaum verbunden werden. Der Baum ist hier jedoch von oben und unten stark abgeplattet (wie ein Brett) und rom zuseschärft, um dem Wasser möglichst wenig Widerstand zu gehen. Er ist 12 Fuss lang und wird an den eisernen Bügeln derart befestigt, dass er in eine besondere breite Öse geschoben wird. Von aussen wird alsdam in die (i) noch ein Holzkeil eingeschlagen.

Gewöhnlich benutzen die Hiderfischer gleichzeitig zwei Gameelenkuren, der Baum der zweiten Kurre hat eine Lünge von 10 Fuss.

Das Netz ist 18 bis 20 Fuss lang, und 2- Fuss hoch ist die vordere öffnung. Das Netz hat rom Maschen von 14 mm, im Steert Maschen ron 11 bis 1 ㄹ mm.

Die Fischer treiben an Fangplatz nit del Ebhe abwärts, indem sie durch Herablassen der Segel die reschwindigkeit des Fortgnnges regeln (Fin. 2-2, Taf'. VI). Wem das Netz aufgenommen ist, segeln sie wieder anf (Fig. 2.:5, Taf. VI) his dahin, wo sie das Netz erfolgreich wieder anssetzen kömmn. 
Der lang mit der Gimmeelenkurre ergah folgendes:

1. Grosse Garneelen nach Absiebung der kleinen netto 201/2 Pfund.

2. Kleine Garneelen, welche durch das sieb sefallen waren, netto:" Pfund.

Hier befanden sich ganz kolossale Mengen der kleinen Rippenunalle Cydippe, welche mit durch das Sieb gingen und nu nach mühevollen suchen entfernt werden konnten, da sie mit den kleinen Garneelen im Himer einen Brei bildeten.

ad 1. Von den grossen Garneelen befinden sich in einer Handvoll:

2.2 'liere mit Eiern,

40 " ohne Eier (darmer aber 4 \& mit Fierresten und 8 o ohne Eier.)

oder in anderer cimppierung

$$
\begin{aligned}
& \text { :H weibliche Tiere. } \\
& \text { ¿s minnliche ". }
\end{aligned}
$$

Die Grössenverhältnisse dieser grossen (tameelen waren folgende:

$$
\begin{aligned}
& \text { I Stück von :3! } \mathrm{mm} \text { bünge }(-) \text {, }
\end{aligned}
$$

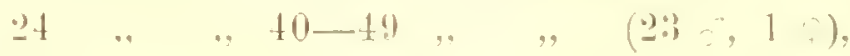

$$
\begin{aligned}
& 20 \quad, \quad, 01-5 ! \quad . \quad, \quad(4 ;, 18 \%) \text {, } \\
& \text { \& , , } \quad 61-1,9, . \quad, \quad \text { (nur \&), } \\
& 1 \quad, \quad .40-85 \quad . \quad, 4,4,4), \\
& \because \quad, \quad \text {, } 81-8 !), \quad, \quad(,,,, \%
\end{aligned}
$$

ad 2. Unter den kleinen abgesiebten Garneelen befanden sich in einer Handvoll:

:S Stück mit Eiern (5)- $6: 3$ mm lang).

4:3 .. ohne Eier (dartunter mutmasslich":3 Minnchen).

Die Grössenverhältnisse waren folgende:

$$
\begin{aligned}
& \text { l Stück vou :3 mm Länge. } \\
& \text { :39 , , } 40-49 \text {, , (darunter 32 mutmasslich } \because \text {, ; q), }
\end{aligned}
$$$$
\text { ; , , } \quad 50-56 \quad, \quad, \quad(2,, 3 \%),
$$

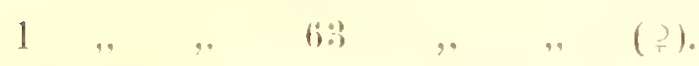

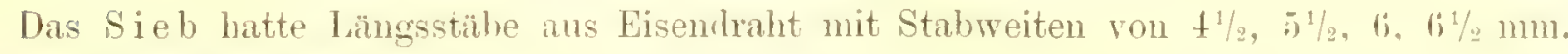
Grösse des Siebes $40 \times 48$ cm.

Der Salzqehalt des Wassers betrug unter Hochsicht mittigs 1 121/2 Uhr hei steifem N.N.W., schönem sonnigen Wetter, ca. I Stunde ror Niedrigwasser

$$
\begin{aligned}
& \text { spee. Gew. }=1,018 ., \\
& \text { Temperatur des Wassers }=18,4^{\prime \prime} \mathrm{C} . \\
& \text { Salzgehalt demmach }=2,41 \% \text {. }
\end{aligned}
$$

Bereits als wir uach Hochsicht segelten, passierten wir auf dem halhen Wege nach dort ror dem orte Vollerwiek 4 Fischerfanzenge, welche in einer Bucht vor Vollerwiek

4) Die Mannchen sind, besnnders unter den kleinen Tieren. ausserlich nicht immer sicher zu erkennen. Eine anatomische Untersuchung koninte aber nicht angestell werden. 
Garneelen fingen. Wir hahen auf tem Rückwege nach 'Tönning hier elsenfalls noch gefischt und hatten dabei folgendes Resultat:

1. Grosse Garmeelen, nach dem Sieben netto $21 / 4$ Pfmond.

2. Kleine Garneelen, ahgesiobt netto 4\% Pfund.

ar 1. Unter den grossen Gumcelen tanden sich in einer Handvoll:

ב.: Siturk nit Eiern.

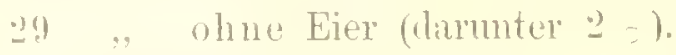

Die Grössenverhältnisse derselben waren folgende:

$$
\begin{aligned}
& 1 \text { Stïrk von :3s. mm Lïnge ( }) \text {, }
\end{aligned}
$$

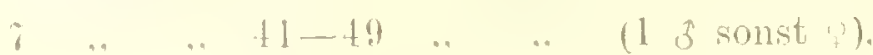

$$
\begin{aligned}
& \text { 栏 .. }
\end{aligned}
$$

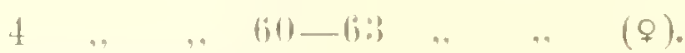

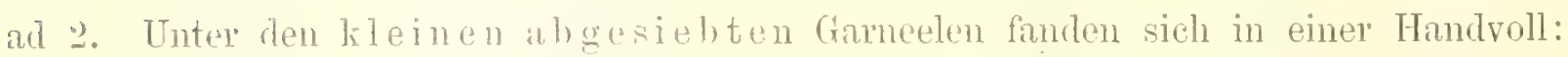

$$
\text { - Stürk m it Fiem. }
$$$$
\text { 5i. .. o hn e Eier. }
$$

Diese aber hatten folgende Dinensionen:

$$
\begin{aligned}
& \text { 20; Stück von } 34 \text {-39) } 1 \text { mm Länge, } \\
& \begin{array}{lllllll}
\because 1 & . . & . . & 10 & 1 ! 1 & \ldots & \ldots
\end{array} \\
& \text {. , . } \quad 50-5 \%,, \quad \text {, }
\end{aligned}
$$

Der Salzgehalt des Wasser's betrug unter Tollerwiek bei dem Wetter usw. wie vorher, aber 1 Stunde nuch Niedrigwasser:

$$
\begin{aligned}
& \text { Spez. Gew. }=1,0161 \text {. } \\
& \text { 'T'empreratur des Wassers }=19,5^{\circ} \mathrm{C} \text {. } \\
& \text { Demmach Silzgehalt }=0,1 \% \text {. }
\end{aligned}
$$

Es geht ans dem vorher Mitweteilten hervor, lass bereits anf der weiter oberhalb liegenden Eiderstreke (Vollerwiek) (lis grossen Carneclen von mehr als $6: 3$ mm Lünge kanm noch rorkanen, währent dafür sine gössere Zahl von farneelen eintrat, deren Länge in die $30 \mathrm{~mm}$ betrug.

Die Behandlungg des lingges ist lieselhe wie üherall bei der Kurrenfischerei mit grösseren Vahrzeugen. Es darf als liegel angenonmen werten, dass das Sieben alsbald nach dem Aufziehen des Netzes stattfindet, dass somit, die kieinen Grunat noch lebensfahig wieder in das Wasser kommen. Auch das kochen finded. sogleidh an Bord statt, nur sind hier an Stelle der kleinen ciscrnen Kochöfen kluine, ans Backisteinen gemanerte IEerde vorhanden.

Die lischer liofern teilweise ihre liange an oinen in Trömning vorhandenen Händler:

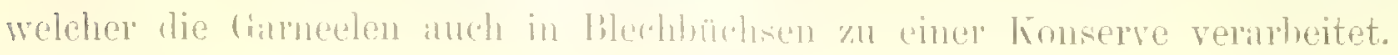




\section{Die Garneelenfischerei von Schobïll und Halebïll (13. Juni 1898).}

Ant' dem hreiten Watt nordlide von Ifusum wid noch eine hesondere IIndifikation der Garneelenfischerei betriehen mu der Bericht würle unvollstandig sein. wenn diese eigentümliche Fangmethode nicht bertucksichtigt wäre. Leider war diese Fischerei derzeit nicht mehr in Betrieb.

Wenn man von Ilalebüll ins nalch der P'ohns-lincht zu anf das Watt heraus marschiert, so kommt man dort, wo sich der weiche sehlick einstellt, in cin zerkilütetes Terrain, in welchem sich gewisse Wasserlanfe tiet angetressen haben. Diese hergion ist für die Fanggeräte (sog. Gande) benutzt. Es ist. hier Buschiverk derart autigestellt, dass dadurch eine

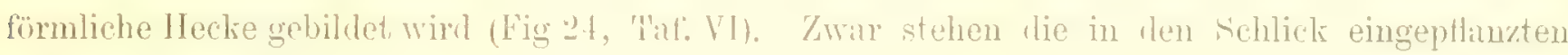

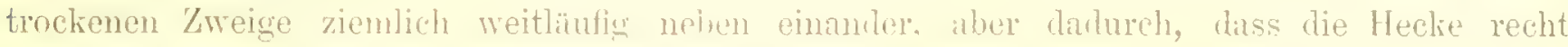
breit ist, kommt doch in Gesanteffekt cin ziemlich dichtes Gebilde zu stande.

Die Hecken werden nun derart ingelegt, dass sic zwei Flügel bilden, welche abwärts

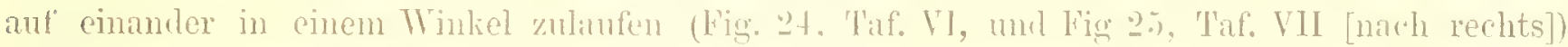
und in der Spitze des Winkels mit einm lach zusammentrefien, den sie vorhej zwischen sich einschliessen. An diesem Winkel stellt num der Fischer seine Fanggeräte auf, für welche die Hecken als Leitwege dienen. In l'ig. "-t. 'Taf. IT, ist der' Fischer gerarle dimit beschältigt, zwei Gamkörhe fanggerecht zu betestigen. Sie schliessen den Winkel des Fanggerätes sehr

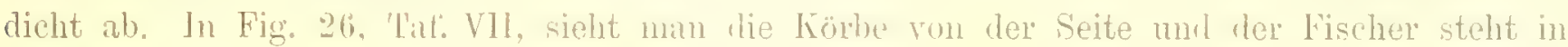
dem Bach und beschaut sein Werk. Die kleine Bunk zur Seite dient dazu, den Korh zu tragen, welchen der Fischer zur Lintleerme der Fanggerite mitbringt.

Aus Fign. 2l, 'Tuf. VIl, wirl klar. dias die Garmkörbe durch zwei Bügel (von etwa $40 \mathrm{~cm}$ lichter Weitu) offen gehalten werelen. Vorn ist der Hamen weit geöffnet, hinten kurz geschlossen und strati' angezogen. Aus Fin. '2S, 'Tat'. VIl, aher' geht klar hervor, dass bei dieser Eimrichtmg dic Maschen weit geölhet sind. Die Maschen massen 12 mm, in dem stratt' gezogenen 'Teile zwischen beiden Bügeln hatten die Uaschen 1:2 mm Lä̈nge und 10 mm

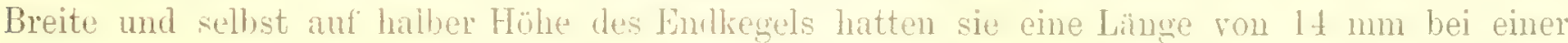
Breite von $5 \mathrm{~mm}$.

Die Gesamtlïnge des Hamens betrügt $90 \mathrm{~cm}$, die Entfermung zwischen heiden Bügelu 26 cm. Hinter Bügel 1 befiudet sich eine Einkehle.

Das in Halebüll henutzte Garneelensieb besteht ans einem Holzreifen. welcher durch ein Netr. mit Quadratmaschen von 14 mm Weite geschlossen ist, also ahnlich wie bei Torden (Seite :::3).

Die im Vorstehemten besprochene "Gaarde" wird durch zwei Gamköhe (.Hamen") abgeschlossen. Es giebt aber auch solche, welche nur einen Hamen an der Spitze tragen, im ührigen aber nicht ahweicheul gebiut sincl.

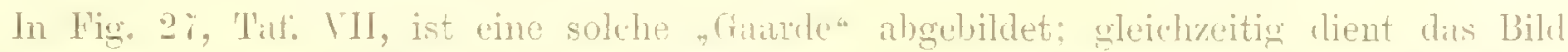

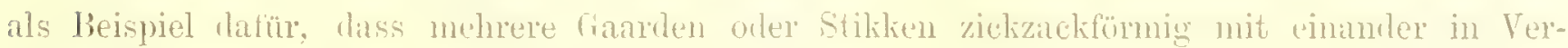
bindung stehen liömen. Nämlich eine Ganrde steht mehr nach rechts in Vordergrundes, ein 
Hamen steht in dem Winkel. wo die heiden liügel zusammentreflen, eine zweite Gaarde schliesst sich links an die erste an mol man sieht an der linkeu Seite deren öffnung, welehe ehentalls inreh einen IJamen geschlossen wird.

Die trockenen Büsche scheinen olt grün geworden zu sein; es kommt dies jedoch ron Rüscheln grüner Ilgen her, welche sich darauf angesiedelt haben. Denn es muss beachtet werden. dass ron der Fhut alle die hier heschriebunen llecken völlig bedeckt werden. IDe Hecken bleiben meist den Winter über stehen. Konmt alsdann stärkerer Frost, so mühen die Eisschollen die Hecken nieder. In einen talle war die Hälfte einer Hecke schart am Boden abrasiert.

Von diesen Gaarden oulur Stiklien steht eine grössere Zahhl auf' den Watt vor Halebüll. Damit die Fischer zu und von ihnen bei Nehel den Weg nicht verlieren, haben sie vom Ufer her sich durch eingeptlauzte Büschel von Ginster und derartigem hrant einen sicheren Weg

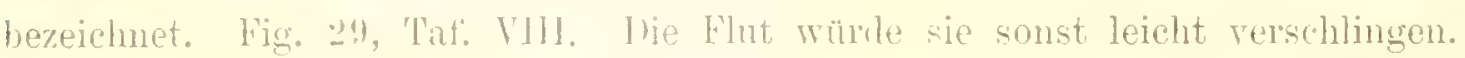

Ausser dieser Fischerei mit Gaarden werden in der Pohnsbucht die Garneelen noch mit Streichern und mit Kurren gefischt. Dit Kinrenfischer liommen meist von Husum.

Die Kurrentischer kochen die Garneelen sogleich an Bord in einem kleinen Ofen, welchen sie im Fahrzeug haben.

Die Trabbenstreicher fischen rom Lfer aus. I)er in Fig. 30, 'Tat. VIII, abgebildete Kischer hatte einen ziemlich guten liung gemacht, da sein Korb fast bis oben him gefült war. Gesiebt hatte or nicht und falls er es zu Hause noch thun sollte, wird es den Garneelen wenig nützen. Ich laufte ihm einige Itanlvoll Cxameelen ab, deren Grössen und dergl. weiter muten angegehen sind. Der lischer hatte es sehr cilig (Fig. 30), einerseits wohl um die Garneelen möglichst bald zu konservieren, anderseits um sie rasch an den Markt nach Husum zu lieferu. Ich erfuhr hier, dass die Garneelen wicht nach Gewicht verkaut werden, sondern nach llaass: : bis 4 , Handvoll" für $10 \mathrm{Pfg}$.

Es erübrigt noch, die letzte, hierher gehörende Figur zu erwähnen. In Fig. 31, 'Thaf. IIH, ist dus Haus des Fischers in Halebüll, mit dem ich die Gaarden besuchte, wiedergegehen.

Die ron einem Fischer ron Sturdebül zum Fischen mit einem Boot benutzte Kurre ist ganz so gehant. wie anch anderwirts. Sie hat IIaschen von $14 \mathrm{~mm}$ im Torderteil, von $11 \mathrm{~mm}$ im Steert. Themerkenswert ist an ihr die scharfe Zuspitzung nach rem Ende zu, welche hier gerade so aulfällt, wie an der Tiure ron Sïder-Dithmarschen (Fig. 10, Tat: III). lis tïuscht jedoch ein solches Bilk insofern etwas, als die Timre in Wirklichkeit doch erhehlich weiter ist, als sie so ersuheint. Es zeigte sich die Weite des Kurrensteertes besonders bei dem Versuche, ein seidenuetz dirüber zu ziehen, wie oben mitgeteilt wurde (Seite 59 60). Auch wird das Netz sich ausdehnen. wenn bein Fischen der Wrasserstrom hineindringt.

Der Fischer von Sterdehüll henutzt ebenfalls ein Sieb. ans einem hreiten Holzrahmen und einem Netz ron $1.1 \mathrm{~mm}$ Maschenweite bestehent. der Durchmesser des IIolzreifens betrug j) (1) ch. 
Die Konstruktion der Siebe ist im Prinzip also lieselbe, welche in meinem roriahrigen Berichte aus Norden, Seite 3:, beschriehen wurde.

Die Gameelen ans dem Schiebehamen und gefangen in der Polmsbucht hatten folsende Beschaffenheit, beurteilt wach einer heliehig gegriffenen Handroll.

1. Acht Weihehen mit Eiem:

$$
\begin{aligned}
& \text { I Stück rou t!) mm lünge, } \\
& 2 \quad . \quad \text {.. } 550.58 \quad \text {.. } \\
& +\quad . \quad \text {. } \quad 00-105 . \\
& \text { 1 ... }
\end{aligned}
$$

2. 59 Weibchen ohne Eier:

$$
\begin{aligned}
& \text { 2) Stück von :3in. is mm länge, } \\
& 2 ! \quad \text {.. } \quad \text {.. } \quad 40-4 ! \quad \text {.. } \quad \text {.. }
\end{aligned}
$$

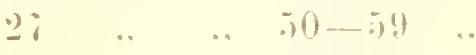

$$
\begin{aligned}
& 1 \quad \ldots \quad \text {.. } 6.2
\end{aligned}
$$

:3. Jiere ohne sichere Erkenubarkeit des Geschlechts (wahrscheinlich ), ohne Eier. j) Stück ron :3:-3: mm Lïnge.

\section{Zusammenfassung.}

Die Ende Mai und Anfmg Juni lsgs angestellten Untersuchungen der Garneelenfischerei wurden durch das Wetter ausserordentlich begünstigt und ergaben somit ein im Verhältnis zu der aufgervandten \%eit rohes Resultat. Nur muss hinsichtlich der (Idenburgischen Garneelenfischerei aut der. Tate wie in Vorjahre bedanert werlen. diass der Fang so üusserst spärlich war. Somit kim die Gewohnheit der dortigen Fischer, den Fing der kleinen firmate zu anderen Zwecken als zum menschlichen Genuss zu verwenden, auch diesesmal nicht zur Anschaunug. Der Fang war viehmehr noch erheblich gevinger als im Vorjahr; in welchem die Untersuchungen etwa einen Nonat später stattfunden. I)enn während die beiden Versuchskörbe Ende Juni 1 Syi zusammen doch 4 I'fimel gefingen hatten, betrug der

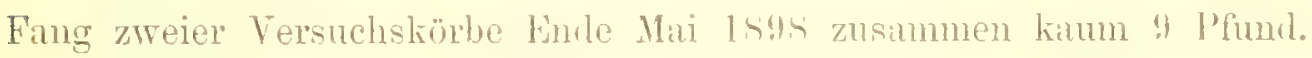

IHinsichtlich der Siebfähigkeit der Vareler Garneelenkïrhe kömen die Beobachtungen res Vorjahres nur bestïtigt werden. Durch das Überziehen ron Seidennetzen wurde bewiesen, dass die grösste Menge der kleinen Garneelen durch die Maschen der Körhe entreichen kann. Im Vorjahre wurle die Ziffer gewonnen, dass die durchgeschlüpten Ganeeleu die sechsfache Menge des Fanges ansmachten; in diesem Jahre ergab ebentalls ein Nachtfang mit zrei Versnchkörben genau das gleiche Resultat: ein sich daran anschliessender 'lagesfang wich etwas davon ab, wohl in Folge les lerweit eingetretenen stürmischen Wetters.

Das Resultat, welches durch die Sellsstanslese der Gameelenlï̈rbe von Varel hinsirhtlich der Grösse der Garneelen erreicht wird. ist in den letzten vier Spalten der anliegenden graphischen Darstellung, Seite (is, gegehen. Es ist in diesem sichemia natch dem im vol- 
stehenden Bericht anfreführten Kahlemmaterial die Menge der verweteten Garneelen durch die schwarze ligur, die Menge der abgesiebten Garneelen dagegen durch eine weisse Figur wiedergegeben. Die Tänge der Garneelen ist derart gemessen, dass dus Mass vom Ende der Schwanzflosse his zu Ende der Schuppe der zweiten Antenne genommen wurde. Man ersieht aus einum Vurgeich der weissen Figuren, dass die Grenze für das Aussieben der Garneelen etwa bei einer länge von $50 \mathrm{~mm}$ liegt. Jedoch werden anch Garneelen Lig. 11. Schema der Garneclenfänge.

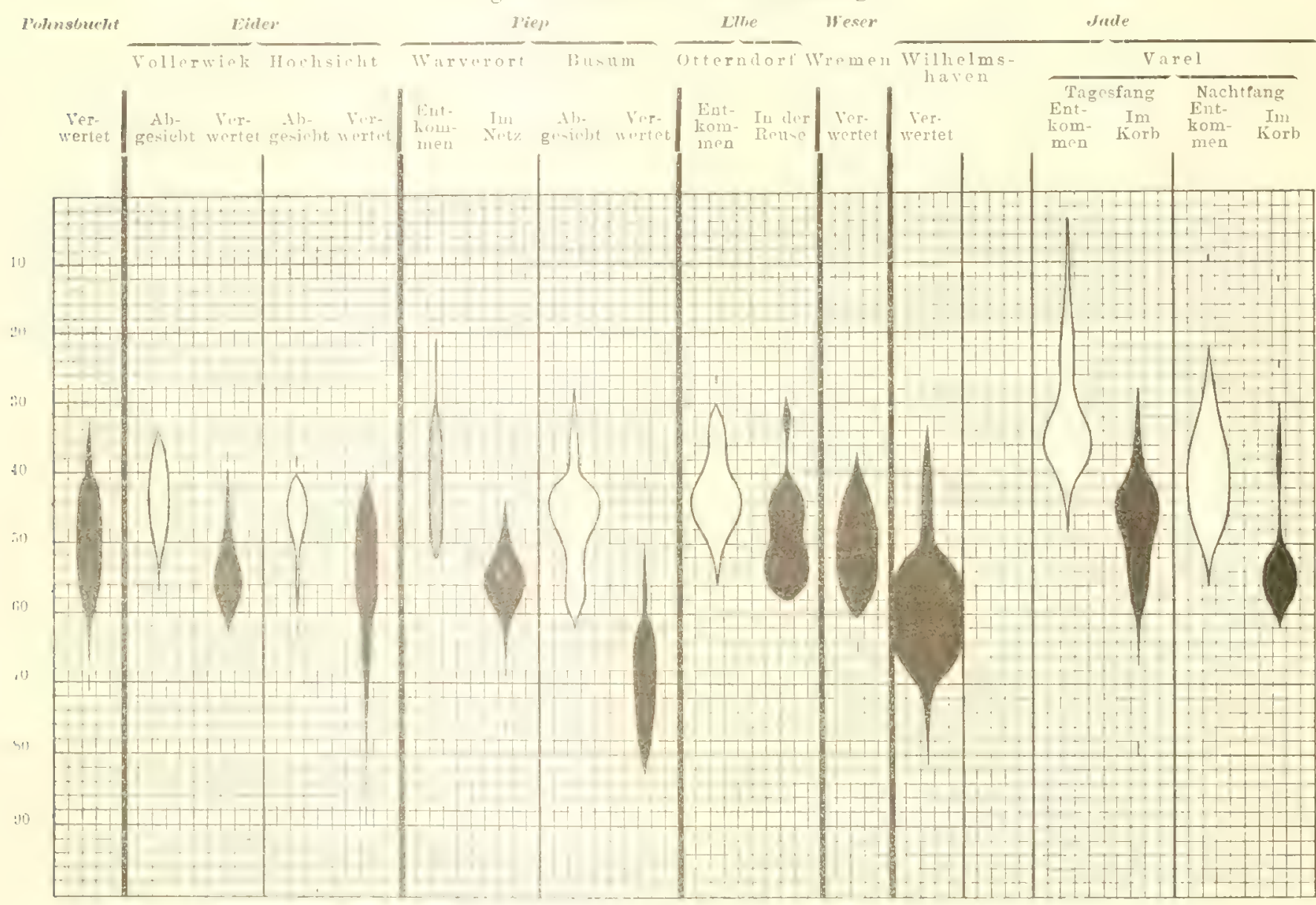

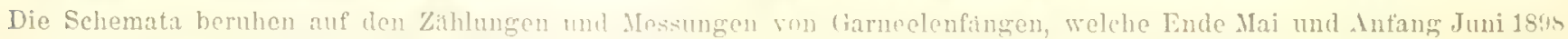
an den genannton Orten vorgenommen sinch. Jio schwarzen Firuren bedenten die für den mensehliehen Genuss

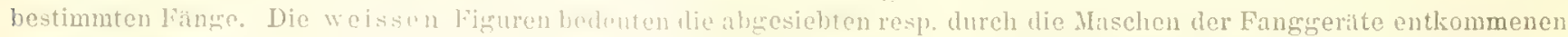
lebenden Gameelen. Die Jireito, der lïguren mpinht die relative Zahlenmenge der betreftenden Grösse, die Höhe aber die Linge der fomesisenen Tiere in mm, entsprechend den Zahlen am liande.

zwischen 40 und $50 \mathrm{~mm}$ länge norh vahlyeich mitgefungen wie die sehwarzen Figuren lehren.

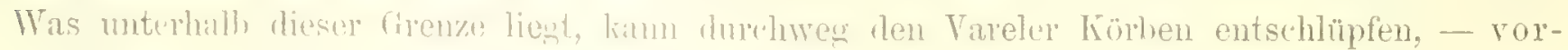

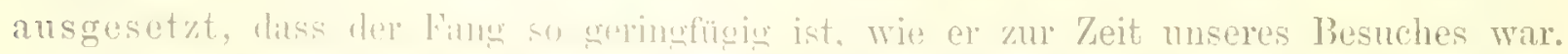

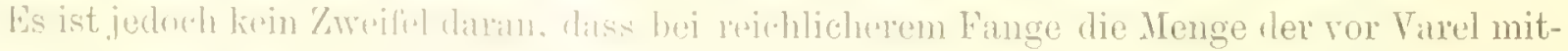

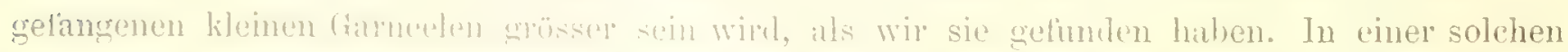
Zeit würde es entschieden ron Nutren scin, wem die Ciarneelen, wie es an der preussischen 
Küste ziemlich regelmïssig geschieht, etwa hei der Rückfaht der Fischer in das Wasser ansgesiebt würden, weil die Schicht der 'Tiere in dem Siebe beliebig dünn genommen werden künnte.

Es ist aus dem Schema also kilar, dass Garneelen von einer Lüuge ron etwa 50 mu aus den Vareler Körben ziemlich durchweg entschlüpfen können, wenu andere Tiere ihnen uicht den Ausgang versperren. Nun haben wir aber ferner beobachten kömnen, dass die kleinsten Weibchen mit anhängenden Eiern ebenfalls etra 50 mm massen. Es ergiebt sich also, dass die Vareler Körbe zu der genamnten Zeit nach bisheriger Aufassung ginz rationelle kischerei betrieben, indem das biologische Hinimalmiss tür die Garneelen gewahrt wird, wohei noch zu bemerken wirre, dass die erheblich kiteineren Mäunchen überhaupt sämtlich würden entweichen können.

Ls ist allerdings von Xiachteil für den imneren Absehmitt des Jadebusens, dass sich gerade hier mit Torliebe die kleinen Garneelen aufzuhalten scheinen.

Werden nun die preussischen Fischereien mit demjenigen verwlichen, was wir bei Varel gefunden haben, so giebt ein Blick auf die schematu sofort Aufklürung. Anch hier sieht man, dass die Grenze für die Benutzbarkeit der Garneelen für den menschlichen Konsmn zwischen 40 und jo mm liegt, also samz wie hei Varel. Ein Blick auf die Schemata zeigt, dass die Fisclierei von Wilhehmshaven, anch ohne dass gesiebt wurde, ein gutes und mnanfechtbares lesultat urgab, und die tischerei ror Carolinensiel steht kaum hinter dem hier erlangten liesultat zurück.

In Büsum sehen wir fast genau dasselbe Bilı. nur wird in diesem hedeutenden Garneeleufischerei-Orte derzeit vielleicht die beste Ware gewomen, da flas Sieben sehr sorgfältig gehandhabt wurde.

Eim ziemlich ehenso gutes Resultat ergib die Eider. Die Srhemata zejgen muzweifelhaft, dass, wofern das Sieben nur richtig ausgeführt wird. alle Ganeelen unter $50 \mathrm{~mm}$ Länge wieder in das Wasser zurückgelangen kömen.

Von den stehenden C'eriaten vor Otterndorf möchte ich dasselbe sagen. Die Versuche mit den übergezogenen Seidennetzen bewiesen sehlagend und zu besonderer Üherraschung des Fischers, dass die siebende Kraft des fierätes ziemlich bedentend ist. Aus dem Schema geht hervor, dass die Geräte in Bezug anf das Sieben denjenigen ron Varel kaum machstehen.

Es bleiben somit nur wenige Punkte der preussischen Küste übrig, an denen vielleicht eine Besserung zu wünschen wäre. Auch hier bitte ich, die Schemata zu vergleichen. Zunächst der Strand vor Wremen. Intolge des ganz geringfügigen Fanges und des bevorstehenden Pfingstfestes habe ich einen Versuch mit den Seidemetzen nicht vorgenommen. Es scheint. die dortige Fischerei infolge geringer Funge angenblicklich anch nicht selur blühend zu sein: ausserdem scheint aus der Terschiedenartigleit der henutzten Körbe hervorzugehen, dass man über die zweckmässigste Methode experimentiert. 
Dann kommt die Pohnsbucht. Das erhaltene Resultat beruht nur auf dem Fang mit Schiebehamen, also einem Instrument, welches über die Versorgung des engsten Lokalkonsums nicht hinausgehen dürte. Dass aher der mit dem Schiebehamen gemachte Fang zu etwas anderem als dem menschlichen Gemss dienen sollte, ist nicht anzunehmen.

Somit bliebe nur der von einigen Gelegenheitsfischern ron der Oste betriebene Garneelenfang. I)ass dieser nachteilig ist und die kleinen Garneelen ziemlich unnütz vernichtet, unterliegt wohl keinem Zweifel. In übrigen ist er olme Bedeutung.

Man wird somit zugeben müssen, dass die Garneelenfischerei an der ganzen preussischen Küste und vor allem an denjenigen orten, an welchen sie von grösserer Bedeutung ist, recht rationell betrieben wird. Was Ostfriesland anbetrifft, so beziehe ich mich auf meinen vorjährigen Bericht. Die Fischerei mit Schleppnetzen oder überhaupt mit solchen Fanggeräten, bei deuen ein ummittelbares Aussieben iles langes stattfinden kamn oder stattfindet, herrscht vor.

Was zimächst die Schleppnetze anbetrifft, so findet schon bei ihnen ein Aussieben statt. Es ist dieses durch die bei Warverort angestellten Versuche direlit ziffermmässig bewiesen.

Ebenfalls ist der hiffermmissige Nachweis erbracht, dass die Verwendung eines Siebes an Bord der Fahrzenge von günstigster Bedeutung ist - wenn die Fischer es regelmässig benutzen. Dass dieses aber in nachteiliger Weise nicht geschühe, für diese Annahme liegt z. \%. kein firund vor. Haben dnch die Hischer von Olversum sich gegenseitig zu einer zweckmässigen Ausübung dieser F'ischerei verpflichtet, und in Büsum steht das Gleiche bevor!

Was die Gamkürbe anbetrifft, so treffen auch sie bereits eine vollkommenere Auslese, als sich vermuten liess. Sie sind durchweg straft angespanut und werden durch Reifen offen gehalten. Bei otterndorf ist die auslesende Kraft der Garnkörbe durch V'ersuche ziffernmässig nachgewieseu.

Im allgemeinen sind allerdings alle die stehenden Fanggeräte, besonders soweit sie bei Ebbe trocken fallen. an wenigsten zu begünstigen, da für den Fall, dass sie nicht regelmässig entleert werden, wie es bei geringem Fang geschehen mag, die gefangenen Tiere in ihnen absterben und nutzlos verkommen. Das würde aber anch bei einer gesetzlichen Maschenweite geschehen. Übrigens spielen dieve stehenden Geräte auf prenssischem Gebiet nur eine geringe Rolle, wenn man fon dem Jollart ahsieht.

In sehr richtiger Erkenntnis des springenden Punlites in der sanzen Frage hatte das Grossherzogliche Amt Tarel in seinem Bericht vom 4. März 1 s.5 den Wunseh, gesetzliche Bestimmungen atuch üher die in Preussen benutzten Fanggerïte zu erlassen, davon abhängig gemacht, dass ähnliche Verhältnisse wie in Oldenburg auch an der prenssischen Küste vorliegen, nimlich, dass loblossale Mengen mindermassiger Granat, deren Menge den für menschliche Nahrung bestmmten firanat $n$ ein Vielfaches ühertriff, vernichtet md im resentlichen zu Dungzwerken benutzt werden. Es diuf wohl mit gutem Gewissen behauptet werden, und ans der gimzen vorhergehmen Darstellung geht das nnweifelhaft hervor, dass derartige Verhälnisse, wie im Onlenhnrgishen, in Prenssen thatsächlich \% \% . nicht rorhmden sind. 
Durch die rorstehenden Untersuchungen ist ferner der Beweis geführt, dass die in dey. Eingabe der Vareler Fischer an das Grossherzoglich Olfenburgische Ministerium vom 1. Februar 1S9\% ausgesprochene Ansicht, die prenssischen Fischer , befinden sich dadureh, dass sie solche Granat, welche den Fiangliörben der hiesigen Fischer entschlüpten, fingen und anf den Markt bringen, in der Lage, bessere Fingresultate zu erreichen, als wie die hiesigen cranatfischer," dass diese Ansicht also nicht länger halthar ist. Die Ansicht hatte unzweifelhaft eine Berechtigung. so lange lieine besonderen brhehungen hierüher vorlagen. Jetzt aber lehrt cin Blick auf die Schemata (Seite (is), dass die Preussen nichts anderes fingen wie die (1)denhurger, und dass den Fangrgeriten heider ungetïhr dasselbe entschlïptt.

$\mathrm{Zu}$ den zeiten des reicheren Fanges, in denen wahscheinlich in den oldenburgischen Körben die grossen Mengen kleiner (irmat zurückgehalten werden, ist die Methode des Anssiebens, wie es die hourentischer machen, entschiehen viel schonenter: aber selbst die Weidenkörbe rom Dollart, welche kleiner sint, als die Körhe der Jale, stehen alstann ganz günstig da, nach dem Gesetz. dass die (b)ertläche eines Förpers im Guadrat zumimmt, wähend der Inhalt im Kulus wächst. Hiernach müssen aher die kleineren liörbe mehr Gelegenheit zum Entschlüpfen bieten als glössere.

Auf Grund dessen, was die Untersuchungsreisen gezeigt haben und was schriftlich und bildlich dargestellt ist, kimn ich demuach die Einführung gesetzlicher Massregeln auf prenssischem Gebiet für jetzt nicht befürworten. Dort, wo die kischereibetriebe ron grösseres Bedeutung sind, haben die Fischer bereits selbst wirksame Schritte gethan, um etwaigen für ihr Gewerbe nachteiligen Übelständen vorubengen, nämlich durch die fründung von Vereinen in Olversum und Büsum und durch bestimmte Vorschriften für die Ausübung der Garneelenfischerei. Derartige freie Entschliessungen dürften ebenso wirksam sein wie gesetzliche Verordnungen. Wem fernerhin die Fischereiaufsichtsbeamten, wie bisher, bemüht sind, die lischer über empfehlenswerte Methoden zur Erhaltung der noch nicht marktfühigen 'liere zu helehren, und wenn sie ausserdem ein aufmerksames Ange darauf haben, dass solche nachteilige Fischereien, wie der Garmeelenfang von Gelegenheitsfischern an der Oste, nicht üherhand nehmen, so witr: m. E. alles geschehen, was sich augenblicklich empfehlen liesse.

Sollten in einer späteren Zeit dagegen gesetzliche Massnahmen erforderlich werden, so haben die angestellten Untersuchungen anch hiertür wertvolle Fingerzeige ergeben. 


\section{Nachtrag.}

In der vorstehenden Darstellung ist anf eine naturgeschichtliche Abwägmg der Beobachtungen kein Bedacht genommen, sodass darüber das Nachfolgende mitgeteilt sein mag.

Nach Ehrenbann tragen die weiblichen Nordsce-Garneelen ('rangon vulgaris) von (i) mm Länge etwa to00 Eier unter ihrem Hinterleilve. I) Zahl der Eier bei kleineren Weibchen schätzt er auf 3000 Stück. [)at es vorkommen kann, dass die Weibchen zweimal in Jahre Eier absetzen, so berechnet Ehrenhanm die jahrliche Eierproduktion pro Weibchen auf jooo Stück.

Wenn diese bier den müterlichen Körlper verlassen hahen, werden sie durch eine klehrige Masse unter dem Hinterleibe der Mutter festgeheftet und bleiben hier bis zum Ausschlüpfen. Das Ausschlüpten geschieht nach Ehrenbaum im Sommer in etwa + Wochen, im Winter in 4-5 Honaten. So lange trägt also das Muttertier die an seinem Hinterleibe äusserlich angehefteten Fier mit sich herum.

Die aus den Fiern schlïpfonden Jungen unterscheiden sich durch ihren Bau (daher werden sie Larven genamut) um durch ihre Lebensweise wesentlich von den alten Tieren. Der bemerkenswerteste Jnterschied ist der, dass die kleinen Tarven ausschliesslich freischwimmende Wesen sind. Sie halten sich zahlreich in den oberen Wasserschichten anf, während die alten 'liure hauptsächlich am Boden leben. Ist die frisch ansgeschlüpfte Lanve etwa $2 \mathrm{~mm}$ lang; so behält sie die schwimmende Isebensweise durch fünf Larvenstadien bei, in welche sie durch eine jedesmalige Häutumg übergeht und wächst dabei auf etwa $5 \mathrm{~mm}$ lünge heran. In dieser firösse wird das 'Tier dem Erwachsenen schon recht ähnlich und hewegt sich numehr als .Jugendform" hald kriechend und bald schwimmend in der Nïhe des Bodens.

Noch ein anderer. Umstand ist von grösster Wichtigkeit, anch bei der Beurteilung praktischer liragen. Die Granatlarven pflegen das Ei mämlide nur in dem stark salzigen Wasser des Wattengebietes und der benachbarten Strommündungen zu verlassen. Im Brackwassergebiet der Strommündungen findet man keine Granatlarven oder jedenfulls nur ansnahmsweise. Dagegen können sir bei den ostriesischen Inseln gelegentlich in ungeheuren Nengen mit feinen Netren gefiseht, werden. 
Ganz anders liegt es mit den jungen Granat, d. h. mit denjenigen 'Tieren, welehe die Iarvemperiode bereits üherwunden haben und num zu der Gestalt der erwachsenen 'Jiere vorgedrungen sind. Derartige junge franat in einer Länge von j- 10 mm sind ron Ehrenbanm hei seinen Untersuchungen der Naturgeschichte unseres T'ieres sowohl im l'rühjihn wie anch im Spätsommer in mgehenren Massen im Dollart und in der Jade nachgewiesen, also tief im Lande.

Die sanze Sachlage wird jedoch darburch norh liomplizierter, dass nach den beststellungen ron Ehrenbanm zwei Iarchzeiten für die Garneelen angenommen werden müssen: Die Hamptmassen der mit abgelegten Eiem behafteten Weihchen finden sirh nümlirh einerseits im Mai-Juni, amlereeits im November-Dezember. Das Ausschlüp f'en der Larren aus den Eiem würde also der Janptsache nach im Juli einerseits mul in II ïr\% anderseits seinen Höhepunkt erreichen. Natürlich werden Schwankungen um diesen 'teitprunkt nach volwïrts oder räckwairts je nach der 't'emperatur und den sonstigen Verhältnissen des betreffenden Jahres und anch nach individuellen Eigenschalten eintreten, und namentlich das Ausschlüpfen ans den im Herbst abgelegten Eiern erscheint noch nicht hinreichend festgestellt: aher im Ganzen wird mit den genannten 'Terminen gerechnet werden können.

Bei den Garneelen lassen sich die fieschlechter von einander unterscheiden. wenn anch nicht so bequen, wie z. B. bei den Flusskrebs (Astacus fluriatilis). Zwar münden die Geschlechtsorgine bei der weihlichen liameele am Itäftglied des dritten limpares, bei dem Mämmehen dagegen in der. Gelenkhaut zwischen der Brust und dem fünften Beimpare nach anssen; jedoch ist das kein leicht festzustellendes Herkmal. Besser ist es, den Innenast des I. Abdominalfusspares zu beachten, welcher heim Weiluchen sehr lang und löftelartig, sowie etwas gebogen erscheint, beim Minnchen dagegen winzigr klein und mud und mit kleinen Härchen besetzt ist. Ansserdem sind die Minnchen im ganzen viel kleiner a]s die Weibchen und nur selten über $45 \mathrm{~mm}$ lang, whihrend die Weibchen etwa die doppelte Lünge erreichen können.

Über die (funtitative Terbreitung der Männchen ist ganz sicheres nicht bekannt. Immerhin möchte ich aus einer Reihe ron Tathlen, welche Ehrenbaum anführt. den Schluss ziehen, dass die grössten Mtengen der erwachsenen Mämchen ausserhalh der Linie liegt, welche von den línstenründen quer üher die Mündung der Ströme bei der letzten grösseren Hafenstadt bei uns gezogen werden kamn.

Da, wie ohen gesagt, die kleinen aus den Fiern ausschlüpfenden Granatlarven sich ausschliesslich in der Region des Wattenmeres atulhalten, so erscheint es selbstrerstandlich, dass auch die Eier tragenden Wreihchen in den grösten Massen hier gefunden werden. Thatsïchlich werden derartige Weshohen weiter anfwäts in den Strömen und Buchten viel weniger gefunden.

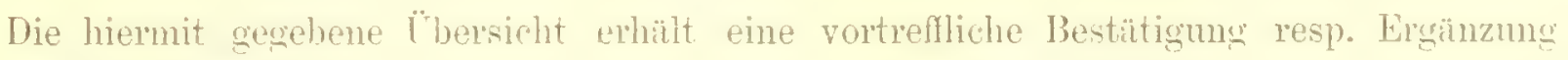
durch dașenige, was Ilortensen*) über eine nohe Verwante unserer Norlseegarneele.

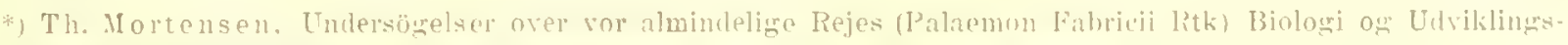

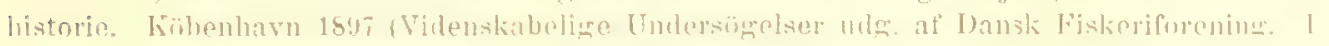


nimlich die Ostseegarneele (l'alaemon Fabricii Rtk = Leander adspersus Rathke) nach seinen sehr sorgfaltigen Ernittelungen üher die Naturgesshichte derselben im Lijm Fjord mitgeteilt hat. Zunachst ist es auch hier sicher, dass die Garmeelen betrïchtliche und mehrfache Wanderumgen unternehmen, in ganz sihnlicher Weise, wie wir es oben von der Nordseegarueele kemmen gelernt haben. Der Vorgang spielt sich im Lijm Fijord in folgender Weise ab:

Den Winter verbringen die grossen und kleinen Garneelen in tieferem Wasser, also fern von der Küste. Im Frühjahr kommen sie alsdamn, wohl der Nahrung und der zunehmenden Wasserwärme wegen, näher: an die Küste und auf Hacheres Wasser. Ls mag dahingestellt bleiben, ob die Mämnchen und die grossen Weibchen dabei immer den Vortrab bilden, wie eimmal beobachtet wurde. Jedenfills kömen die Weibchen, welche zum Laichen bestimmt sind, nicht lange in Kústemmähe bleihen: Aemn Anfung Mai beginnt bereits das Laichen, und zwar sollen die Weibchen von etwa 60 mm Lïnge hiernit die ersten sein, während die kleineren und grösseren Weibehen später nachfolgen und das Laichgeschätt his Mitte Juli himansziehen. Als II auptlaichmonat kam der Ma angesehen werden.

Die ersten jumgen Larven treten Anfung Juni auf. Eimen Nonat also etwa trägt die Ostseeganneele (wenigstens im Lijn lijorl) die Eier mit sich am Lörper.

Ehe die Eier aber ausschlüplen, muss die Mutter cilen, dass sie mit ihnen in tieferes Wasser kommt. Denn wie hei der Nordseegurneele sind die anschlüpfenden Larven freischwimmend (pelagisch); sie gedeihen besonders dort, wo Strom geht. Mortensen hat sie sogur im Kattegatt, Öresund, lem Grossen und Kleinen Belt und in der freien Ostsee im Juli gefaugen. In den Buchten und Fiorden dagegen fehlen sie. Im Juni geht das Ausschlüplen der Larven aus den Eiern (Rogen) meist vol sich.

Die Larven scheinen eine Kkleinigkeit grösser zu sein als diejenigen der Nordseegarneelen. lieim Ausschlüpfen aus dem Li etwa $3 \mathrm{~mm}$ lang, machen sie ebenfalls 5 Larvenstadien (4 Häntungen) durch und verdieren mit der fünften Jäutung ihren Schwimmapparat, müssen damit dem freischwimmenden Lehen entsagen und sich zu der am Boden liriechenden Lebensweise der Erwachsenen bequemen, denen sie an Gestalt num ahnlich geworden sind, wemn sie auch erst die bescheidene firösse von $\ddot{i}$ - $\$$ mm erreicht haben.

Das pelagische Lehen der I sarven danert etwa 4 (3-5) Wochen: dem Anfang Juli sind die ersten Jungen vom Hahitus der Elwachsenen zu finden.

Hier sei eingeschaltet, dass die grösseren Weibchen bald nach dem Ausschlüpfen der arsten Jungen einen zweiten Sat\% Eier ablegen. Es ist dieses von Mortensen direkt beobachtet. Von den Weibchen zwischen etwa .) - 10 mm Länge laicht anf diese Weise mehr als die Hälte in gleichen Jahre zom zweiten Male. Aber Fude ouli sind in der Regel auch die letrten Eiex unsgeschlüplt.

Die Zahl der Eier eines Weibchens varint nach der furösse des MInttertieres, je grösser das 'Tlier, un so mehr Fier sim vorhauden. Mortensen nimmt an, dass die kleinsten Weihehen cal.800, dio grössten his 2500 Eier in einem Sitz ablegen. Direkt beobachtet 
wurden z. 13. bei einem Weibchen fon etwa : $36 \mathrm{~mm}$ Länge fise Eier, und bei einem soldenn von etwa so mm Iänge gass Eier (mit eintr Anzalıl von Zarischenstufen).

Wemn die Larven der Ostseegarneele ihr freischwimmendes Lehen aufgegehen lahen ma zu den Jungen von der. Gestalt und Lehensweise der Lrwachsenen geworden sind, sudhen sie wieder die Landnähe anf, wo sie in den kieinen Buchten und Fijorden und in der daselbst und in dem flachen Wasser whehernden Vegetation ihre besten Lebenshedingungen finden. Mortensen vermutet, dass diejenigen. Inngen, welche zu weit rom Lande abgeirrt sind und das Hache Wasser nicht erreichen kömen, zu Grunde gehen müssen.

In den Buchten und Fijorden, wohn anch die alten There sich nuch dem Brutgeschät zurïckgezogen haben, wachsen $11 m$ die Jungen unter den alle para Wochen stattindenden Häutungen zienlich rasch heran, derart, dass sie wahrscheinlich schon in dem Herbst ihres Geburtsjalnes eine Länge von etwa :30 $\mathrm{mm}$ und mehr erreichen.

Die Geschlechtsunterschiedc bei den Jumgen werden schon bei tiner Länge ron etwa $25 \mathrm{~mm}$ äusserlich sichtbar, noch nehr aher. Wenn die fliere grösser werden. Damn zeigt es sich, dass das erste Abdominalbein bei den Männchen grösser ist als bei den Weibchen, dass ferner die Männchen am zweiten Ahdominalbein einen hesonderen, mit einer spiralreihe ron Borsten besetzten Anhang erhalten hahen, welcher Appendix masenlina genamnt wird und den Weihchen feht und dass bei den Mämehen zwischen dem letzten Thorax-Beippar sich ein Zapten erhebt, welcher der hreiteren Brust der weiblichen 'liere fehlt, - von anderen geringeren Unterschieden abgesehen. - Nunnehl lïsst sich das Wachstmm der Männchen und Weilohen getremnt verfolgen.

In Winter hört das Warchstum der diarneelen auf und beginnt wieder im Frühling des niichsten Jahres.

Es gelang jedoch Nortensen nimht. in Hai noch ältere und jüngere $M$ it nnchen an der Grosse von einander zu unterscheiden. Viehmehr hatten sie vom Mai bis Juli zwar sämtlich

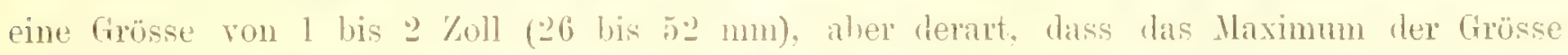
in dieser ganzen Zeit zwischen 36 bis to mu lig. Da die Il än nehen überhaupt. selten über 2 Zoll (ca. 52 mm) lang werden, so haben sie also schon nach $1 / 2$ bis $3 / 4$ Jahr fast inre definitive Gröse envelcht.

Etwas anders liegt es mit den W eibchen. Sie begimen den Mai des nenen Jahres meist mit einer Grösse von etwa 30 his $: 31$ mu und wachsen bis zum Ende ihres zweiten Sommers bis auf etwa 50 mm heran. Nun ist es kam mehr möglich, sie von der alteren Generation mit drei Sommern zu unterscheiden, weldhe nach Mortensen an Finde des dritten Sommers eine mittlere lirösse von 50 his $6010 \mathrm{~mm}$ erreicht hat.

Dimnit ist jedoch das Wachstum der weiblichen 'l'iere nicht abgeschlossen; vielmehr werden von ilmen alte Matronen ron $;$ his 4 \%oll (80 bis 10.5 mm) Länge gefunden.

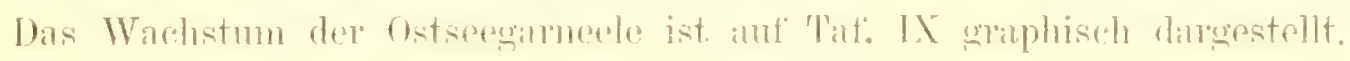


Del' grösste 'Teil der Reohachtungen an Nordseegarneelen, welche ich auf den Untersuchumgsahrten 1 s.s habe anstellen kömen, ist von mir in Tafel IX festgelegt. Die Messungen, welche den Fintragungen zu Grunde liegen, dürften darum besonderes Interesse verlienen, weil sie dank der ausgezeichneten Betörlermgsnittel und des sehr glücklichen Wetters in recht kurzer \%eit ingestellt wurlen. Sie erstreckten sich über die Zeit vom 2. Mai his 1:\%. Juni, und wem sie imnerhalb dieser Zeit auch durch das Pfingstfest unterbrochen wurden, so kömnen sie doch gewissermassen als ein Nomentbild von dem Bestande der Garneelenbevölkerumg in den besuchten Distrikten betrachtet werden. Die Beobachtungen ans dem Jahre vorher liegen etwa einen Monat später, kömen also passend zur Ergänzung heringezogen werten.

Die drei Gebiete der Jade, l'iep und Eider zeigen übereinstimmend das gleiche Gesicht: T'iefer im Lande die kleineren Garneelen mit verhältnismässig wenig Eier-tragenden Weibchen, weiter" nach See zu die grösseren 'Tiere mit der grossen Menge Eier-tragender Weibehen. Die Beohachtungen von der Elbe (ottemdort) und der Weser (Wremen) bestatigen nur das erhaltene Bild: An beiden Stellen, welche sich schon mehr der Region des Süss- resp. Brackwassers nähern, nur kleinere und mittelgrosse Carneelen, darunter nur ganz wenige Eier-tragende.

Nicht wesentlich anders liegt es mit dem Husumer Watt (Pohnsbucht) und dem Watt vor Neuharhingersiel (oster-Balje). Die Oster-balje liegt erheblich näher an der offenen See und zeichnete sich durch das Vorhanlensein zahlreicher grosser, Eier-tragender Weibchen aus, die Pohnsbucht ist noch durch mehrere lnseln von (ler Nordsee abgeschnitten*) und hier überwogen die mittleren (iarneelen ohme Eier.

Sehr auffallend ist ferner der Unterschied in der Menge der grossen, Eier-tragenden Weibchen an der See nahe liegenden Distrikten. Die grösste Kahl fand sich in der Jade nnterhalh Wilhelnshaven, wie ein Blick auf die 'Tafel IX sofort zeigt. Namentlich diejenigen von for $\mathrm{mm}$ Lünge und darüher waren hier noch zalhlreich vorhanden. Ganz erheblich weniger' sind diese Grössen bei Büsmm (Pielu) und noch geringer bei Hochsicht (Eider) rertreten. Wem dürtten daher nicht lie Klagen beredhtigt erscheinen, welche nenerdings von der Eider über die Abnahne des Garneelen-Bestandes liommen? Denn dass die auf der 'Tafel IX graphisch dargestellten Messungen auf einem Zutill bernhen sollten, ist wohl kaum anzunehmen. Spiegeln sie aber die wirklichen Verhältnisse wieder, dam dürften sich an der Eider, vielleicht anch schon an der Piep tie Anzeichen ciner Öherfischung einstellen, da die grossen, Eier tragenden Weibchen in erheblich seringerer Zahl vorhanden waren als in der Jade-Mündung.

Hier stellt sich die finge rin. wie rasch sich denn die Garmeelen vermehren? Man betritt damit ein sthwieriges (iehiet, dir as nicht möglich ist, dic dinzelnen Tiere von ihrer

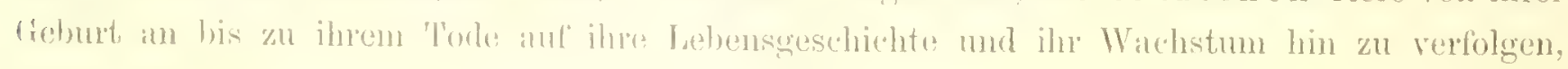

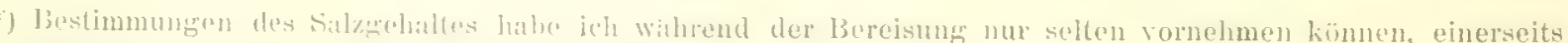

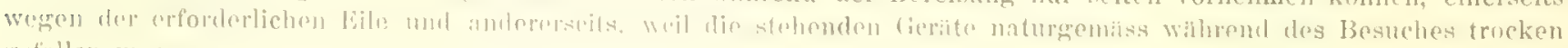
retallen watien. 
wie es erforderlich wäre, wenn man zu sicheren Sihlüssen kommen wollte. Man kann daher nur ans der beschaffenheit zalulreicher versehiedener Individuen. wie sie sich nehen einander finden, einen Rückschluss auf die Lebensgeschichte des Ei nzelindividumns zu machen versuchen. Ist das hinsichtlich des Wachstums selbst schon bei solchen 'lieren schwierig, welche, wie die Fische, eine allmählivhe Verlüngerung des liöpers ertahren, so häufen sich die Fehlerquellen bei den Kirebstieren, da die Grössenzmahme hier jedesmal nu bei den Häutungen, also ruekweise, erfolgt. Eine weitere Fehlerquelle liegt darin, dass die beiden Geschlechter eine erheblich verschiedene Grösse erreichen und erst verhältnismässig spat insserlich zu unterscheiden sind, sowie, dass nach Ehrenbaum hei der Nordsee-(ianeele zwei Laichzeiten augenommen werden müssen.

'Trotzdem wird es möglich sein, unter herücksichtigung der von Lhrenbaum angegebenen Zahlen mit einige Wahrschemlichkeit die Grössenzmahme der Nordsee-Garneelen zu rertolgen.

Sicher ist zunichst, dass meine Beohachtungen in die Sommer-Laichperiode der Garneelen gefallen sind, sowie, diss zu dieser / teit die kleinsten Eier tragenden Weibehen eine Lainge*) von ts bis $50 \mathrm{~mm}$ hatten.

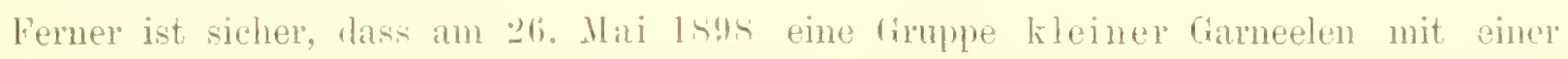
Lange von b bis 1 t mm sich scharf von ten übrigen abheht (siehe Tatel IX di, von Varel), Wir gehen lamm fehl, wenn wil hierin die gleichen Garneelen sehen, welche Ehrenbaum im Il a in einer Länge von g) his $10 \mathrm{~mm}$ in urossen Jassen in Brackwasser, zo 13. der Dollartwatten, angetroffen hat. Es dürtte kaum hezweifelt werlen, dass diese kleinen Vareler Garneelen ron der Herbstaichzeit des Vorjahres (1s:6) herstammen und jetzt bis Enle Mai (1598) zu der angegeheneu Grösse herangewachsen sind.- Hiermit stehen meine Beobachtmgen ans dem Jahre 189 völig in Einklang: Die kleinsten Granat im Dollart (pag. :3i) massen am :. Juli $15 \mathrm{~mm}$, sehr viele 20 bis 2:) mm. In gleicher Weise zeigten die kleinsten Garneelen in der Ems bei Larrelt (1)ig. it) eine Lïnge von 14 mm. Die kleinsten im diudebusen

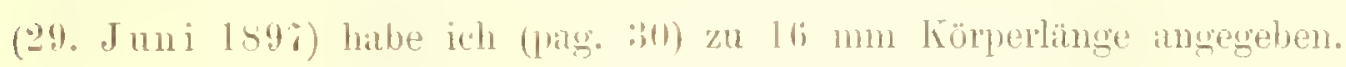

Die an Grösse folgenden Garneelen (Varel, Warverort-Büsum, otterndort') messen

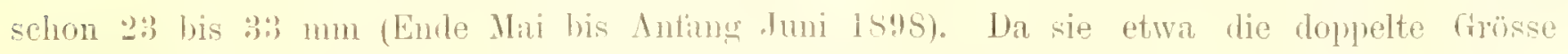
der ersten Gruppe hahen, so müssen sie erheblich älter sein. Sie dürtten daher von der Sommerlaichzeit des Vorjahres (1s!i) herstammen. Dies wirl die entsprechende deneration

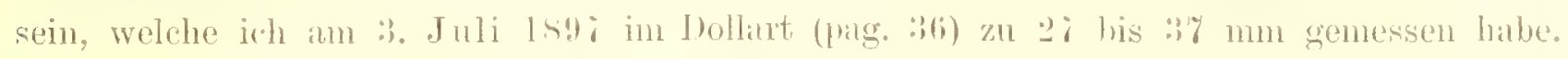

Bei Vollerwiek (2) heht sich num wiederum eine Gruppe recht schart ab, welche am 12. Juni 189 dängen von :it his etwa $50 \mathrm{~mm}$ aufweist. In ihn sind schon die getrennten

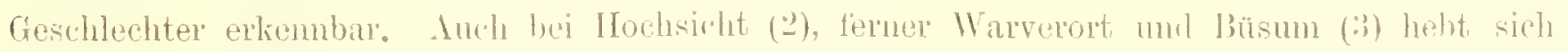
die gleiche Gruppe merlshar ah und kam violleicht antgefisst werten als eine solde, welche

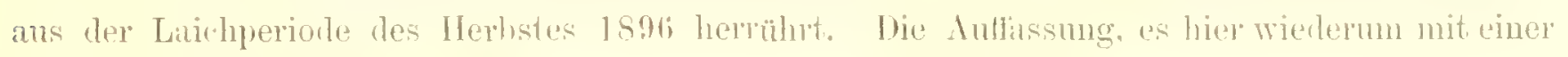


besonderen Altersgeneration zu thun zu haben; wird dadurch bestäkt, dass die kleinsten farneelen vom Watt vor Grolinensiel (25. Mai 189S) ebenfalls eine Lünge ron 34 bis $35 \mathrm{~mm}$ besassen (vgl. pag. 41 bis 42 ).

Die hierauf folgenden Grössen würden alstimm vom Sommer 1896 herzuleiten sein. Hiernach kïme man zn del Auffassung, dass die gesamten Garneelen von Wremen (5) umd von Otterndorf (t), welche ja eine ziemlich abgeschlossene Vereinigung bilden, ein Gemisch von Sommer- und Herbsttieren von 1 s 96 bilden müssen, und die Verhältnisse der Pohnsbucht (1) wurden dies lediglich bestïtigen.

Es verdient hierbei hervorgehoben zu werden, dass sowohl in l'ohnsbucht (1) wie vor otterndorf (4), wie weiter oben gesagt, fast auschliesslich weib]iche l'iere vorhanden waren.

Überall aher beginnen die Weibchen von 48 bis 50 mm Länge zu laichen und alsdamm das salzhaltivere Wasser antzusnchen. Hiernach wäre also anzunehmen, dass die frühreifen Tiere aus dem Herbst 1596 in Mai 1 s.9. laichreif geworden sind (also nach etwa 18 Ionaten) und ferner mit ihnen die spätreifen von Sommer IS96 (also nach etwa a Monaten).

Ehrenbaun giebt au, schon weibliche Tiere von 36 bis 40 mm Länge mit Abdominaleiem angetrotlen zu haben. (Heinckes (1S56) Mitteilung, dass schon 'liere ron kaum 20 bis $25 \mathrm{~mm}$ Länge Eier tragen, heruht zufolge einer brietlichen Nachricht nicht anf eigenen Messungen.) Es ist das ein bemerkenswerter. Unterschied gegenüber meinen Beobachtungen. An der von Ehrenbanm angegebenen 'I'hatsache zn zweifeln, liegt jedoch durchaus kein Grund vor. Die Verschiedenheit in der Auffissung erkinet sich ungezwungen vielleicht so, dass im Herbst schon kleinere Weibchen zu Eiablage schreiten als im Frühsommer. Weine Beobachtungen nnd Berechungen basieren lediglich auf den letzteren.

Meine Vermutung, dass die im II erbst zum Laichen kommenden 'l'iere teilweise eine seringere Grösse haben, also eine jüngeve reife Generation darstellen, welche in diesem Falle eine besondere Herbstgeneration bilden würde, erhalt anf meine Antrage durch briefliche Mitteilungen ron Khrenbaum eine gewisse Wahrscheinlichkeit. Ehrenbaum ermittelte und schrieb mix nämlich aus den Naterialien seiner früheren Untersuchungen folgendes:

"Am 16. Januar 1890 wrulen hei schönem Wetter itusserhalb der eigentlichen Fangraison auf meine Vermlassung in der (Osterbalje bei Carolinensiel Garneelen gefischt und eine Anzahl meist kleiner aher anch einige bis 76 mm grosse*) Tiere gefangen und zwar

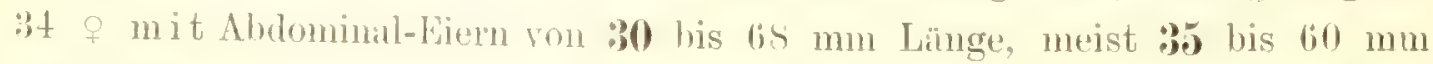

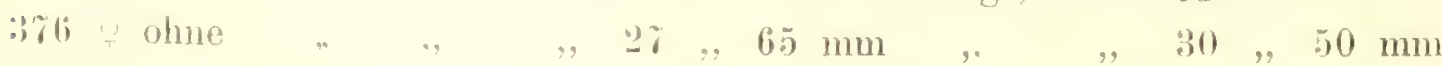

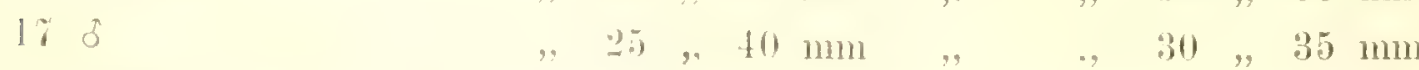

Es finden sich anch noch einige andere Angaben, ans denen hervorgeht, dass man die kleinsten mit Abdominal-Fiern im Spätherlst oder Winter im salzigen Wasser findet,

\footnotetext{
) Die von Ehrenbaum angrgobenen Lingennasse beziehen sich nach brietl. Mitteilung immer aut den Abstand

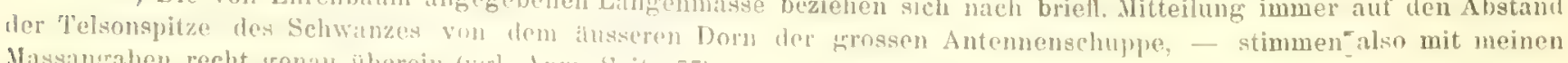

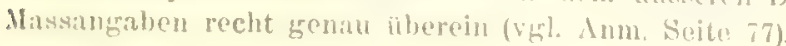


doch sind die Angaben der Längenmasse nicht so genau. Ws heisst z. B. Gramattimg bei Virrel rom 11. November 18 s:

145 grosse mit Eiern, is ohne Mblominal-kier

11 kleine ㅇ .. . . , ,

wozu irh bemerken uuss, dass als, kleine" im allgemeinen Tiere moter $40 \mathrm{~mm}$ Lünge verstanden worden sind."

Bei den grossen Tieren üher völlig unsicher sein und kann daher füghich unterhleiken. Ws möge daher nur noch der Ilinweis gestattet sein, dass das grösste non mir heobachtete Weibchen mit Abdominaleiern eine Länge ron $80 \mathrm{~mm}$ hatte. Die noch grösseren Weibehen ron 81 bis $90 \mathrm{~mm}$ hatten derzeit nicht gelaicht, womit selbstrerstindlich nicht gesagt sein soll, dass sie dazn völlig unfihlig wären.

Das grösste Männchen, welches ich gemessen habe, hatte dagegen nur eine lannge von $60 \mathrm{~mm}$. Die grösste Kahl der Männchen ist ferloch unter $50 \mathrm{~mm}$ langr.

Hervorzuhehen wäre terner norh. dass bei mehreren Weibchen bereits am 11. bis 12. Juni die Larven ans den Eiern ansgeschlüplt waren (vgl. 'Tilfo IX [3] Bäsum und [2] Jochsicht), sodass bei diesen 'Tieren die Eiablage schon Anfung Mai stattgefunden hahen dürfte.

Ferner laichen durchaus nicht alle Weihohen der geeigneten Gröss' von über 50 mm im Frühjahr. Denn unter diesen grossen J'iren ron otterndorf ( $t$ ) betand sich nur ein einziges Exemplar mit Abdominaleieru, von Wremen (j) nur drei der grössten, und anch in l'ohnsbucht (1), Vollerwiek (2) und Warverort (3) finden sich noch zahlreiche grosse Weihehen ohne Eier.

fianz anders lag es weiter nach. See zu: die Weibchen, welche üherhaut die erforderliche Grösse ron etwa $50 \mathrm{~mm}$ besassen. trugen mit verhätnismässig wenigen Ausnahmen anch Ahdominaleier.

Bei der Betrachtung der Lintragungen aut 'I'at. IX muss jedoch noch folgendes beachtet werden: I)ie genessenen Iengen won den einzehen fundorten dürten nicht ohne weiteres als ausreichend genaue Verhältniszahlen der vorhandenen Altersstadien mit einander verglichen werden. Es ist nämlich nicht üherall das gleiche quantum genommen. In welcher Weise vorgegangen wurde. ist nachfolgend zusammengestellt:

1. Pohnsbucht. Fine Handvoll des Finges wurde gemessen.

‥ Vollerwiek.) Je eine Handvoll grosse, und je eine Handvoll kleine Carneelen,

3. Hochsicht. I wie sie anf dem Sieb blieben resp. durch das Sieb gefallen waren, sind analysint.

t. Warverort. Eine Handvoll im Steert der Kiure. kleine aus dem Gazenetz. Norder Miele. Ausserdem wurden aus dem fang noch ¿ot Stück besonders kleine und besonders grosse fliere ansgesucht und gemessen. 
․ Büsum. Fine Handvoll grosser Granat und

$$
\text { , " kleiner abgesiehter (rranat ist gemessen. }
$$

1i. Otterndol. Es wude je eine Handvoll ans dem ansseren Gazenetz und aus ier Reuse analysiert.

i. Wremen. Ilier ist eine Handroll gemessen.

s. Vor Wilhelmsharen (Hooksiel). Hier sind drei Handroll gemessen. Dabei ist jedoch zu hemerken, diss diş Verhältuis der Eier tragenden 'Tiere zu den nicht Fier tragenden hier durchans korvekt ist, da samtliche 'I'iere der Stichprobe gemessen wurlen.

1. Varel. Nachtang. Ias Schema täuscht, weil die Eier tragenden. \& aus dem imeren Holzkort, sämtlich gemessen wurden, riejenigen ohne Lier aber. nur nach einer probe (palg. 4t). Vorhanden also it mit, 1 th ohne Eier, Verhïltnis $=1: 4$.

Targesfang. Auch hier ist. zu heachten, dass die Eier tragenden aus beiden Körben in voller 'bahl gemessen sind, die nicht Eier tragenden aber nur zur Hälfte (So) Stück statt 161).

Terden diese Angaben beachtet, so dürfte das Schena doch anch Vergleichungen der einzelnen fangulitye gestatten, wem beachtet wird, dass von kleinen Tieren anf dis gleiche Mass eine grössere Zahl geht als ron grossen Tieren.

Die Genanigkeit der Stichproben halte ich für ansreichend. Ich glanbe, dass sich in dom Fangugerit schon eine gentigende Nischung der Grössenstadien vollzieht, um den Verhïltniszahlen eine solche Znverlïssigkeit. zu gehen, wie sie die von mir angerandte einfache Methode äherhampt erreichen kam.

\section{Litteratur, \\ ansser' les" unter' dem 'l'ext gemanten.}

1: Iloincke. Die Granatischerei an der Oldenhuroischen Küste („Mitt. d. Sektof: Küstenund Hochseefischerer 185\%, Seite 1 $29 \mathrm{fr}$. ).

H. Fhrenbanm. Zoologische Wanderstation an der Nordsee (das. 1889 , Seite $4 \mathrm{fr}$.).

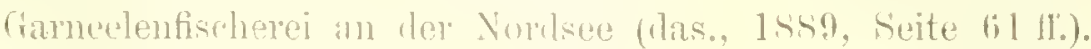

- yur Naturgeschichte von (rangon vulgaris (das., Somterheilage 1690$)$. (Hien ist die weitere liachlitteratur anfgefühnt.)

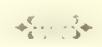




\section{Die Garneelenfischerei.}

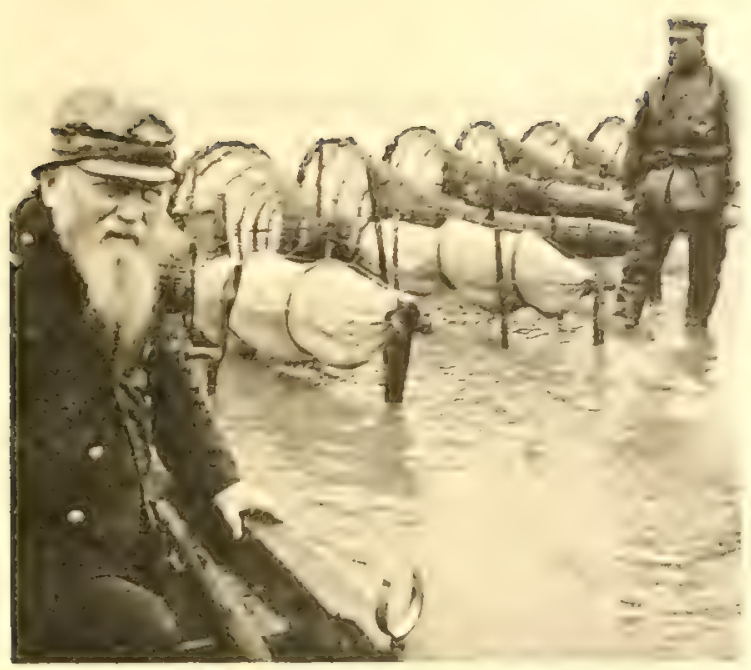

Fig. 1 .

Jadebusen (Virel).

Garneelenkörbe mit Leitkorb ans Weiden. Die Fangkürbe sind mit Gazenetz überzogen.

(Im Vordergrund Oherfischmeister Decker.)

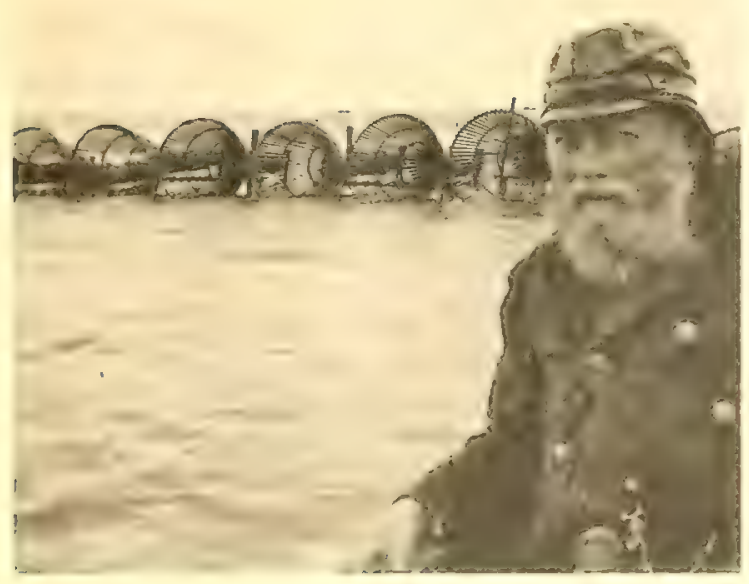

Fig. :

Jadebusen (Varel).

Garneelenkürbe, von vorn gesehen.

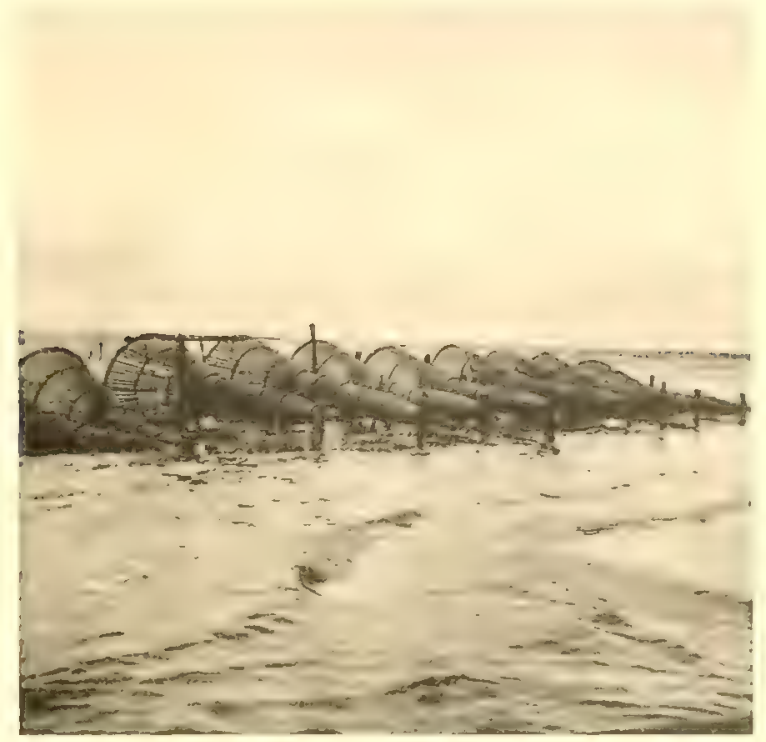

Fig. :-

Jadebusen (Varel:

Garneelenkörbe aus P'iteh-pine-staben,

von hinten gesehen.

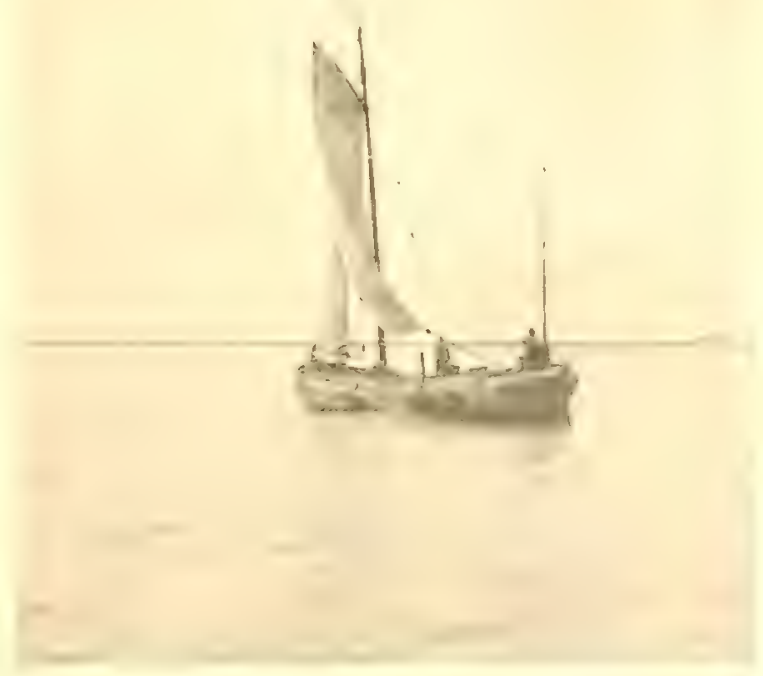

Fing. 4 .

Aussenjade (unterhall) Wilhelmsharen Schaluppe von Neuharlingersiel bein Garneplonfang unweit Hooksiel, mit der hiurre am (ipurd. 

'Taferl II.

\section{Die Garneelenfischerei.}

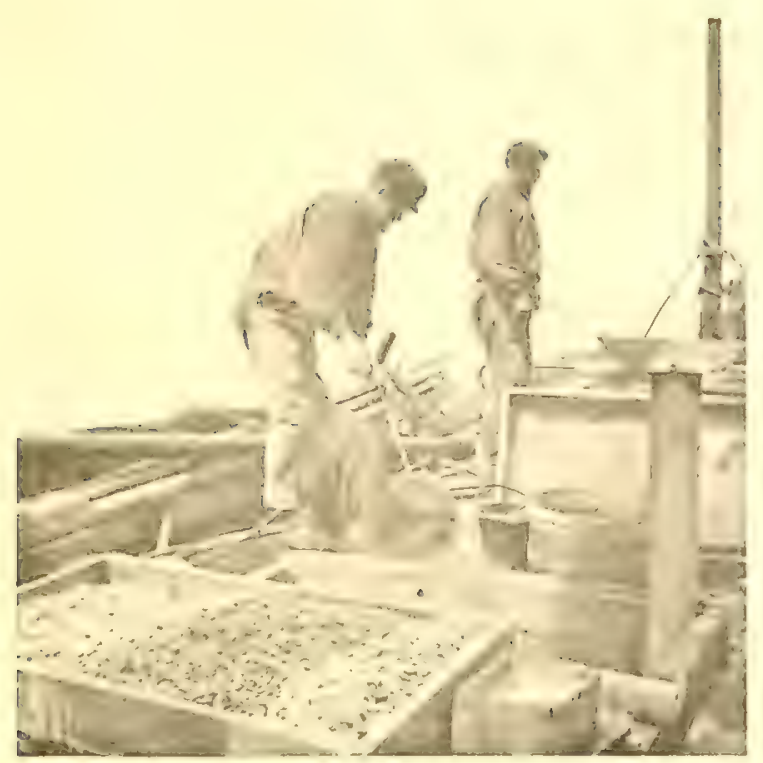

Fig. 5.

Aussenjade. An Bord der Schaluppe Fig. 4, Taf. I. Die Gameelenkurre ist soeben an Deck geholt. Vorn: abkühlende Garıeelen.

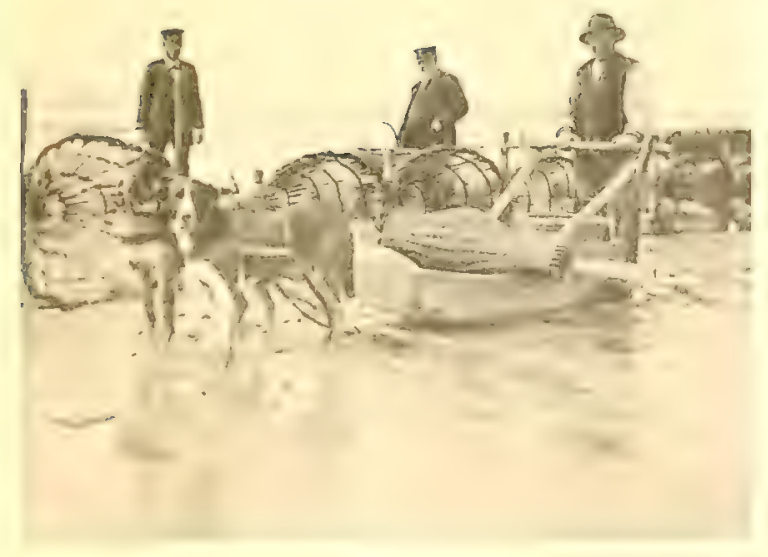

1.in: :

Wesermiindung (vor Wremen).

Fischer mit Schlickschlitten, die Weidenkörbe entleerend.

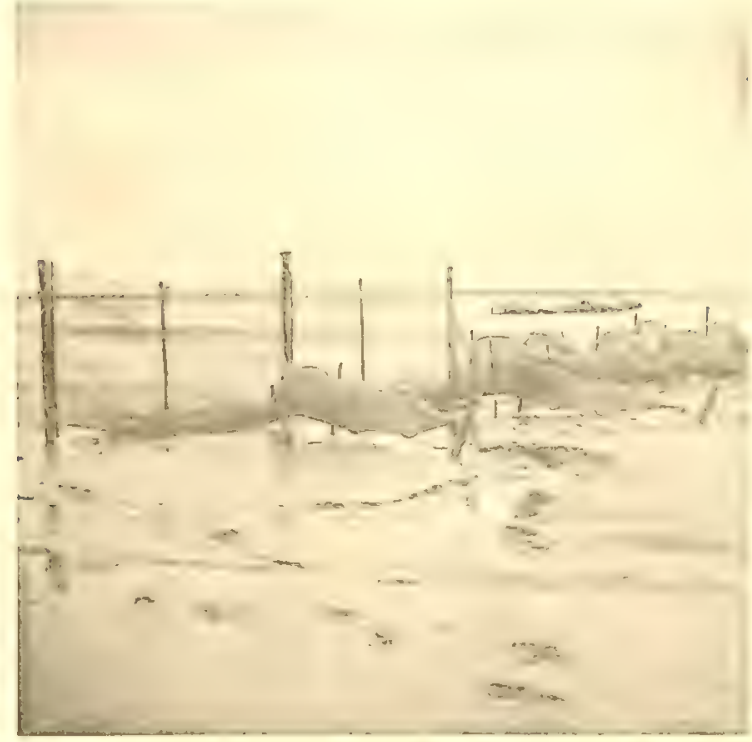

Fig. 6.

Wesermündung (vor Wremen).

Garnkirbe und Weidenkörhe anf dem Watt bei Niedrigwasser.

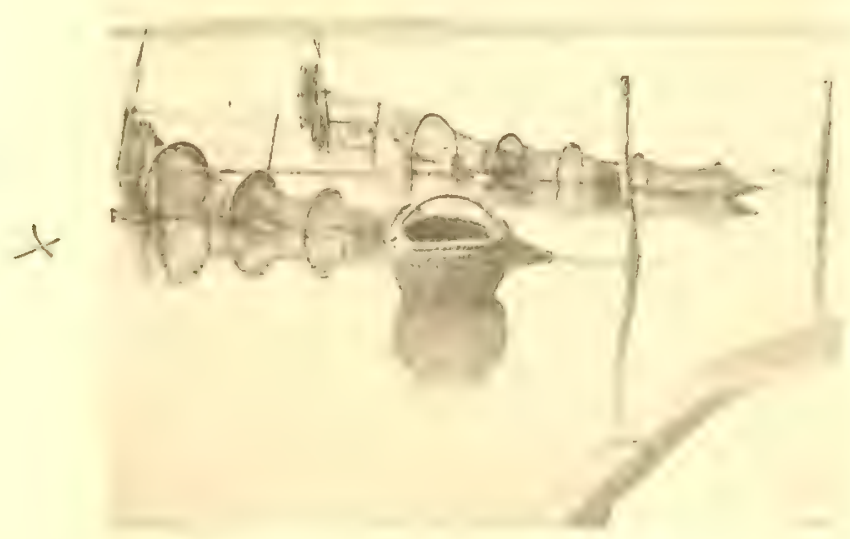

[ivin. s.

Elbmündung (Vor etterndort)

Paarige Gamliobro zum (amerelentang aut dem Elbwatt. 
, 


\section{Die Garneelenfischerei.}

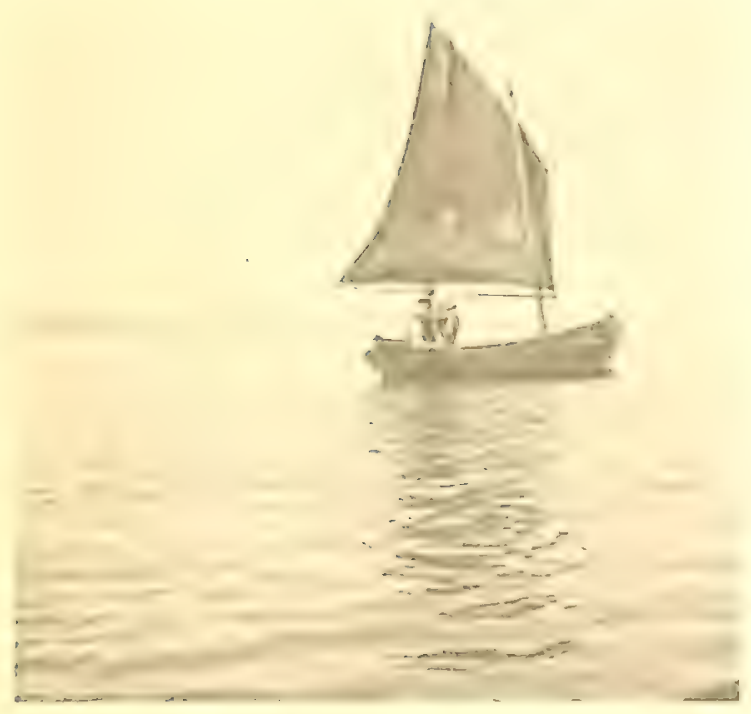

Fig. 4.

Elbmündung (wor Otterndort")

Gelegenheitsfischer von der Oste beim Garnelenfance mit der Hamenkurre.

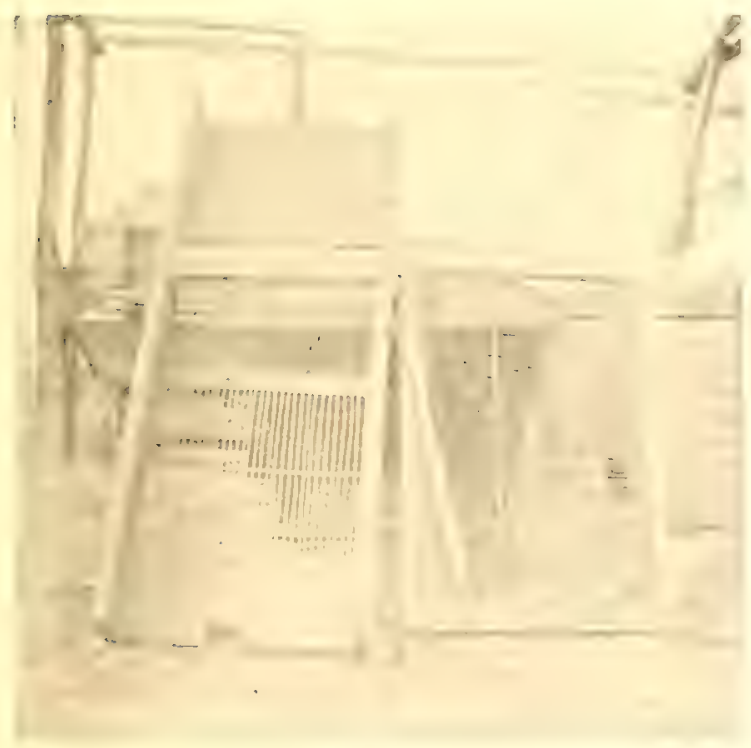

Fin. 11 .

Schafstedt (Uithmalschen:

Garneelensiebe.

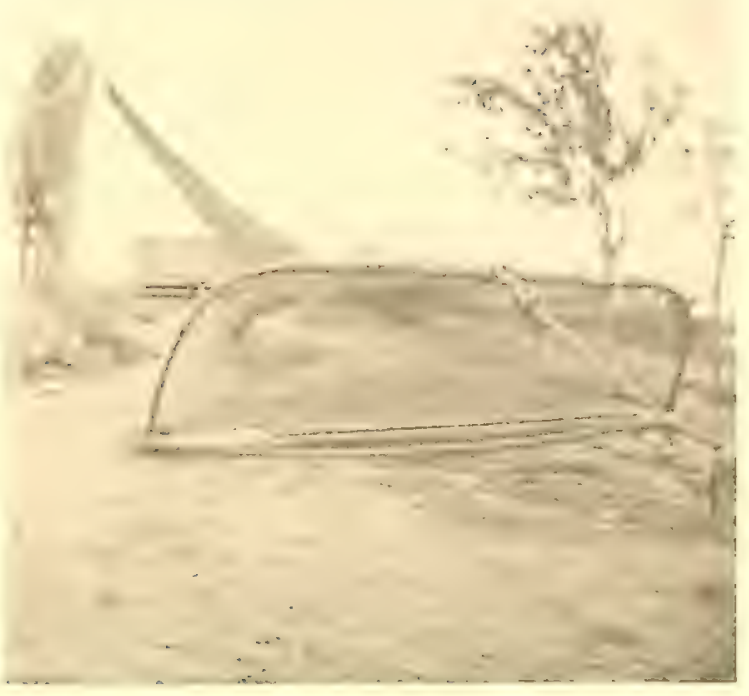

Fig. 10.

Schadendorf (Uithmarschen . Gameelenkurse

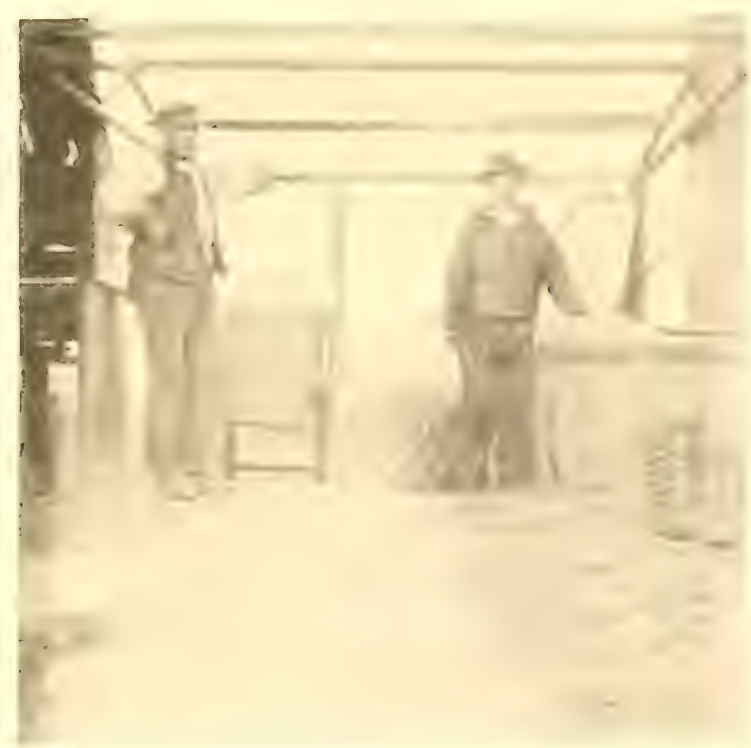

fin: 1:?

Schafstedt.

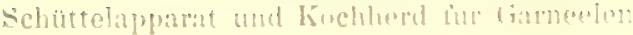





\section{Die Garneelenfischerei.}

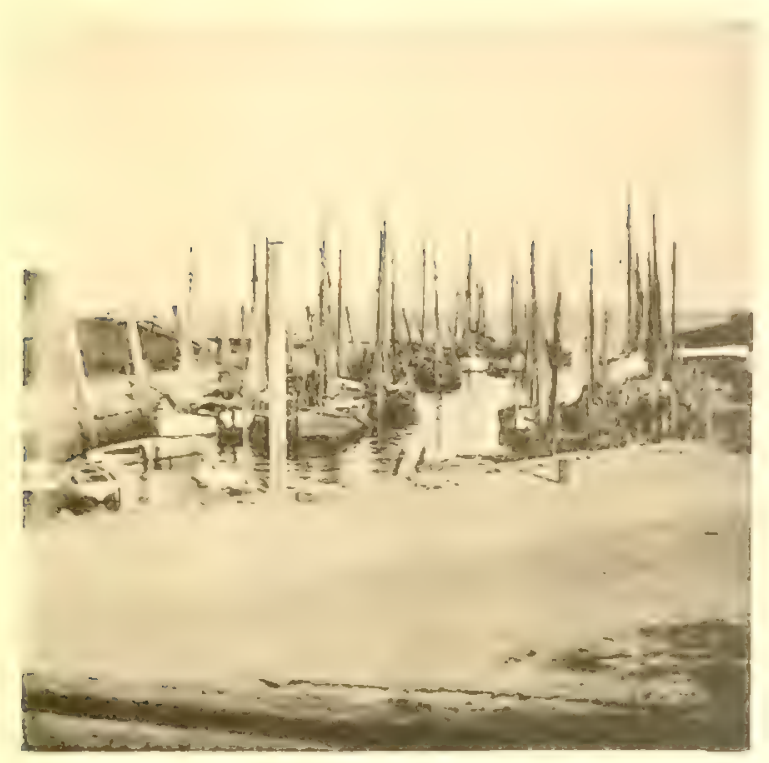

Fin. 13.

Biisum.

Hafen mit Garmeelenkuttem.

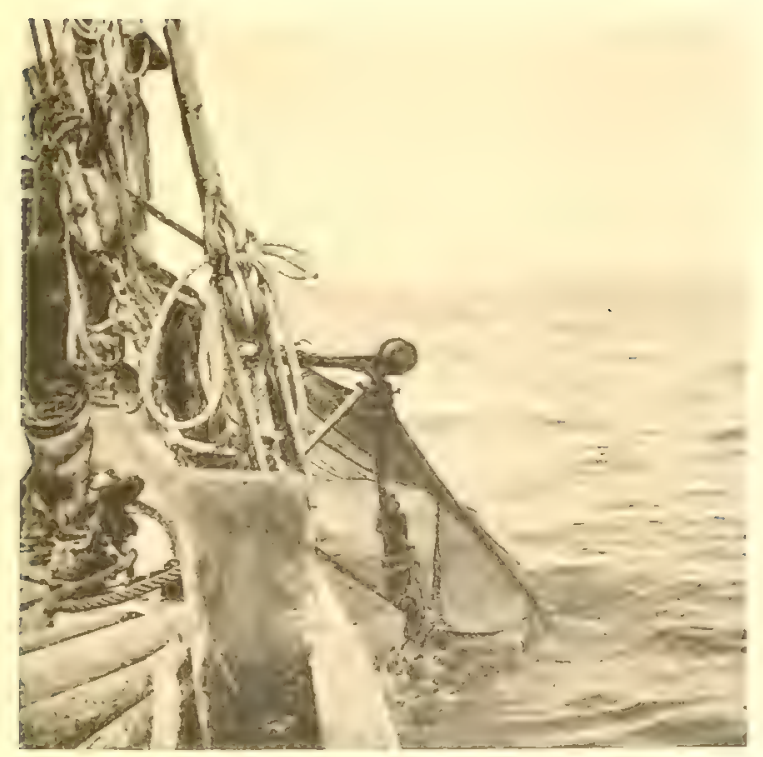

Fig. 15.

Suider Piep.

Garneelenkutter won Busum die Kurre einziehend.

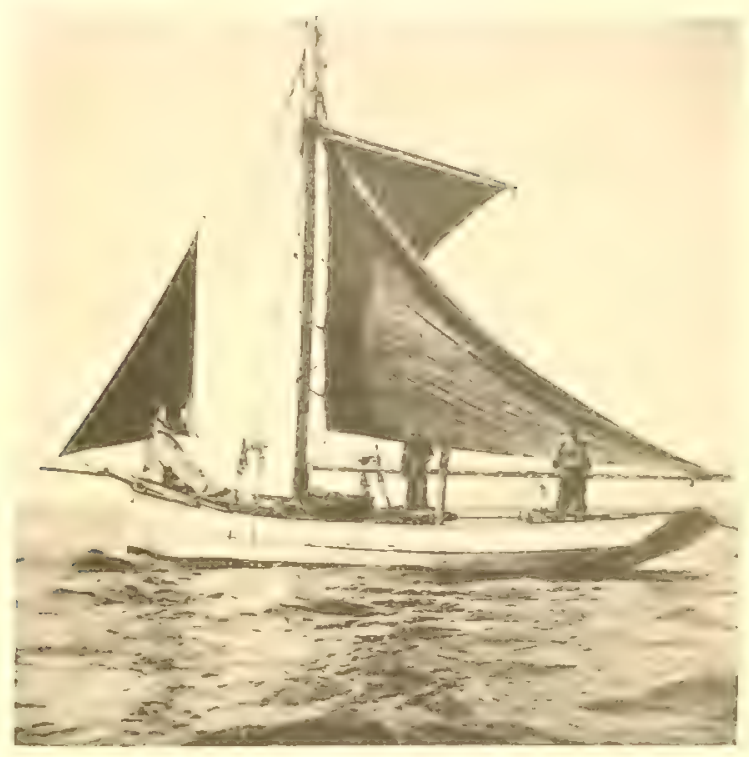

1.1. 14

Süder Piep.

Garneelenkutter yon Busum mit dep liure am tirund.

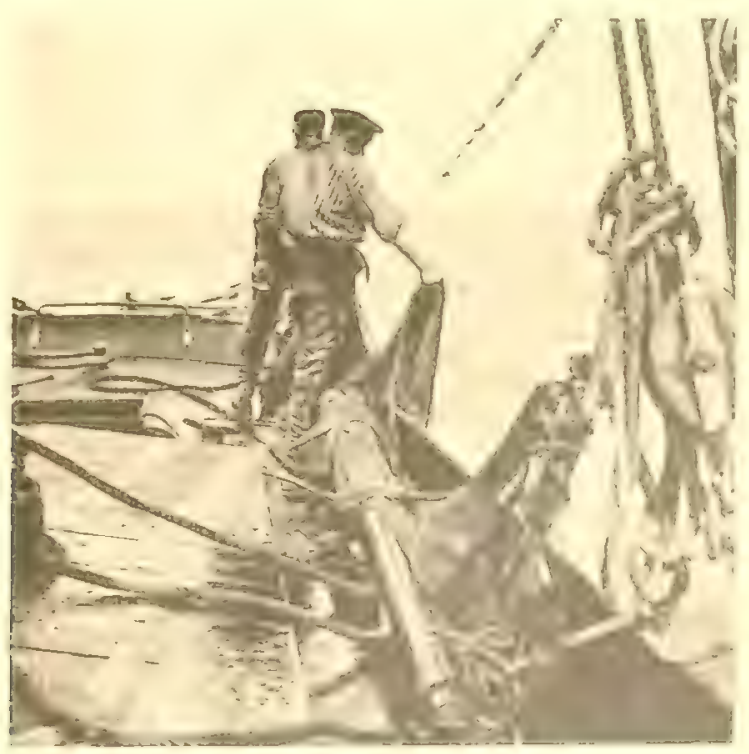

l.ip. 16.

Süder Plep

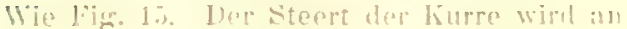




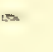


Talel r.

\section{Die Garneelenfischerei.}

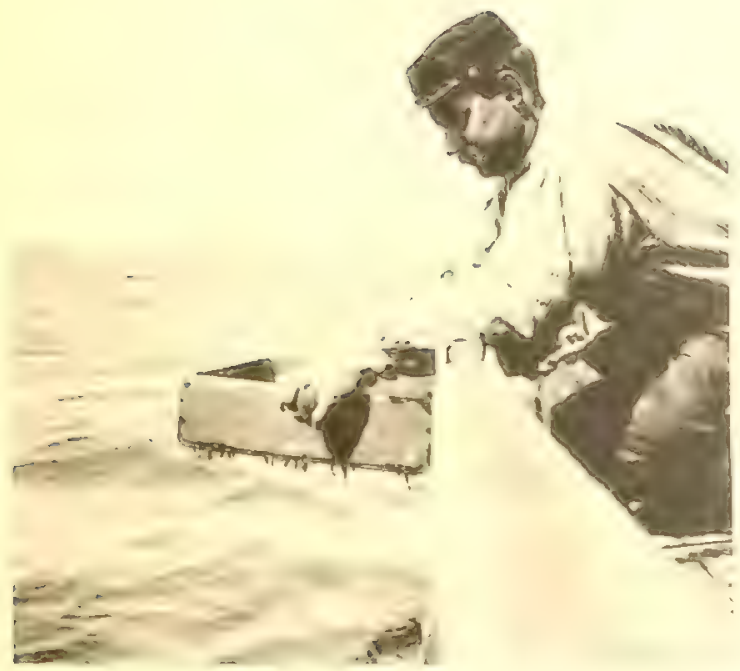

Fin : :

Süder Piep.

Das Sieben des Fanges.

Die Garneelen ragen mit den Schwänzen durch das Sieb.

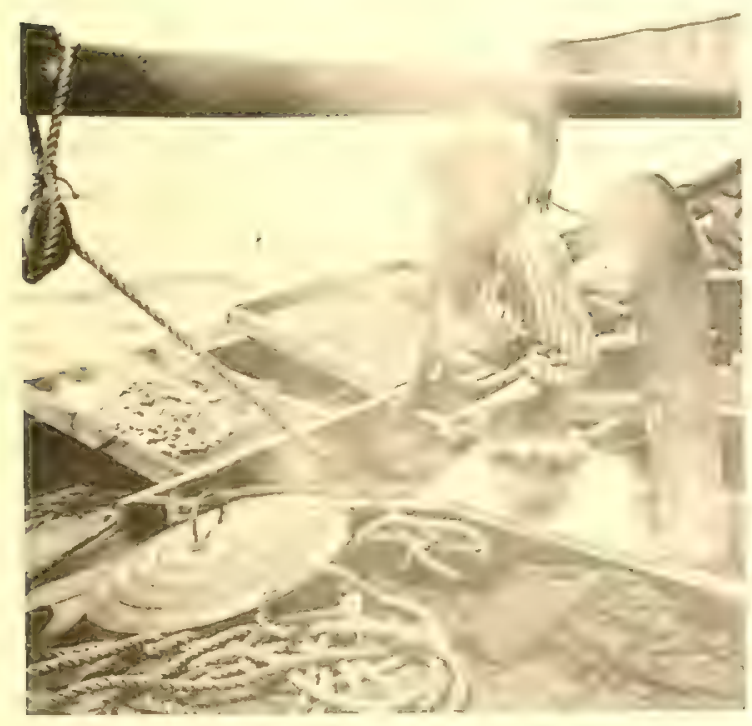

Fig. 19.

Süder Plep.

Die gekochten Garneelen werden aus dem Resse! genommen und zum Abkihlen ausgobreitet.

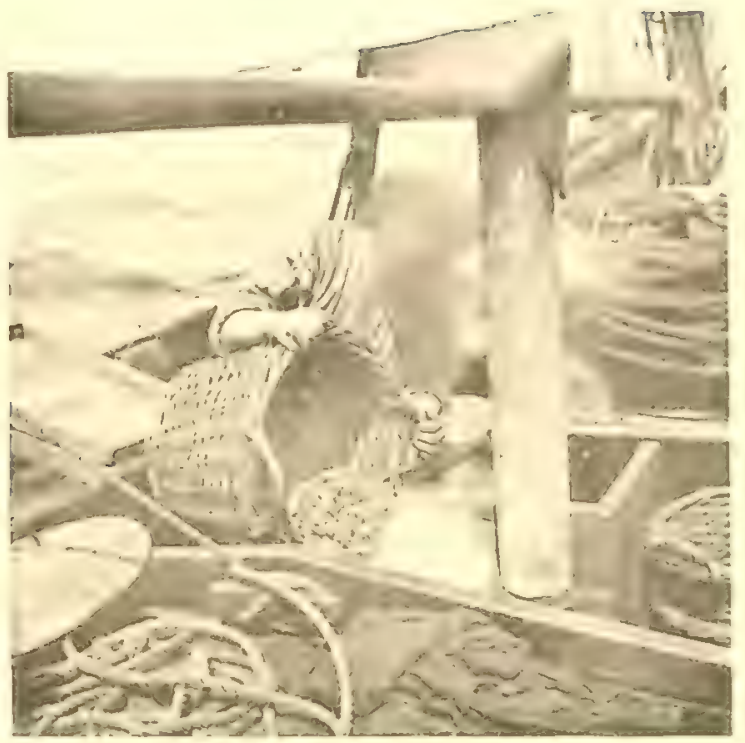

Fig. 18.

Süder Piep.

Die gresiebten Garneelen werlen in den hinchkessel geschuittet.

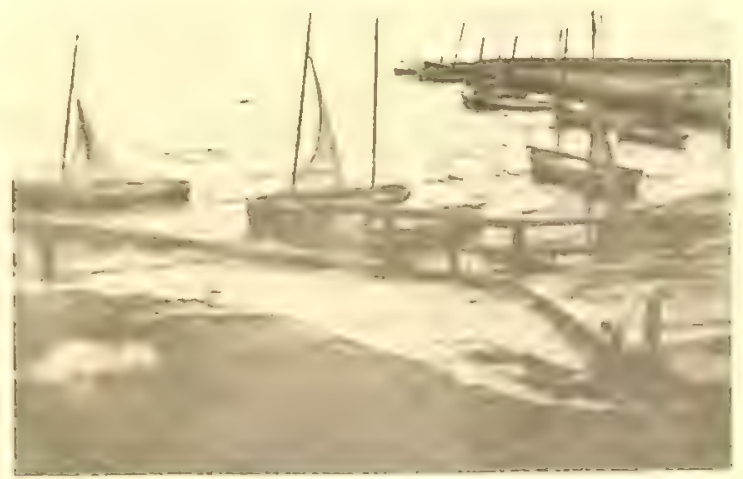

living. $: 0$.

Warverort (Piep).

Der Hafen mit Girneelenbiten, in denten dip hurre zum :T'rockuen aufehangt ist 



\section{Die Garneelenfischerei.}

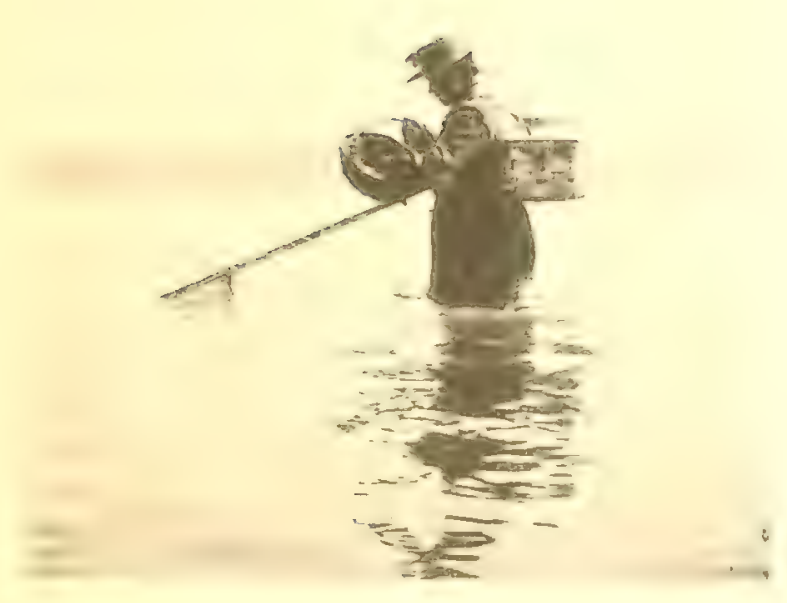

Fig. 21.

Vor Warverort.

Eine Frau in der Süder Miele mit Schiebehamen fischend.

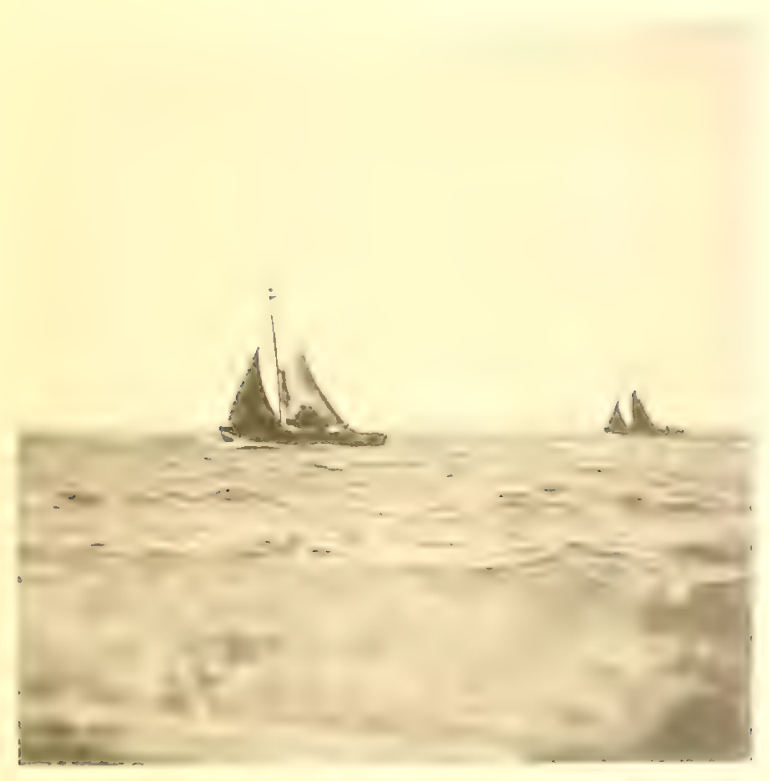

Fig. 23.

Eidermündung.

Wie Fig. 22, aber die Fahrzeuge zum Auswerfen der Kurre wieder aufsegelnd.

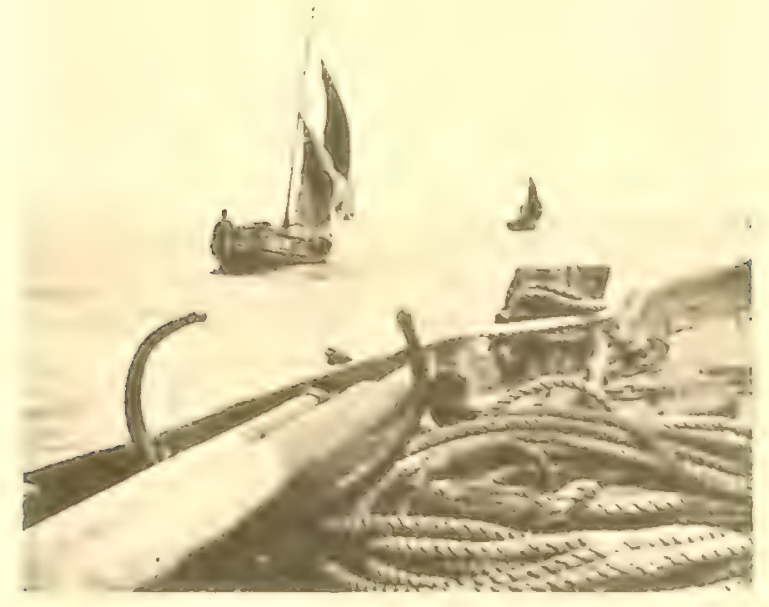

Fin. '22.

Eidermündung.

Zwei Garmeelenfischer-Fahrzeuge von Olversum, die hurre schleppend.

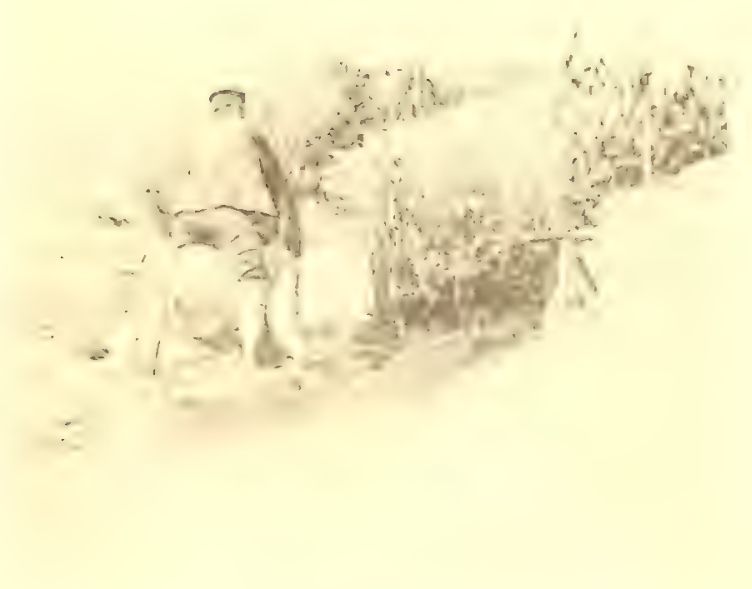

Tim. 21.

Auf dem Watt vor Halebüll.

Ein Fischer stellt bei Yiedriswaser die Hamm vor die Uttnung der Gaarle. 


\section{Die Garneelenfischerei.}

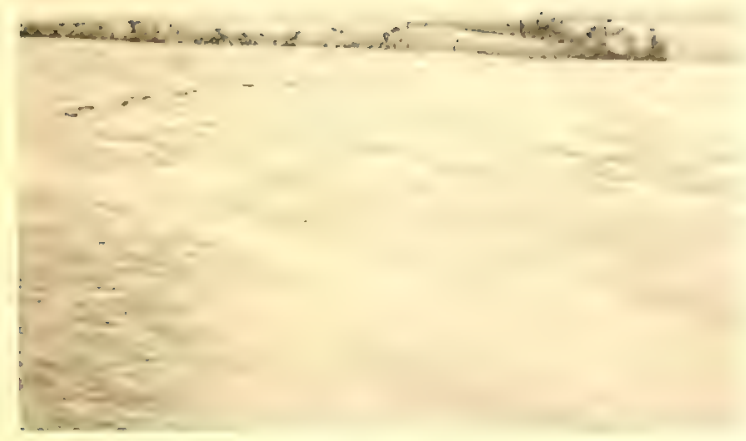

liign. 25.

Auf dem Watt vor Halebüll.

Eine trichterförnige Gaarde.

Rechts dasor der Fischer.

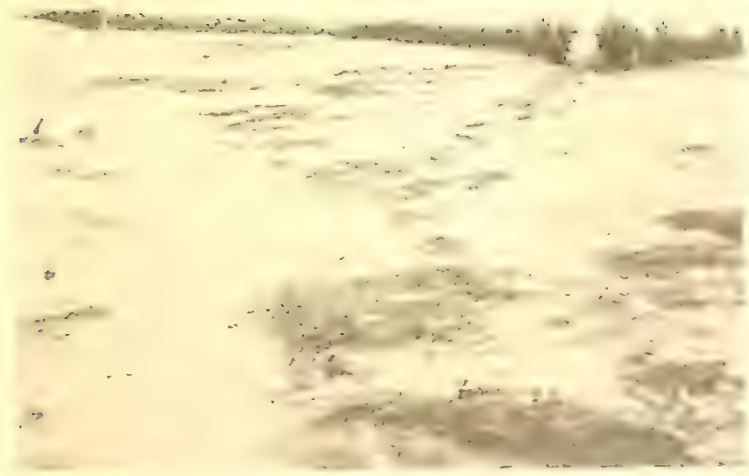

Fig. 27.

Auf dem Watt vor Halebüll.

Zwei winkelförmig zusammenhikngende Gaarden mit je einem Fanglinrb im kndwinkel.

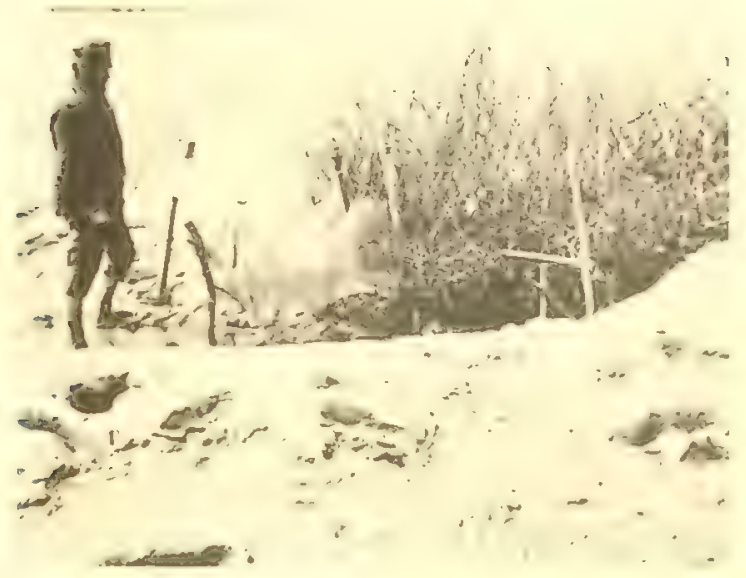

l'in. .2";

Auf dem Watt vor Halebüll.

Seitenansicht der Suitze der Gaarde mit den

? Fanghamen und der Wasserrime.

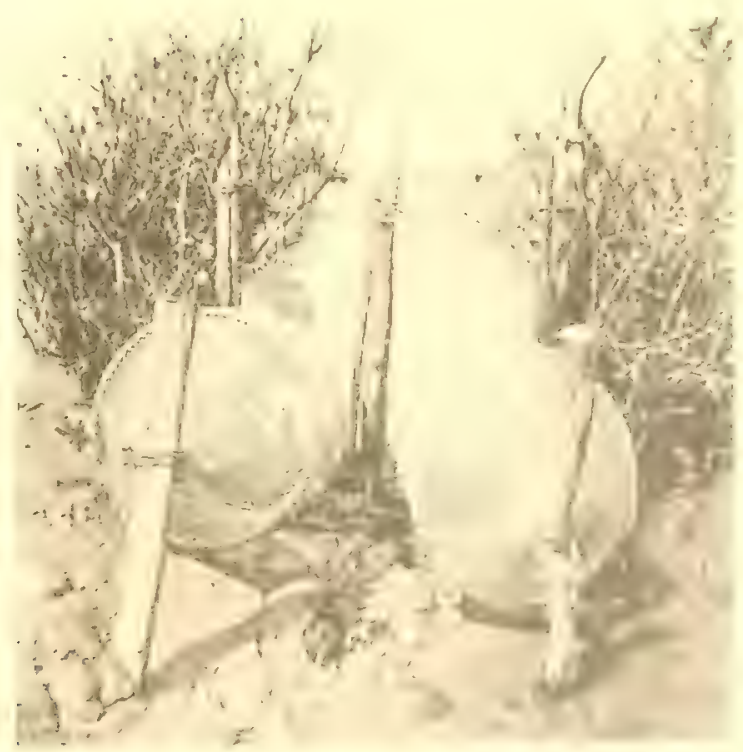

Fig. :-

Auf dem Watt vor Halebüll.

Fanglürhe der Gaarden mit Stellung der Maschen. 


\section{Die Garneelenfischerei.}

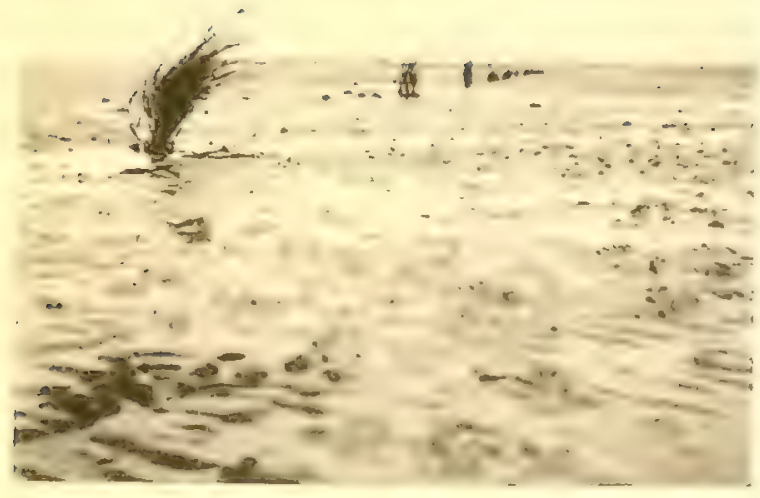

Fig. 29.

Auf dem Watt vor Halebüll.

Wegzeichen von den Gaarden uber das Watt zum [fer, als Rettungramittel bei Nebel.

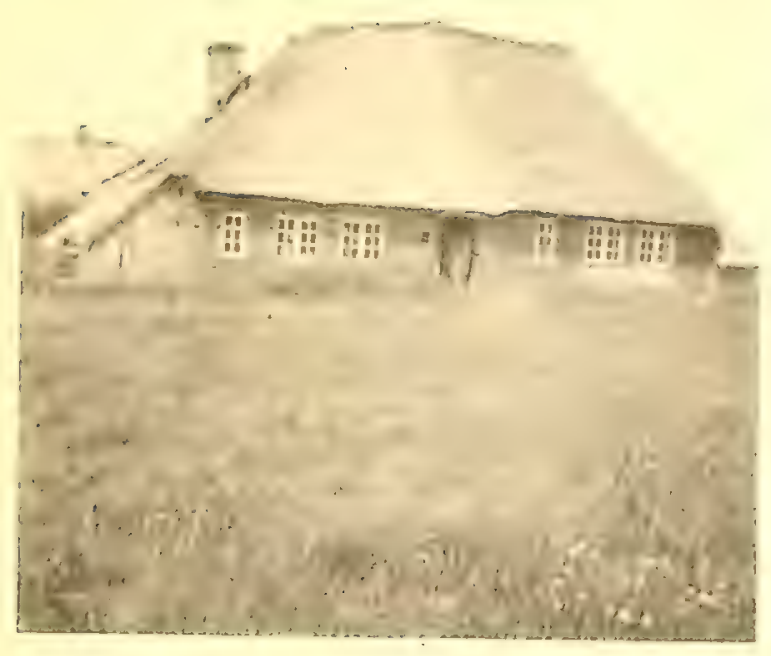

Fig. 31.

Hatebuill.

Ein Fischerhaus.

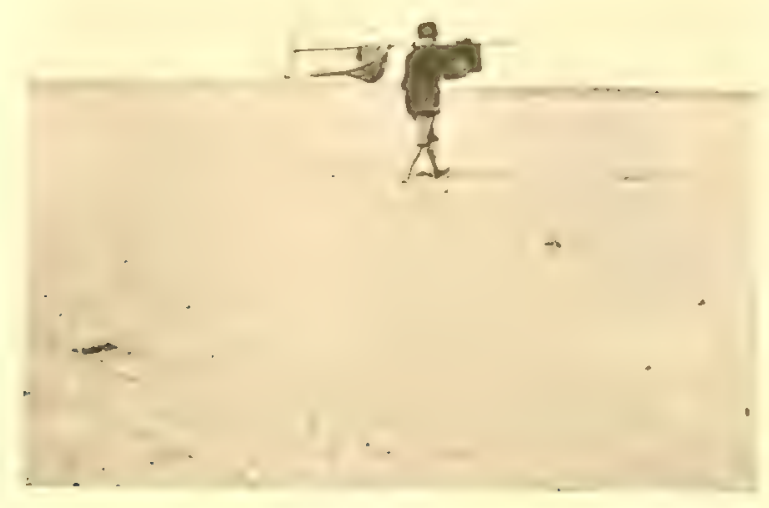

Fig. 30,

Auf dem Watt vor Halebüll.

Ein Garneelentischer mit Schiehehamen vom Fang kommend.

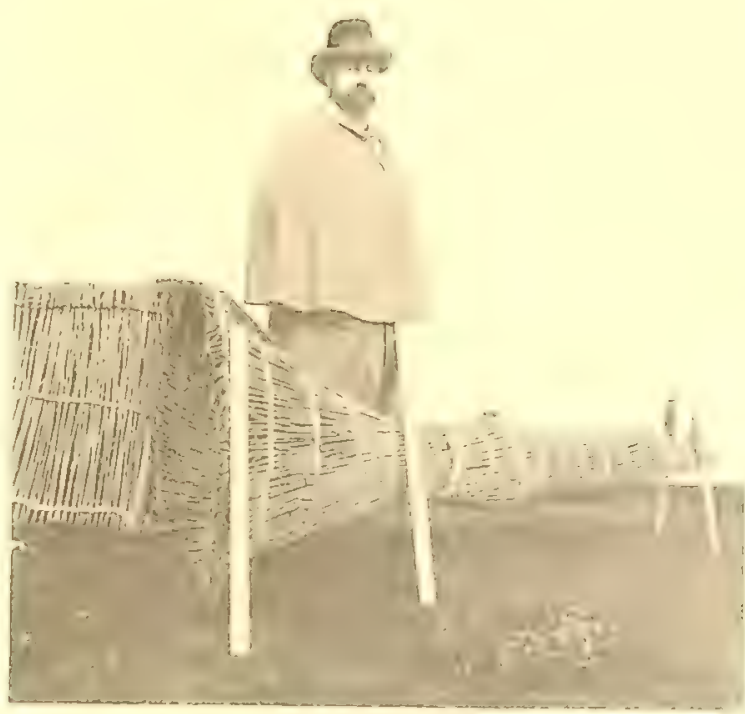

Fir. 32.

Ditzumer Verlaat (Dollart.

Ein Garncelenkorb mit Leitkorb und Flügel (Pannschütten) fangrgerecht aufgestellt. (Der Verfasser daneben als Massstab.) 


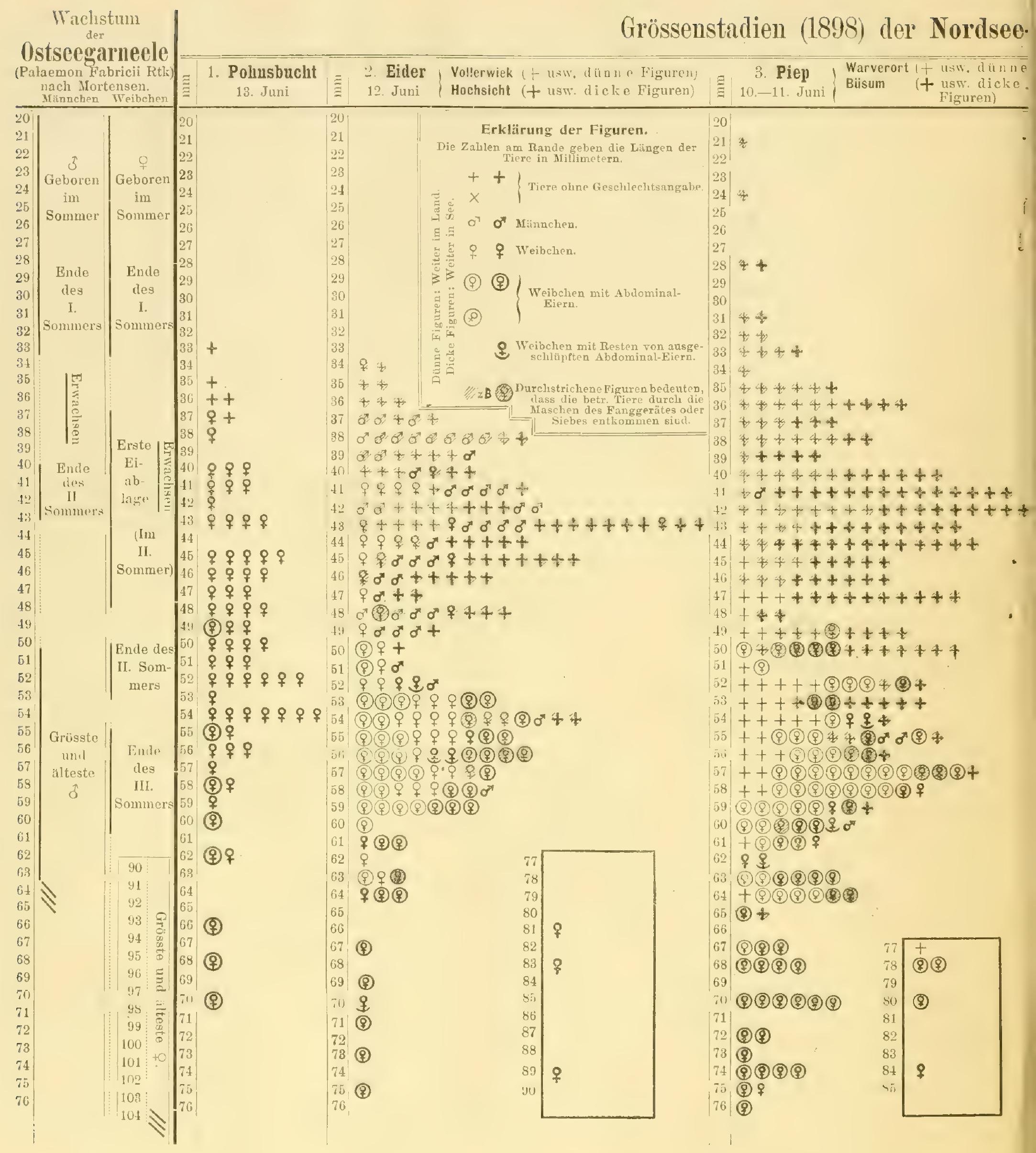




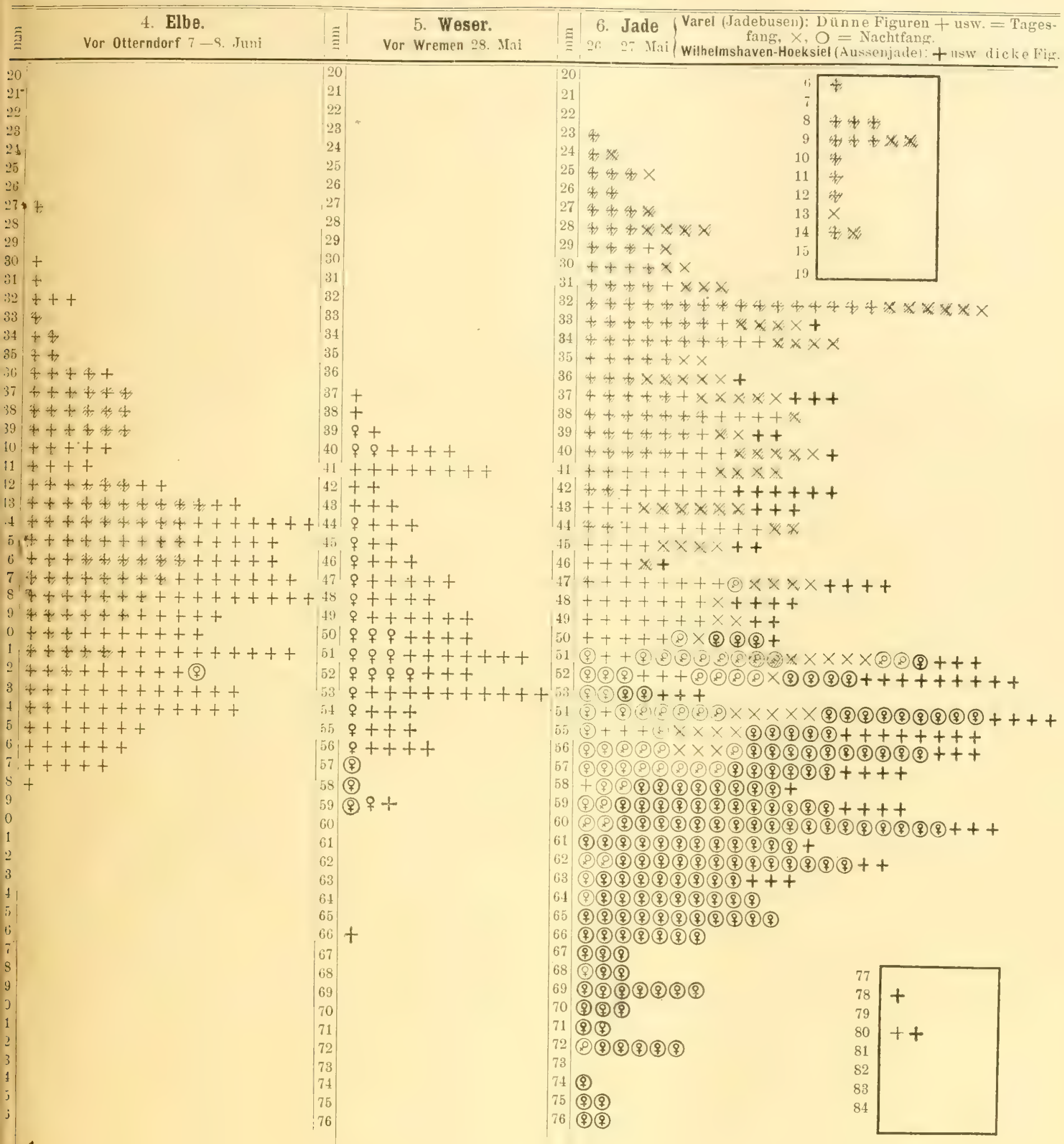





